\title{
To what extent does personal relevance impact behavior after attending a laboratory safety training session?
}

Sandra E. Fouch

West Virginia University

Follow this and additional works at: https://researchrepository.wvu.edu/etd

\section{Recommended Citation}

Fouch, Sandra E., "To what extent does personal relevance impact behavior after attending a laboratory safety training session?" (2006). Graduate Theses, Dissertations, and Problem Reports. 2714.

https://researchrepository.wvu.edu/etd/2714

This Dissertation is protected by copyright and/or related rights. It has been brought to you by the The Research Repository @ WVU with permission from the rights-holder(s). You are free to use this Dissertation in any way that is permitted by the copyright and related rights legislation that applies to your use. For other uses you must obtain permission from the rights-holder(s) directly, unless additional rights are indicated by a Creative Commons license in the record and/ or on the work itself. This Dissertation has been accepted for inclusion in WVU Graduate Theses, Dissertations, and Problem Reports collection by an authorized administrator of The Research Repository @ WVU.

For more information, please contact researchrepository@mail.wvu.edu. 


\title{
To What Extent Does Personal Relevance Impact Behavior After Attending a Laboratory Safety Training Session?
}

\author{
Sandra E. Fouch \\ Dissertation submitted to the Faculty of the \\ College of Human Resources and Education \\ at West Virginia University \\ in partial fulfillment of the requirements for the degree of
}

DOCTOR OF EDUCATION

in

Educational Psychology

Floyd L. Stead, Ed.D., Chair

Sebastian R. Diaz, Ph.D.

Ernest R. Goeres, Ph.D.

Daniel E. Hursh, Ph.D.

Perry D. Phillips, Ed.D.

Department of Advanced Educational Studies

\author{
Morgantown, West Virginia \\ 2006
}

Keywords: Safety Practices, Safety Training, Andragogy, Training Principles, 


\begin{abstract}
To What Extent Does Personal Relevance Impact Behavior After Attending a Laboratory Safety Training Session?
\end{abstract}

Sandra E. Fouch

Each year in the United States, millions of dollars are spent to educate adults. Therefore, there has been a flurry of interest in answering the question, "How do adults learn?" There are different answers and therefore, different theories. The method selected for this study incorporated Andragogic learning into the laboratory safety training at Carnegie Mellon University. This design involved a number of features that recognized the essential maturity of the learner.

The training was developed to present the Laboratory Safety and Hazardous Waste Trainings at Carnegie Mellon University. The new training provided additional discussion points to allow the adults to interact more with the trainer and therefore, become more involved in their learning. The current training ("old" training) did not incorporate the adult learning strategies. The new training began with providing objectives and real-life examples as well as a quiz that was graded and then the correct answers given, as opposed to allowing participants to change their responses before the grade is recorded. These educational concepts would hopefully transfer to improved safety practices in the laboratories. This was measured and recorded through staff observations during laboratory inspections. The observations recorded the number of safety violations exhibited by each participant.

The employees were divided into two groups: those that received the "old" training and those that received the "new" training. Staff members at Carnegie Mellon University trained to evaluate laboratory safety observed the employees. The employees were observed on three separate occasions to determine compliance to the safety behaviors described in the training.

After the observations were complete, t-tests were analyzed and a significant decrease in violations was found for participants in the "new" training. The results demonstrate significant decreases only when comparing the two training groups, not when other variables were considered: employee's department, male vs. female and training session attended. 


\section{Acknowledgments}

I would like to acknowledge several individuals without whom I would not have been able to complete this dissertation.

First, I would like to thank my family. Without the support of my husband, Michael, I would not have been able to even begin the pursuit of this degree. He challenged me and gave me support and invaluable assistance when I needed it. My

parents offered moral, monetary, and babysitting support throughout the entire process. And my son, Jacob, spent time alone while his mom was working on the computer.

Secondly, I would like to thank the members of my doctoral committee: Dr. Larry Stead (my advisor), Dr. Daniel Hursh, Dr. Sebastian Diaz, Dr. Perry Phillips, and Dr. Earnest Goeres. These members were supportive throughout the entire process and offered many useful suggestions. 


\section{Table of Contents}

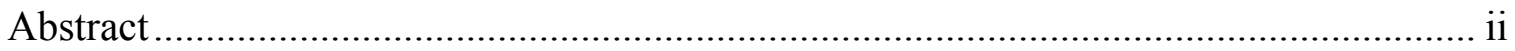

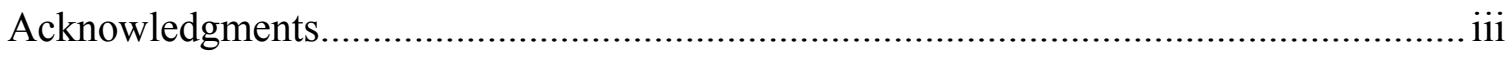

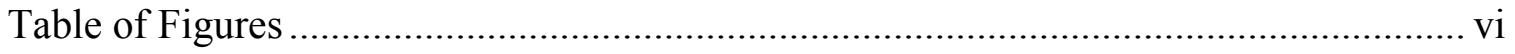

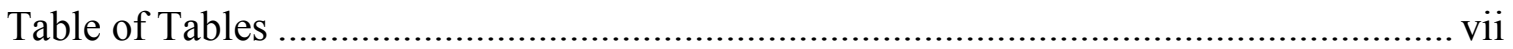

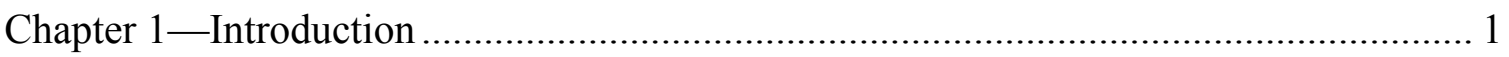

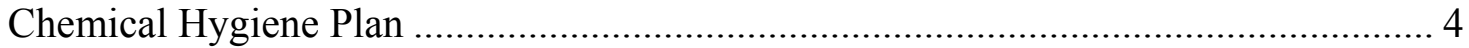

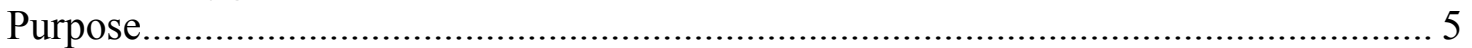

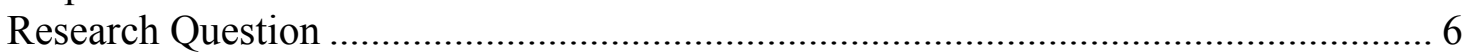

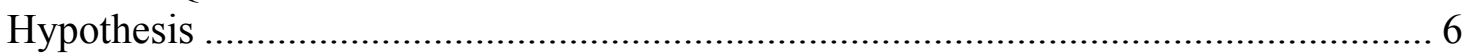

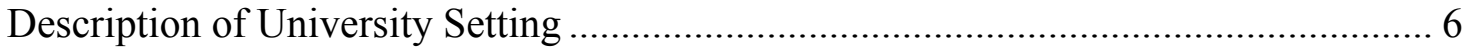

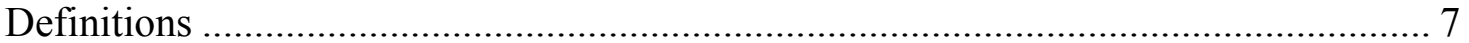

Description and Past Results of Laboratory Safety Training ..................................... 8

Significance and Importance of the Study .............................................................. 8

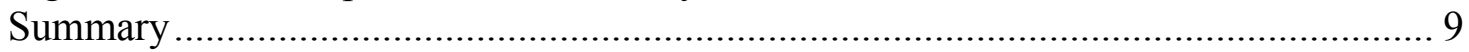

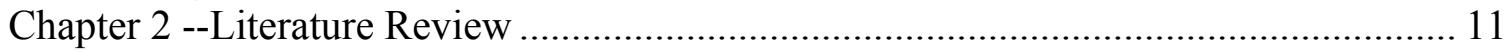

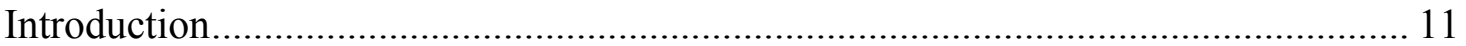

Existing Research on Adult Educational Theory..................................................... 12

Comparing Adults' Learning and Childs' Learning ................................................ 15

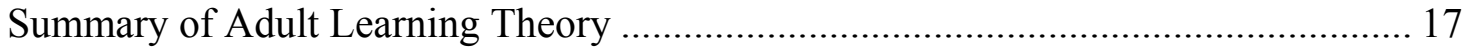

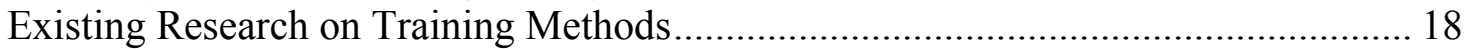

Strategies to Help Motivate Adult Learners ............................................................. 20

Characteristics of a Motivating Instructor ............................................................... 21

Existing Research on Training Design ............................................................. 22

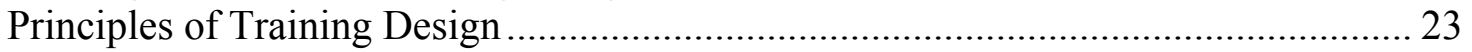

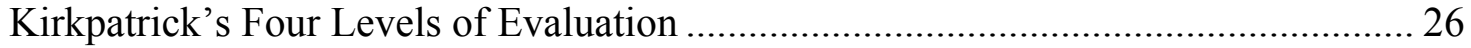

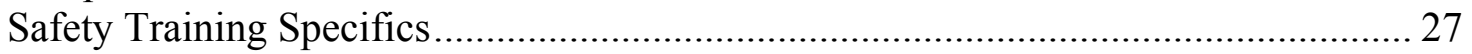

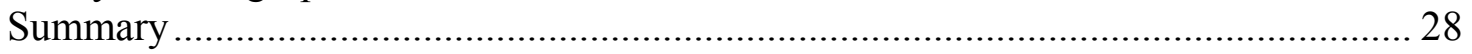

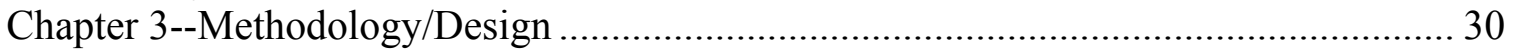

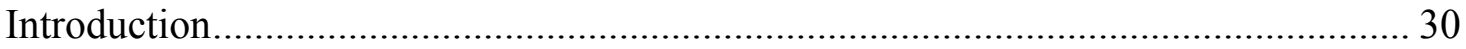

Procedure Used to Develop Training .................................................................. 33

Delphi Process ................................................................................................... 34

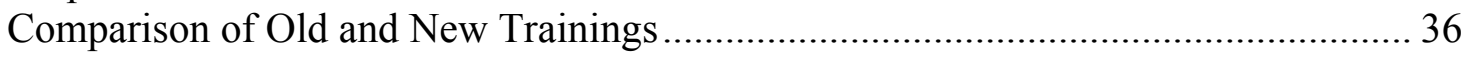

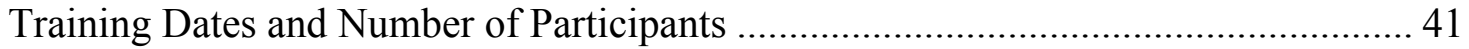

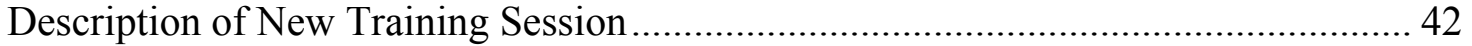

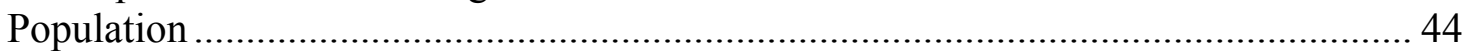

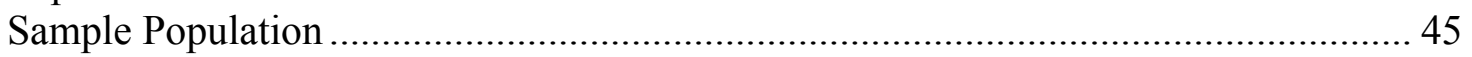

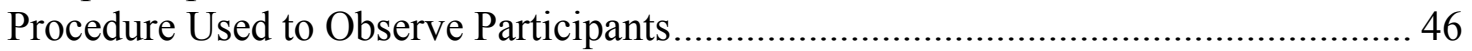

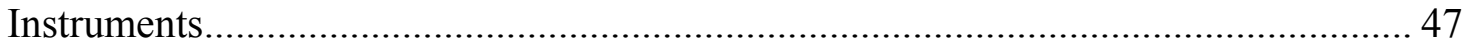

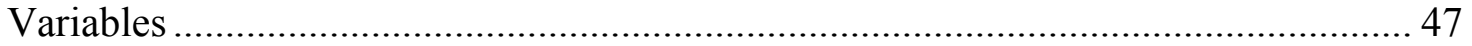

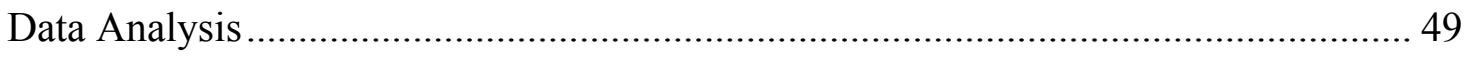




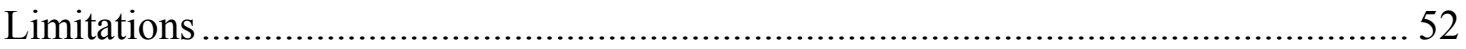

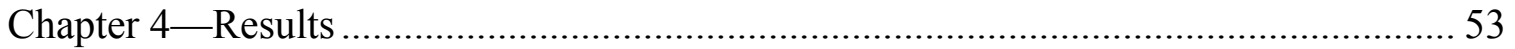

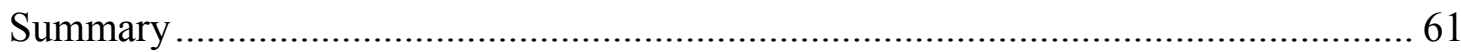

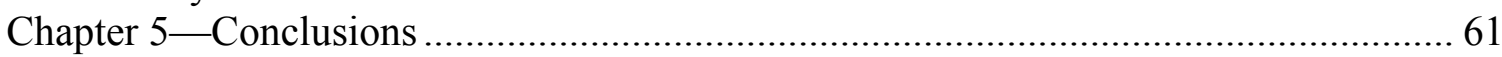

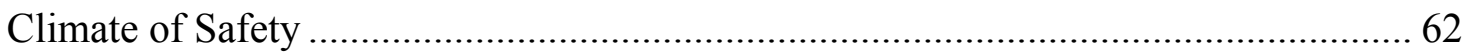

Implications for Carnegie Mellon University Environmental Health and Safety ........ 64

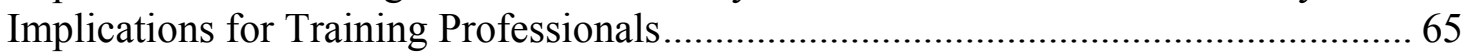

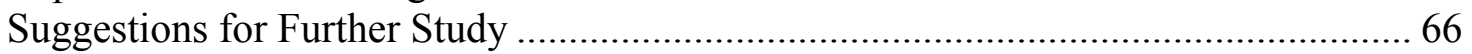

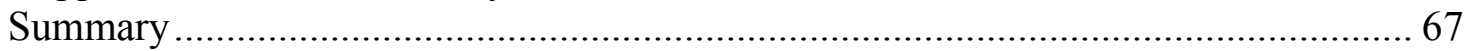

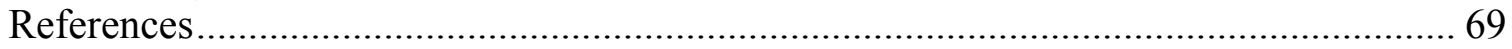

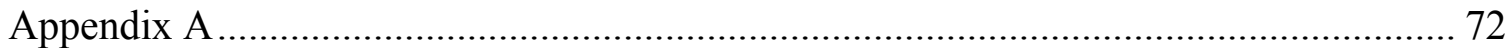

Safety Standards for Carnegie Mellon Laboratories....................................................... 72

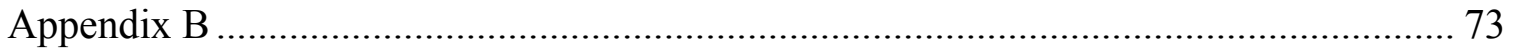

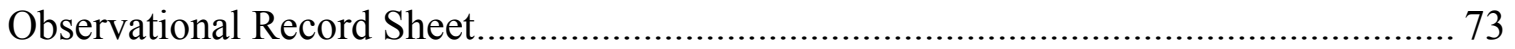

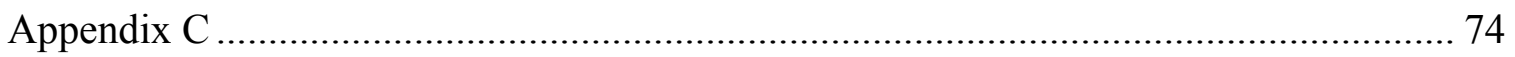

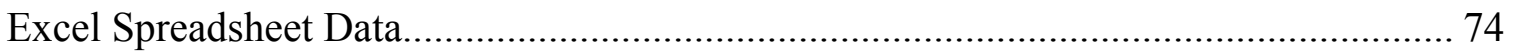

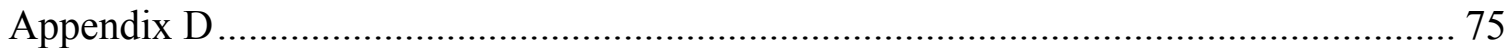

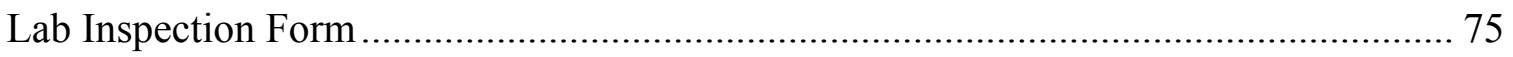

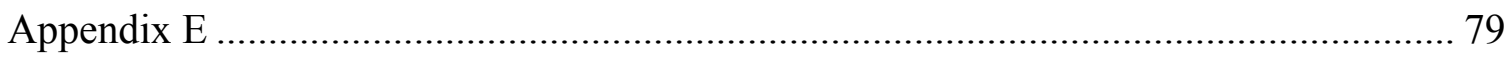

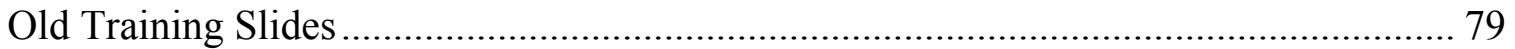

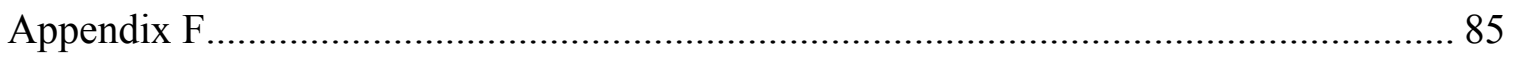

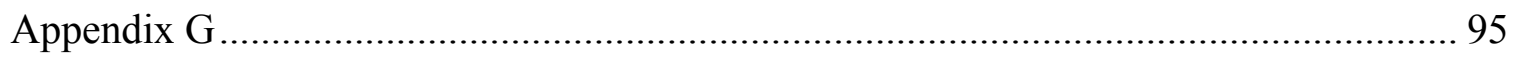

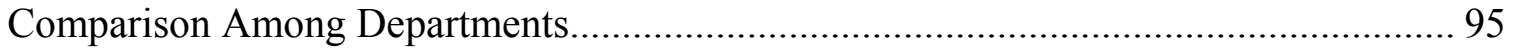

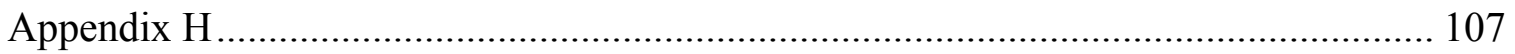

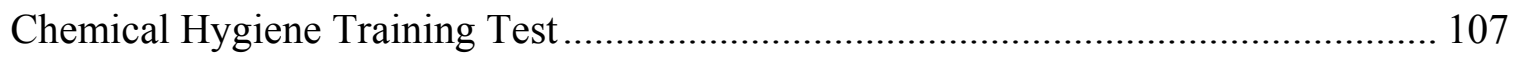

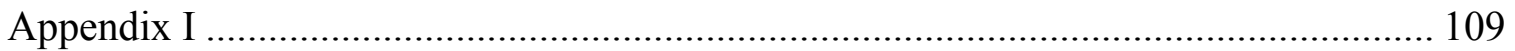

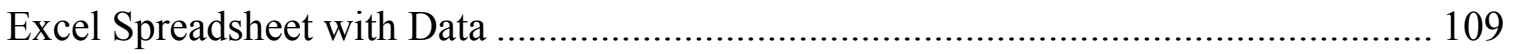




\section{Table of Figures}

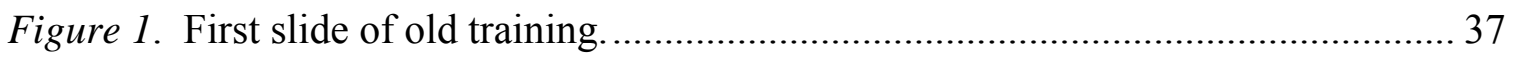

Figure 2. First slide is training objectives to be discussed in the new training.............. 38

Figure 3. Second slide of objectives in new training................................................... 39

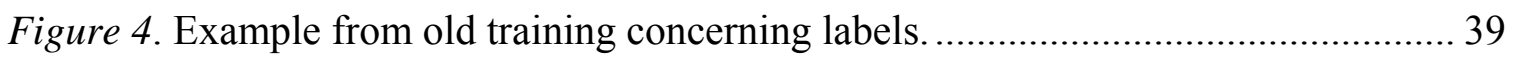

Figure 5. Example from new training concerning labels. ......................................... 40

Figure 6. Example of spreadsheet data for the biology department participants in the old

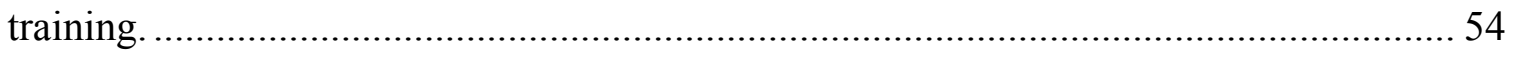

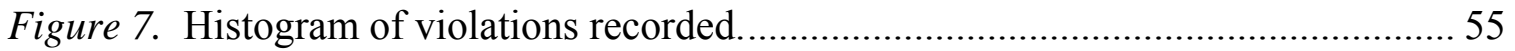




\section{Table of Tables}

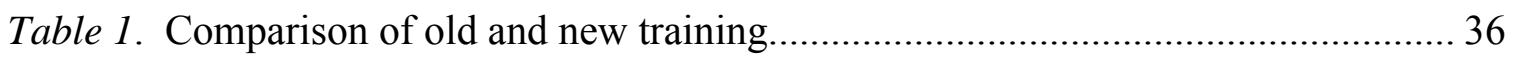

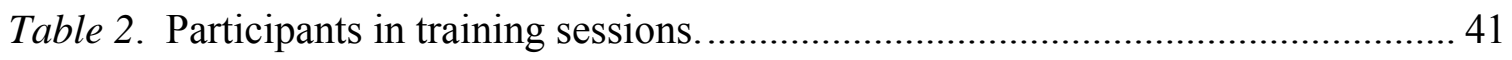

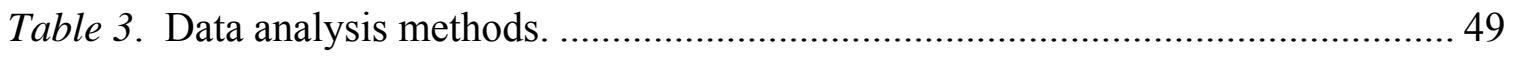

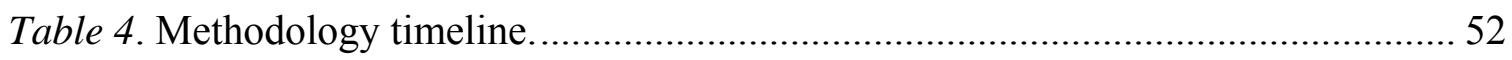

Table 5. Average safety violations comparing old and new training group participants. 56

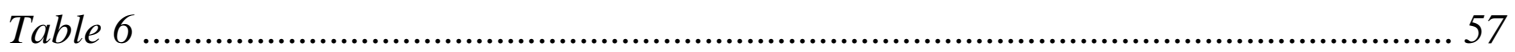

Table 7. Old training violations by department. ........................................................ 58

Table 8. New training violations by department.......................................................... 59

Table 9. Comparison of males and females in the old training. .................................. 60

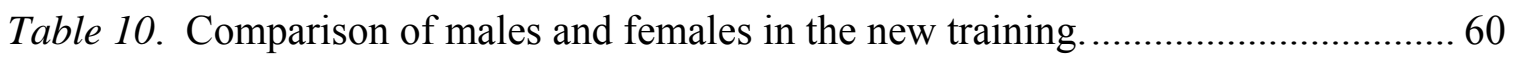




\section{Chapter 1-Introduction}

Effective training and instruction of adult learners involves a basic understanding of ways in which adults learn. Adult learning is distinct from children since adults have different needs and requirements. There has been a proliferation of adult learners returning to school or participating in workplace training programs. The question then is, are the specific needs of adult learners being addressed? Are we meeting the needs of this market? Without recognition of these needs, can trainers attain the outcomes necessary for skills learned in training to transfer to the workplace?

Each year in the United States, millions of dollars are spent to educate adults. This is accomplished in the workplace through training and at colleges, technical schools and universities. Many government-sponsored programs require training of employees as part of the effort to promote safety, growth and development. Other agencies and corporations use training to advance productivity, train new employees, or advance employees to higher positions. Although, training is required, many times the person selected to provide the training, may know the content to be presented; however, they may not be aware of the most effective methods to use in presenting the information. In many job settings, the difference between effective and ineffective training may be death, injury, pain, suffering, and lost profits (Robotham, 2001).

The Occupational Safety and Health Administration (OSHA) recognizing the unique characteristics of the laboratory workplace tailored a standard for employees who work in laboratories. This standard is often referred to as the "Laboratory Standard" (Prudent Practices, 1993). Under this standard, the employer is required to produce a Chemical Hygiene Plan, which addresses the safety precautions required to maintain a 
safe working environment. This Laboratory Standard was conceived to protect the public, the environment, and the individual laboratory worker. Noncompliance to the standards may expose workers to unnecessary risks, undermine the public's confidence in its institutions, and lead to employers receiving fines that may exceed $\$ 25,000$ per day of violation and severe criminal penalties. The laboratory standard's safety practices are mandated by law and enforceable through citations. (Robotham, 2001)

OSHA's standards and policies work to provide employers regulations to “furnish to each of his employees ... a place of employment . . f free from recognized hazards that are likely to cause death or serious physical harm . ..." The individual employer is required to "comply with occupational safety and health standards and all rules ... which are applicable to his own actions and conduct." (OSHA Standard 1910.1450) The Laboratory Standard applies to all laboratories which handle chemicals or chemical waste or other hazards (lasers, radiation, or biological) in regard to requirements for training and other safeguards.

Public concern for safety in the workplace and protection of the environment through pollution prevention has resulted in a voluminous array of regulations designed to control every stage of the transportation of chemicals to and from laboratories, their handling within the laboratory workplace, and their final disposal, in other words, controlling chemical usage from "cradle to grave" (Prudent Practices, 1993). Safe practice by laboratory workers requires continuing attention and education; it cannot be assumed to be optional. An increasing climate of litigation has also sharpened the awareness of everyone on the ladder of responsibility about the price that may have to be 
paid if accidents occur as a result of the illegal or irresponsible handling of chemicals (Robotham, 2001).

In an effort to maintain safe working laboratories, the "Laboratory Standard" includes the following requirements: (OSHA Standard 1910.1450)

- Chemical Hygiene Plan --a written program developed and implemented by the employer which sets forth procedures, equipment, personal protective equipment and work practices that are capable of protecting employees from the health hazards presented by hazardous chemicals used in that particular workplace.

- Chemical Hygiene Officer -- an employee who is designated by the employer, and who is qualified by training or experience, to provide technical guidance in the development and implementation of the provisions of the Chemical Hygiene Plan.

- Employee information and training --the employer shall provide employees with information and training to ensure that they are apprised of the hazards of chemicals present in their work area. Such information shall be provided at the time of an employee's initial assignment to a work area where hazardous chemicals are present and prior to assignments involving new exposure situations.

Many steps have been taken to improve the safety of equipment for handling and experimenting with chemicals. Unquestionably, most laboratories are safer places to work now than they were 15 years ago. However, the ultimate key to maintaining a safe environment lies in the attitude and behavior of the laboratory worker. Affecting 
attitudes and behaviors would be the area where proper training, although required, is also helpful in educating workers.

The Department of Environmental Health and Safety at Carnegie Mellon University has recognized the need to not only meet the requirements in OSHA's Standards, but exceed those standards in the hope that anyone working in laboratories at the university will be utilizing safe practices. Through the Chemical Hygiene Plan, Carnegie Mellon University has developed several different training programs. The university is working to improve the trainings and evaluation methods in order to take a pro-active stance to improve safety.

\section{Chemical Hygiene Plan}

The chemical hygiene plan is a document that is required by OSHA's Laboratory Standard. This document is specific to each institution and overseen by the Chemical Hygiene Officer. Carnegie Mellon University developed this plan and evaluates the plan annually and makes revisions as needed. Carnegie Mellon's Chemical Hygiene Plan (CHP) includes: 1) periodic monitoring of the performance of ventilation systems, 2) periodic safety inspections of laboratories, 3) procedures that ensure that disposal of waste chemicals occurs at regular intervals, and 4) training opportunities for all laboratory workers. Implementation of these Chemical Hygiene Plan (CHP) procedures is a regular, continuing effort, endorsed by administration and faculty. All Carnegie Mellon University laboratory faculty and staff shall follow its recommendations.

The sections of the Chemical Hygiene Plan that impact this study:

- 2.6.9 Provide training to laboratory workers concerning the provisions of 
the Chemical Hygiene Plan and hazardous waste disposal.

- 2.6.10 Provide hazard awareness training to ancillary workers.

- 2.6.10 Provide hazard awareness training to ancillary workers.

- 2.7.8 Train laboratory workers regarding the specific work practices, and procedures according to the provisions of their laboratories' Standard Operating Procedures (SOPs.)

- 2.8.1 Individual Laboratory workers complete Carnegie Mellon's hazard communication, laboratory safety, and hazardous waste training.

- 4.1 Inspections EH\&S performs laboratory safety inspections periodically to ensure that adequate safety equipment is available and functioning, personal protection is available, chemicals are properly used and stored, MSDSs are readily accessible and good housekeeping is being practiced. Housekeeping and chemical hygiene inspections are recommended and should be conducted by the principal investigator, laboratory instructor, or appointed representative.

- 10. Training and Information The purpose of chemical hygiene training is to provide employees with information about the physical and health hazards of the hazardous chemicals in their work area, and of the methods and procedures employees should follow to protect themselves from these materials.

\section{Purpose}

The purpose of this study was to determine if applying relevance and other adult learning theory strategies will improve safety behaviors exhibited in the Carnegie Mellon University laboratory settings. A new version of the training was developed that incorporated the new strategies. Random laboratory observations were conducted to see 
if the number of infractions of safety behaviors of employees participating in the "new" training decreased when compared to employees participating in the "old" training.

\section{Research Question}

To what extent does personal relevance impact behavior after attending a laboratory safety training session?

\section{Hypothesis}

The participants in the new training will show a significant decrease in the number of safety violations observed in Carnegie Mellon University’s laboratories during laboratory inspections.

\section{Description of University Setting}

Carnegie Mellon University was founded in 1900 by industrialist and philanthropist Andrew Carnegie. Students attended Carnegie Technical Schools (19001912), the school then became the Carnegie Institute of Technology (1912-1967) and then merged with Mellon Institute to become Carnegie Mellon University (1967-present).

Carnegie Mellon is located in the heart of downtown Pittsburgh, Pennsylvania and is the only top 25 university founded in the 20th century. The university's more than 8,000 undergraduate and graduate students pursue specialty programs that are consistently ranked among the best in the country and applications for undergraduate admission continue to rise annually.

The university has seven colleges and schools: The Carnegie Institute of Technology (engineering), the College of Fine Arts, the College of Humanities and 
Social Sciences, the Mellon College of Science, the David A. Tepper School of Business (formerly the Graduate School of Industrial Administration), the School of Computer Science and the H. John Heinz III School of Public Policy and Management. Carnegie Mellon also has campuses in Silicon Valley, California, and the Arabian Gulf nation of Qatar, and is expanding its international presence through many educational partnerships around the globe.

There have been fifteen Carnegie Mellon University alumnus or faculty members to win a Nobel Prize. And Carnegie Mellon University annually ranks among the country's top national universities, according to U.S. News \& World Report magazine. The university's undergraduate program ranked 22nd overall in the magazine's 2006 survey.

\section{Definitions}

Relevance- $\quad$ pertinence of the information to the adults' personal situation; the more the information pertains to the situation, the more likely the adult is to learn the information (Knowles, 1984a)

Participation- the learner actively works and discusses with the instructor and others during the training session

Safety Violation - violation of safety standards in the laboratory as presented in the laboratory safety and hazardous waste trainings and specified in the Chemical Hygiene Plan (See Appendix A)

Proper Clothing- no open-toed shoes, and no shorts, and hair pulled back if long 


\section{Description and Past Results of Laboratory Safety Training}

In the past, the training that was developed was presented to employees through largely a lecture-only format using PowerPoint slides. The training utilized clip art designs and presented the information required by the Laboratory Standard. The training participants were told the training was given to satisfy regulations and standards. This is demonstrated by the first slide of the training (See Appendix E). The participants were given a handout containing the presented information to refer to during and after the training as needed. The training utilized homework activities that were well-designed and would possibly help provide participants with relevance to their situation; however the homework was voluntary and not discussed or expected to be completed. The training involved a quiz at the end, as required by OSHA, but the quiz was not taken seriously because at the end, the correct answers were read and the participants changed their answers so everyone had a score of $100 \%$. The training was done in the same settings as the new training; however, there was little interaction between the presenter and the participants. There was a question and answer portion at the end of the session.

\section{Significance and Importance of the Study}

What do trainers need to learn? Although most possess the fundamental knowledge to teach in their field of study, many seemingly lack the ability to relate to their participants, specifically adults in a meaningful way.

Therefore, Carnegie Mellon University is seeking to employ theories concerning adult learning to its laboratory safety and hazardous waste training program. In the past, the training has met the standards specified by OSHA; however, staff wanted to improve 
the training to incorporate adult learning strategies. There have been a high number of employees observed through laboratory inspections not following the safety regulations defined by the Chemical Hygiene Plan.

\section{Summary}

The purpose of my study was to develop a new training that incorporates adult learning strategies and then observe participants to see how much of the training transferred to behavior change in the laboratories. The new training began with providing objectives and real-life examples as well as a quiz that was graded and then the correct answers given, as opposed to allowing participants to change their responses before the grade was recorded. The new training provided additional discussion points to allow the adults to interact more with the trainer and, therefore, become more involved in their learning. This training provided additional opportunities for the participants to derive relevance and increase their learning. This was done by encouraging discussion and having participants bring information to the training regarding specific chemicals and concerns that they had in their laboratory. By bringing information with them, the participants were able to clearly see similarity between the training and their laboratory. Similarity was found to be the most crucial element leading to transfer of training skills to the workplace. These educational concepts would hopefully transfer to improved safety practices in the laboratories. This was measured and recorded through staff observations during laboratory inspections.

In terms of validity, observational research findings are considered to be strong because the researcher is able to collect a depth of information about a particular behavior. Such "self report" data is subject to many sources of error, including memory 
effects, and the unconscious motivations of respondents to tell the interviewer what they think the interviewer wants to hear. Direct observation can reduce or negate much of this error, by relying on pure observed behavior rather than secondary accounts of that behavior. However, there are negative aspects. There are problems with reliability and generalizability. Reliability refers the extent that observations can be replicated. Seeing behaviors occur over and over again may be a time consuming task. Generalizability, or external validity, is described as the extent that the study's findings would also be true for other people, in other places, and at other times. In observational research, findings may only reflect a unique population and therefore cannot be generalized to others. There are also problems with researcher bias. Often it is assumed that the researcher may "see what they want to see." Bias, however, can often be overcome with training or electronically recording observations. Hence, overall, observations are a valuable tool for researchers.

Therefore, this safety training is developed utilizing educational theory and motivational strategy and then observed by trained staff to determine the amount of transfer of the training skills to the workplace. The staff member observing the employees is trained to evaluate the behaviors as part of their job. This training should account for bias on the part of the observer.

This study may provide guidance for others working to develop training practices and evaluation practices for their place of employment. In the following chapters, the review of literature will be presented and then the methodology used in this study. The final two chapters will analyze the data and discuss conclusion and information for further study. 


\section{Chapter 2 --Literature Review}

\section{Introduction}

Andragogy is a term that was first used in 1833 by a teacher in Germany and was reintroduced by a German social scientist in the 1920's. The term was further adopted by adult educators in Europe in 1957 before coming to the United States (Thoms, 2001). Andragogy and pedagogy refer to the study of teaching, "andra" meaning "man, adult," while "peda" meaning "child". Although pedagogy originated with early monks who recorded common characteristics among children who were learning basic facts, it was not until the middle of the $20^{\text {th }}$ century that instructors realized their assumptions about how children learn did not apply to the adults they were teaching (Knowles, 1984a). Therefore, the more formal discipline of andragogy research continues to expand.

So now the question is, "Just what is an adult learner?" Malcolm Knowles, one of the most frequently cited theorists in adult education, and is frequently referred to as "the Father of Adult Learning", identified adults by two criteria. The first criteria, an individual who performs roles associated by our culture with adults (i.e. worker, spouse, parent, soldier, responsible citizen) and the second criteria, as an individual who perceives himself or herself to be responsible for his/her own life (Knowles, 1984a). In an attempt to formulate a comprehensive adult learning theory, Malcolm Knowles published the book The Adult Learner: A Neglected Species. Building on the earlier work of Eduard Lindeman, Knowles asserted that adults require certain conditions to learn. Lindeman had a concern for praxis. His early work looked to the process of youth organization and to group work. Such questions of process remained a concern of his in his writing. 
In this dissertation, the author will discuss how the various learning and teaching theories can be applied in the area of adult training. The author will also discuss the various methods used to motivate adult learners and design instruction that will more likely transfer into the "workplace".

\section{Existing Research on Adult Educational Theory}

There has been a flurry of interest in answering the question, "How do adults learn?" There are different answers, and therefore, different theories. There are five fundamental adult learning theories that seemed to incorporate most literature: Sensory Stimulation Theory, Cognitive Theory, Reinforcement Theory, Facilitation, and Andragogy (Munoz, 1999). The Sensory Stimulation Theory states that for people to change, they must invest their senses in the process. The people who manage the learning process must try first to stimulate and control what the learners see, hear, touch, and do during a learning session (Laird, 1985). This can be accomplished through a greater variety of colors, volume levels, strong statements, facts presented visually, and use of a variety of techniques and media.

The Cognitive Theories equate man with brain, based on the proposition that the one that distinguishes human beings from other living things is that they possess brains that are capable of critical thinking and problem solving. The purpose of learning, accordingly, is to teach the brain to engage in critical thinking and problem solving. (Munoz, 1999) The emphasis here is on the importance of experience, meaning, problem-solving and the development of insights.

The Reinforcement Theory is based on behavioral psychology, especially B.F. Skinner's findings. The instructor presents the stimulus to the learner. After that, there is 
an exchange of adapted stimuli and responses. This exchange is punctuated by reinforcement in which the learner and the instructor desire to produce mutually beneficial behaviors. (Munoz, 1999)

Facilitation, a theory developed by Carl Rogers, has outlined a different theory of learning which emphasizes the learner's involvement in the learning process and especially the relationship between the learner and the instructor. The instructor is a facilitator of the learning process, in contrast to a purveyor of knowledge. A facilitative instructor is able to listen, and be flexible to others styles of learning, as well as accepting both positive and negative feedback. (Laird, 1985) The emphasis here is for the instructor to provide an atmosphere in which learners feel comfortable to consider new ideas and are not threatened by external factors. (Laird, 1985)

Andragogy is the final model to analyze. Andragogy and pedagogy refer to the study of teaching; "andra" meaning "man, adult," while "peda" meaning "child". Thus andragogic learning designs involve a number of features which recognize the essential maturity of the learner; they are problem-centered rather than content-centered; they encourage the learner to introduce past experiences into the processes in order to reexamine that experience in the light of a new data; the climate of the learning process must be collaborative as opposed to authority-oriented; planning and evaluation are mutual activities between learner and instructor; evaluation leads to reappraisal of needs and interest and activities are experiential, not "transmittal and absorption" as in standard pedagogy. (Laird, 1985)

There has been some criticism of Andragogy and Malcolm Knowles. Some criticism concerns the portrayal of this as a learning model as opposed to a teaching 
model. Other criticism concerns the students need to learn from others, thereby, not utilizing the full capacities of the instructor's knowledge base. In other words, teachers were being paid and not teaching, but allowing students to control their learning. Other criticisms included applying the assumptions of adult learning to all learning situations, and gearing his ideology to middle-class norms and to the status quo. (Thoms, 2001)

While the author too shares the opinion that Knowles' andragogy theory is more a teaching method, as opposed to a learning model, this encompasses the techniques and issues that instructors should be utilizing. When learners are actively involved in their learning, they tend to remember more and are more likely to transfer this learning to the workplace. The remaining portion of this chapter concentrates on detailing the aspects of Knowles' theory that are easily incorporated into training sessions.

"Adult learners, like children, need to play...taking initiative, making choices, acting and interacting. Much learning should be playful and exploratory, and people in that stage of learning don't need challenges, they need shared enthusiasm.”(Jones, 1986) When beginning to examine adult learning styles and methods, many similarities exist in how adults learn compared to how children learn. There did seem to be three basic differences: life experience as a barrier, life experience as a positive trait, and needing to see the relevance of the material to their lives. (Alexander, 1999)

Adults come to us with much additional 'baggage' when compared to children. They have many more life experiences, demands on time, as well as, more psychological barriers, such as past negative experiences. These experiences require more from the instructor in terms of attracting and maintaining attention, and evaluating the experiences that exist that may hamper the learning process. Adults may have past educational 
experiences that are negative and need to be overcome in order to participate in learning new skills. Also, adults may be plagued by more incorrect information and knowledge than children that needs to be overcome in order to learn new concepts.

However, in contrast, the life experience that adults bring to learning may provide many experiences to be the foundation for their new learning. Therefore, "adults usually benefit from reflection, sharing, and communicating their ideas and insights with others."(Alexander, 1999)

This life experience can be a real asset during the discussion times; however, the instructor must know how to encourage, as well as to curb, "This is how we did it..." discussions. This can lead to others not wanting to change procedures, or not being able to 'think beyond the box' for new ideas. (Thoms, 2001)

Adults also must see the relevance of the material to their immediate needs since time limitations and commitments apart from work may make it difficult to make learning a priority. (Alexander, 1999) This will many times be what is needed to gain the adult's attention in the beginning.

\section{Comparing Adults' Learning and Childs' Learning}

What differentiates adult learners in general? According to Knowles, adults are self-directed, goal oriented, practical and problem solvers, and they have accumulated life experience. Therefore, the Andragogic model asserts that five issues be considered and addressed in formal learning. They include (1) letting learners know why something is important to learn, (2) showing learners how to direct themselves through information, and (3) relating the topic to the learners' experiences. In addition, (4) people will not learn until they are ready and motivated to learn. Often this (5) requires helping them 
overcome inhibitions, behaviors, and beliefs about learning. Andragogy usually is cited in education texts as the way adults learn. Knowles himself concedes that four of andragogy's five key assumptions apply equally to adults and children. The sole difference is that children have fewer experiences and pre-established beliefs than adults have and thus have less to relate.

However, there are several differences to note when comparing an adult and child in a learning situation. While children are dependent, adults see themselves as selfdirecting. Children expect to have questions which must be answered by outside sources, while adults expect to be able to answer part of their questions from their own experience. And possibly the most important distinction, children expect to be told what they need to do, while adults may have a very different viewpoint on that issue, because they value their past experience. Adults many times, want to have input over their learning.

Children and adults learn for different reasons. Adults are not impressed or motivated by gold stars and good report cards. Instead, they want a learning outcome which can be put to use immediately, in concrete, practical, and self-benefiting terms.(Thoms, 2001) Adults frequently tend to be slower in some physical, psychomotor tasks than children. The adults are also less willing to make mistakes; often they compensate by being more exact. Therefore, adults tend to ask for clarification on assignments more often than traditional learners.

Because adult learners acquire psychomotor skills more slowly then younger students, adults should be given the opportunity to proceed at their own pace, often in a 
self-paced learning package. If self-paced learning cannot be integrated into the learning session curriculum, than the challenge to meet the needs of a variety of learning paces and styles lies squarely on the shoulders of the instructor. The learning session is sometimes brief, therefore, even more difficult.

\section{Summary of Adult Learning Theory}

As adult learners, they make decisions about what, or indeed, even whether, they choose to learn. Knowles, who is generally credited with being on the originators of modern adult learning theory, based his theory on primary assumptions about how adults learn. These include the need for training to be grounded in real-life experiences and the premise that skills or knowledge learned must be applicable to immediate circumstances. Adults are pragmatic in their learning. Unlike children in a classroom, they will not put energy into learning what does not appear relevant to their lives. For training to be effective, adult learners need to know why they need to learn something. The training should be self-directed and related to prior experience. The adult must be ready and motivated to learn. The adults must believe that what they are learning is oriented toward problem solving. In order for adults to be motivated to learn, they must believe they will be successful and they have a choice in whether or not to learn. In other words, they must see the training as valuable and relevant. The most compelling reason for providing training is to try to change people's behavior in some fashion. The adult must be part of this dialogue and 'buy into' the training in order for this transfer to take place. 


\section{Existing Research on Training Methods}

Training involves an expert working with learners to transfer to them certain areas of knowledge or skills to improve in their current jobs. This concept is as old as apprenticeships, learning the family business, and learning to keep a household. Until the fairly recent past, the trainer is simply a person who is an 'expert' in the job or field within the company or family. That person did not have knowledge of the best practices to employ when delivering this training. Unlike providing training that involves manual skills such as how to work a cash register or fix a carburetor, where modeling is the obvious method, many times one uses only lecture to teach non-manual skills.

Approximately 82 percent of firms use lecture in their training. (Adams, 2000) Unfortunately, lecture is generally ineffective as a teaching tool for adults, since adults remember approximately 10 percent of what they hear. However, when information is seen and heard, retention level jumps to about 50 percent. When adults discuss their learning with others, their retention rate increases to approximately 70 percent. Finally, when trainees participate in the learning process through demonstration (both physical and verbal), retention increases to 90 percent. (Adams, 2000)

According to The Role of Occupational Training and Evaluation in the Learning Organization by Munoz, et. al. (1999), there are general areas in which training occurs in most businesses:

1. Communications: The increasing diversity of today's workforce brings a wide variety of languages and customs.

2. Computer skills: Computer skills are becoming a necessity for conducting administrative and office tasks. 
3. Customer service: Increased competition in today's global marketplace makes it critical that employees understand and meet the needs of customers.

4. Diversity: Diversity training usually includes explanation about how people have different perspectives and views, and includes techniques to value diversity

5. Ethics: Today's society has increasing expectations about corporate social responsibility. Also, today's diverse workforce brings a wide variety of values and morals to the workplace.

6. Human relations: The increased stresses of today's workplace can include misunderstandings and conflict. Training can help people to get along in the workplace. 7. Quality initiatives: Initiatives such as Total Quality Management, Quality Circles, benchmarking, etc., require basic training about quality concepts, guidelines and standards for quality, etc.

8. Safety: Safety training is critical where working with heavy equipment, hazardous chemicals, repetitive activities, etc., but can also be useful with practical advice for avoiding assaults, etc.

9. Sexual harassment: Sexual harassment training usually includes careful description of the organization's policies about sexual harassment, especially about what are inappropriate behaviors.

There are a number of general benefits that employers find when they provide training to their employees. These benefits include:

1. Increased job satisfaction and morale among employees

2. Increased employee motivation

3. Increased efficiencies in processes, resulting in financial gain 
4. Increased capacity to adopt new technologies and methods

5. Increased innovation in strategies and products

6. Reduced employee turnover

7. Enhanced company image

8. Risk management

\section{Strategies to Help Motivate Adult Learners}

Unlike children and teenagers, adults have many responsibilities that they must balance against the demands of learning. Because of these responsibilities, adults have barriers against participating in learning. Some of these barriers include lack of time, money, confidence, or interest, lack of information about opportunities to learn, scheduling problems, "red tape," and problems with childcare and transportation.

As I stated earlier, gold stars and report cards do not always motivate adults, therefore trainers must have other tactics available to motivate their audience. So what motivates adult learners? Some typical motivations include a requirement for competence or licensing, and expected (or realized) promotion, job enrichment, a need to maintain old skills or learn new ones, a need to adapt to job changes, or the need to learn in order to comply with company directives. (Broadwell, 1995) Individuals are motivated in many ways; one must have several methods available to motivate a diverse audience. I have devised a list of suggestions, attributed to no particular authors or sources, but rather personally construed.

- put materials into "bit-size chunks" which people are able to understand

- use the whole-part-whole concept, showing the overall picture followed by the details and then a refresher with the overall picture 
- make the material relevant, as close to the actual requirements of that person's job

- let the students work in groups, since they would rather ask other students for assistance rather than ask the course instructor

- create a climate of "exploration" rather than one of "prove it"

- keep the course requirements in perspective to the amount of time for the course

- make certain the student is equipped with enough knowledge and skill to complete the task, rather than setting the person up for failure

\section{Characteristics of a Motivating Instructor}

Although motivating instructors give us that special desire to learn and they have their own personal strengths and style, there are some common characteristics that can be learned, controlled, and planned for by anyone who instructs adults. Four cornerstones have been identified: expertise, empathy, enthusiasm, and clarity. (Wlodkowski, 1993)

According to Wlodkowski (p. 17), the practical definition of expertise is threefold: we know something beneficial to the student; we have a through grasp of the content, and we can and are prepared to convey this information through an instructional process. Sometimes, the instructor may be younger than some of the students; therefore just our name and title will not impress them. In addition to the expertise of the content, the instructor must be able to covey this knowledge through an effective instructional process. This will in turn, garner the respect of the students.(Wlodkowski, 1993)

Empathy involves the human factor associated with learning; it is separate from the computers, the software programs, and the attendance requirements.(Wlodkowski, 1993) Adult learners have different needs and troublesome issues than children, but the more the students' needs and expectations are met, the more motivated they are to learn. 
An enthusiastic instructor is a person who cares about and values his subject matter and teaches it in a manner that expresses those feelings with the intent to encourage similar feelings in the learner. If emotion, energy, and animation are outwardly visible in the instructor's presentation, the more likely learners are to have similar interests and attend to the material being presented. (Thoms, 2001)

Demonstrating clarity is really the power of language and organization. This final cornerstone is absolutely critical in teaching adult learners. (Wlodkowski, 1993) Along with the formation of a presentation that is well planned and well orchestrated, the delivery of the content must be through, fluid, and understandable.

In addition, adults appreciate an instructor to follow the session plans and maintain the training focus. Adults also appreciate documentation and appropriate evaluation, as well as, the opportunity to evaluate the instructor. (Robotham, 2001)

\section{Existing Research on Training Design}

The adult learner must relate to the training and the training must relate to the learner. Some examples could be providing scenarios and problems as opposed to rote memorization and lecture. The trainer must ensure that examples, scenarios and problems relate to the adult learner's frame of reference.

The training must meet an immediate need of the learner and be communicated clearly to the learner. Adults have many time demands and some resent the time taken away from their work schedule to attend training. Also, with many demands, both work and home, adults need a reason to attend to the information. If the trainer helps the adult 
learner understand the value of the training to their personal situation, the learning experience is enhanced.

Also, the adult learner should be involved with setting the goals of the training. Opening the lines of communication and assessing needs expressed by personnel can derive goals to provide focus and purpose to the training activities. Too often, training is provided solely to meet legal requirements and its effectiveness is not measured quantitatively or qualitatively. (Adams, 2000) When allowing employee input in planning and guiding training, attention is increased and the employee's value of the training is increased.

\section{Principles of Training Design}

In order to develop an effective training program, certain elements should be implemented (Robotham, 2001):

1. Perform a needs assessment

2. Establish training objectives

3. Specify training content and media

4. Account for individual differences

5. Evaluate Training

Conducting a needs assessment is the first step in the design process. The purpose of the needs assessment is to uncover what the performance problem is, whom it affects, how it affects them, and what results are to be achieved by training. The starting point is the location of existing performance problems in each job category, and individual training needs. Then, it should be to identify the knowledge, skills, and attitudes necessary for employees to perform competently. (Munoz, 1999) Sometimes, as 
in the laboratory safety training at Carnegie Mellon University, governmental agencies define skills, information, and concepts that must be included in training.

The next step is to identify the training objectives. They guide the remaining steps in the instructional design process by describing precisely what the targeted learners should know or do on completion of a planned training/learning experience. They also communicate the results sought from the learning experience. In a sense, training objectives create a vision of what learners should be doing after they master the instruction. (Munoz, 1999) Training objectives can be identified as one of three major types of learning: affective, behavioral, and cognitive. Affective learning involves the formation of attitudes, feelings, and preferences. Behavioral learning includes the development of competence in the actual performance of procedures, methods, operations, and techniques. And cognitive learning includes the acquisition of information and concepts. (Knowles, 1984a)

Specifying training content and media is the next stage in the planning/design process. It is an overall plan governing instructional content (what will be taught?) and process (how will it be taught?) During this step, the instructor organizes the learning content into meaningful instructional sequences. (Nadler, 1984) There are numerous ways to organize instructional sequences: simple to complex, concrete to abstract, practical to theoretical, logical order, or based on a problem-centered technique. (Nadler, 1984) There are several considerations when it comes to choosing the instructional materials, the characteristics of the learner population, facilities and equipment, cost, time, and the nature of the subject matter. 
Once the instructor has written the objectives, designed the content and media, the next step is to assess and then account for individual differences among the learners. This may occur prior to the training or lesson by evaluating the learners or during the lesson as it is presented. The instructor must be cognizant of the learners' mastery of the material being presented.

The training evaluation can be performed at any of three stages: input, output, and outcome. The input involves evaluating the costs or time used to develop the training compared to the overall training budget. Output can be assessed in terms of the number of people trained, cumulative training costs and/or percentage trained versus a performance standard. (Robotham, 2001)

Outcome can be determined by measuring and evaluating the following criteria:

- Reaction - surveys or interviews to gauge the emotional response of the participants

- $\quad$ Knowledge — usually involves pre and post tests of knowledge

- Behavior - may involve proficiency tests, direct observation or self-reports of skill performance

- Results - determined by direct calculation of losses, change in productivity, safety, or quality

Of course with regard to training, the amount of learning the participants transfer from the training room to the workplace depends primarily on two variables: similarity, and ease of integrating.(Robotham, 2001) In order to be successful in this area, one must encourage the learner to look for similarities and reflect on how to incorporate what they 
are learning. The learners must actively construct this knowledge with activities, discussion, simulation, or practice during the training. (Knowles, 1984a)

\section{Kirkpatrick's Four Levels of Evaluation}

Donald Kirkpatrick developed a four-level model to assess training effectiveness (Kirkpatrick, 1994). According to Kirkpatrick, evaluation should always begin with level one and then move up the pyramid as budget and time allows. Level one evaluates reactions. This level measures how participants in a training program react to the program. The questions that can be answered are questions regarding the participants' perceptions - Did they like it? Was the material relevant to their work? The type of evaluation is usually done with a "smile sheet" (Kirkpatrick, 1994) or other survey immediately after the training. This level provides information for the trainer to use to improve their training and motivational methods.

The second level in the evaluation plan is learning. Assessing at this level moves the evaluation beyond learner satisfaction and attempts to assess the extent students have advanced in skills, knowledge or attitude. The methods of evaluation at this level range from formal to informal testing. If possible, a pre-test is given prior to the training and then a post-test to measure the amount of learning that occurred.

Level three is transfer. This level measures the transfer that has occurred in learners' behavior due to the training program. Evaluating at this level attempts to answer the question, "Are the newly acquired skills, knowledge, or attitude being used in the everyday environment of the learner? For many trainers this level represents the truest assessment of a program's effectiveness. However, measuring at this level is difficult as it is often impossible to predict when the change in behavior will occur, thus 
when to evaluate and how often to evaluate. As stated earlier, transfer of training content and skills is the most crucial element in training.

Level four in the evaluation model is the results level. This level measures the success of the program in terms that managers and executives can understand, such as: reduced frequency of accidents, increased production, increased sales, and higher profits. Determining results in financial terms is difficult to measure and is hard to link directly with training. Therefore, this level's results are usually not typically addressed.

When looking at the four levels of this model, the Director of the Environmental Health and Safety Department was most interested in evaluating level three, transfer. Level one would not necessarily improve safety practices and level two is already somewhat in place with the quiz at the end of training. The amount of transfer would be observed directly and would possibly lead to fewer safety violations.

\section{Safety Training Specifics}

Adults are motivated to learn those things that will be helpful in solving problems or will provide what Knowles call an "internal payoff" rather than an external one (p. 149). While this does not mean that adults don't value promotions or pay raises that may result from increased training, the stronger motivator is the satisfaction of perceived internal needs (p. 149). This is especially true when it comes to safety training. Adults will try to learn and perform what they see as valuable to them as individuals. This is where the objectives of safety training need to come into the forefront rather than just training to satisfy regulatory agencies. Adults will pay attention if the hazards that they see in the training are similar to something that they may come into contact with in the workplace. The hazards in a laboratory environment can take many forms: sharps, 
chemicals, gases and fumes. These are some of the inherent hazards, and then workers add more hazards with poor housekeeping and storage, failure to note dangers, and not wearing personal protective equipment properly. In order for adults to begin to learn these hazards and methods for safe handling, they need to see the relevance and similarity to their situation. This can be done by establishing a climate of safety in each laboratory and an overarching climate around the campus. This culture has four basic characteristics (Noe, 2002):

- All employees hold safety as a value.

- Each individual feels responsible for their own and co-worker's safety.

- Each individual is willing and able to "go beyond the call of duty" on behalf of the safety of others.

- Each individual routinely uses safe practices for the benefit of others.

"A 'climate of safety' requires continual attention to the person, the environment and the behavior" (Noe, 2002).

This was the basis for the development of the new training program. The slides present ways that each individual can contribute to the overall climate of safety at Carnegie Mellon University.

\section{Summary}

With this information on andragogy and training design and methods, there are more similarities than differences between andragogy and pedagogy. Instructors must find the best techniques to meet the needs of the learners regardless of the age of the learners. In order to do this, much planning and evaluation need to occur prior to the training class. The instructor needs to write objectives that closely resemble the work the 
learners will be performing in the work place and make sure the learners are aware of this similarity. If adults see the relevance of the information to their situation, they will be motivated to learn and achieve regardless of the media used in the presentation. If adults see the relevance of the information, they will pay attention if it is a lecture, demonstration or discussion. Of course, they may pay attention, but to be more likely to utilize and remember the information, adults should be given time to process and reflect. There are many methods to use to help adults see the relevance of the information. Some of the methods are: discussion, role play, demonstration, simulation, working with selected materials and examples, and using real examples when possible.

The participants in the new training presented in this study are provided additional opportunities to make the training relevant to their individual laboratory settings through discussion and real-life applications and photos. The participants are also given a quiz that is graded as opposed to a quiz in which everyone scores $100 \%$. This will add to the perception that what is being discussed is important, since most adults attach grades with learning priorities. The training will be more like what they will see in the laboratories, therefore, aiding transfer of skills from the training to the workplace. The new training will incorporate similarity and demonstrate the ease of integrating the safety practices into their daily activities in the laboratories, the two areas that aid in transfer of skills. This transfer of skills will be observed during the laboratory inspections and violations recorded. 


\section{Chapter 3--Methodology/Design}

\section{Introduction}

The purpose of this study was to determine if adult learning strategies could be incorporated into a required employee training session (Laboratory Safety Training) and have those strategies result in a statistically significant reduction of the number of observed safety violations. Carnegie Mellon University requires that all employees who work with hazardous materials in a laboratory setting take Laboratory Safety Training. This training in the past, has involved a series of power point slides followed by a short quiz to ensure that some level of retention was achieved. No statistical data was ever collected to measure if the training was effective or achieved its goal, which is to reduce the number of OSHA and EPA violations in the laboratories. New power point slides were developed for the "new" training, a class activity was included and several props were used. The changes were done to add relevance to the new training. Adult learners are shown to learn better if the material presented to them has some relevance to their lives or work. (Laird, 2001) While there is no formal scientific procedure to test for relevance, the study will assume that if the observed violations are significantly reduced compared to the old training then the new training must be more relevant. The participants were divided into two groups; those that attended the "old" training and those that attended the "new" training. The "old" training met the required OSHA standards, but did not employ many of the recommended strategies for adult learning theory. Based on the inspections and observations of Environment Health and Safety staff members, there was little transfer of the behaviors discussed in training. The "new" training was designed to incorporate activities that would involve the adult learners and by doing so 
demonstrate how the training was relevant to their individual situation. This

accomplished a significantly greater transfer of behaviors to the laboratory environment and a reduced number of observed safety violations.

The new training incorporated the following elements of adult learning theory: providing objectives for the participants, incorporating the employees' prior knowledge and utilizing the participants' experiences during the training, and utilizing the wholepart-whole concept, making the material as close to the worker's actual environment, providing scenarios and problems, and making the training meet the needs of the participant. By showing the objectives of the training in the beginning so everyone would know what to expect, and then organizing the training by major categories, relevance for the employees should be enhanced.

The trainer in the new training sessions began each session by questioning the participants about why they were attending the session. The employees were given the opportunity in the beginning of the new training to rationalize and vocalize why they were attending the training and what would be accomplished during the training. In the new training sessions, employees invariably stated that they were attending the training in order to be safer in their respective laboratories and enhance the credibility of their research by using prescribed methods of housekeeping procedures, safe chemical storage, and appropriate safety precautions. This was distinctly different from the old training beginning, which started by stating the regulation that required the employees to take the training.

Also within the new training sessions talking points were used to allow participants time to provide input describing their particular setting, chemicals used and 
the opportunity to ask questions for clarification. Whereas in the old training participants were given opportunity to ask questions, very few opportunities were presented for discussion and actually soliciting participants' active participation.

The new training also incorporated the whole, part, whole concept of instructional design. This was done by beginning with the "big picture" that the participants vocalized when they stated that they were there to learn how to be safer. This would incorporate the whole concept. The parts were then presented through the presentation that specified how to be safer by demonstrating chemical handling and storage, personal protective equipment, how to read material safety data sheets, how to use the chemical inventory system and how to maintain proper housekeeping practices. The training concluded once the trainer reiterated the goal of the training and then reviewed the material with the participants.

The past experiences and questions presented by the participants was used by the trainer to determine focal points of the training. For example, in one group, the employees were mainly concerned with housekeeping and spill response; this was focused on by the trainer throughout the training and used in examples throughout. In another group, there was more concern with the chemical inventory system and how to utilize this program in their laboratory setting. By utilizing adults' experiences and allowing the adult to help focus the training, the training became more relevant to their situation.

Staff members from Carnegie Mellon University’s Environmental Health and Safety Department randomly observed the training participants after the employee attended the training session to verify that safety precautions were being followed. The 
staff members were trained in the safe handling of hazardous materials. Every member of the EH\&S department has a four year college degree. One individual has a Masters degree in Industrial Hygiene. These individuals routinely inspected the laboratories and observed the employees working as part of their daily job function. The staff utilized the laboratory inspection form (Appendix D) during the study. No further training of the EH\&S staff was necessary to perform this study, since the recording of safety violations fell well within the realm of their daily job functions. By using the EH\&S staff, a source of bias was eliminated, since the laboratory workers would not alter their behaviors when the EH\&S staff member walked into their laboratory.

\section{Procedure Used to Develop Training}

This project began nearly one year ago with a conversation with the Director and Assistant Director of Environmental Health and Safety at Carnegie Mellon University. They were interested in improving the laboratory safety training and in the process be able to determine if the training was effective. The staff participated in meetings to discuss the needs and requirements facing the department regarding training and evaluation. During laboratory inspections, employees were observed not practicing safety requirements as presented in the laboratory training. The discussions involved incorporating motivational strategies and adult learning theory into the training. A timeline was developed and research began regarding training principles, motivational strategies, and adult learning theory. After researching these areas, the author began to make suggestions to improve the training program. Meetings were organized to discuss and evaluate the planned training. During the meetings, a two-part plan was developed to phase in the new training. Phase One (discussed and evaluated in this document) 
involved updating the laboratory safety and hazardous waste training given to participants in training sessions. Phase Two (to be implemented next year) involves an online training portion and then a hands-on training session in a laboratory.

While the planning meetings were continuing, the old training was given to employees during the months of October through December. During this time, employees taking the training were then observed to note the number of safety violations in their laboratory settings. The new training was in place and ready to go beginning in January and is continuing at the present time. The employees who participated in the new training during the months of January through March were observed to also note the number of safety violations in their laboratory settings.

\section{Delphi Process}

A modified version of the Delphi Process was the process selected to develop the training. The Delphi Process is a technique used to take advantage of the judgments of a group of experts for the purpose of making decisions, determining priorities, or making predictions. It provided an opportunity to obtain opinions from a wide variety of experts across a defined geographic area, without having to physically convene a meeting. An advantage of using a Delphi approach was that it allows each expert to share his or her opinion, without being swayed or pressured by others in the group. (Adler, 2004) The Delphi Study process essentially provided an interactive communication structure between the researcher and the 'experts' in a field. Questions can be asked of the experts and the information was then analyzed and fed back to each person, via further questions, and their responses are analyzed and fed back, and so on, until the consensus was 
reached. The researcher is basically a good facilitator, but the process helps to strengthen the validity of the results.

The Delphi Process is an extremely flexible methodology; it is applicable to a wide range of investigators. Despite this malleability, experts maintain that four elements are critical to the process. These elements include: feedback in the form of individual contributions or responses; assessment of the group opinion; opportunity for individuals to revise their original responses following the initial assessment of the group opinion; and guaranteed anonymity for the individuals who participate in the process. (Adler, 2004)

This was the process chosen to develop the new training. The staff members in the EH\&S department are experts in the environmental health and safety field. Drafts were sent via electronic media to gather input on formatting and content of the slides.

The first draft of the new training included behaviors that are taught in the laboratory safety and hazardous waste training and are included on the laboratory evaluation sheet used by the university. This draft was refined with assistance from the assistant director of the environmental health and safety department at Carnegie Mellon University. The assistant director continued to offer guidance and suggestions during the construction. The author also sent the draft of the training to a professor to evaluate the slide regarding design and aesthetic issues. Revisions to the slides were made according to the feedback received from the experts. The slides were then discussed with the panel of individuals at the bi-weekly meetings to improve the training program at Carnegie Mellon University. 
The training was revised based on the suggestions gathered from these meetings. The researcher then sent the revised slides to all of the experts again. After further comments were received, the slides were revised again. This became the final training to be used with the employees during the training sessions beginning in January.

\section{Comparison of Old and New Trainings}

The old training (See Appendix D) began by discussing the regulations involved, whereas the new training (See Appendix E) begins by showing the objectives of the training so employees know what to expect and how it impacts them personally.
"Old" Training
"New" Training

No objectives specified

Limited emphasis on discussion

Use of clip art

35 participants (randomly selected

20 to represent different departments)

October- December
Objectives given in the beginning Increased emphasis on discussion

Use of actual laboratory photos

38 participants (randomly selected

20 to represent different departments)

January- March

Table 1. Comparison of old and new training.

The old training was primarily a lecture only training session with a handbook and question and answer session at the end. The participants were also given a quiz at the end and the answers were discussed prior to a grade being recorded. The participants were told this would be the procedure prior to the training beginning. The training 
immediately delved into the rules and regulations guiding the training instead of focusing the employees on safety in the workplace. The training began by describing the rules and regulations requiring their attendance and no other discussion to make the information that was to be presented relevant to the employee. The trainer provided each participant with a handbook at the onset of training. The handbook was referenced on the slides and the employees were given instructions to complete the questions when they returned to the laboratory. There was no incentive discussed for completing this task, nor was it checked. The adults would not necessarily be motivated to complete these tasks following the training, unless they were able to see impact on their personal safety - this was not something emphasized. Therefore, the handbook would at best be kept available as a resource or reminder of the training.

The old training began with:

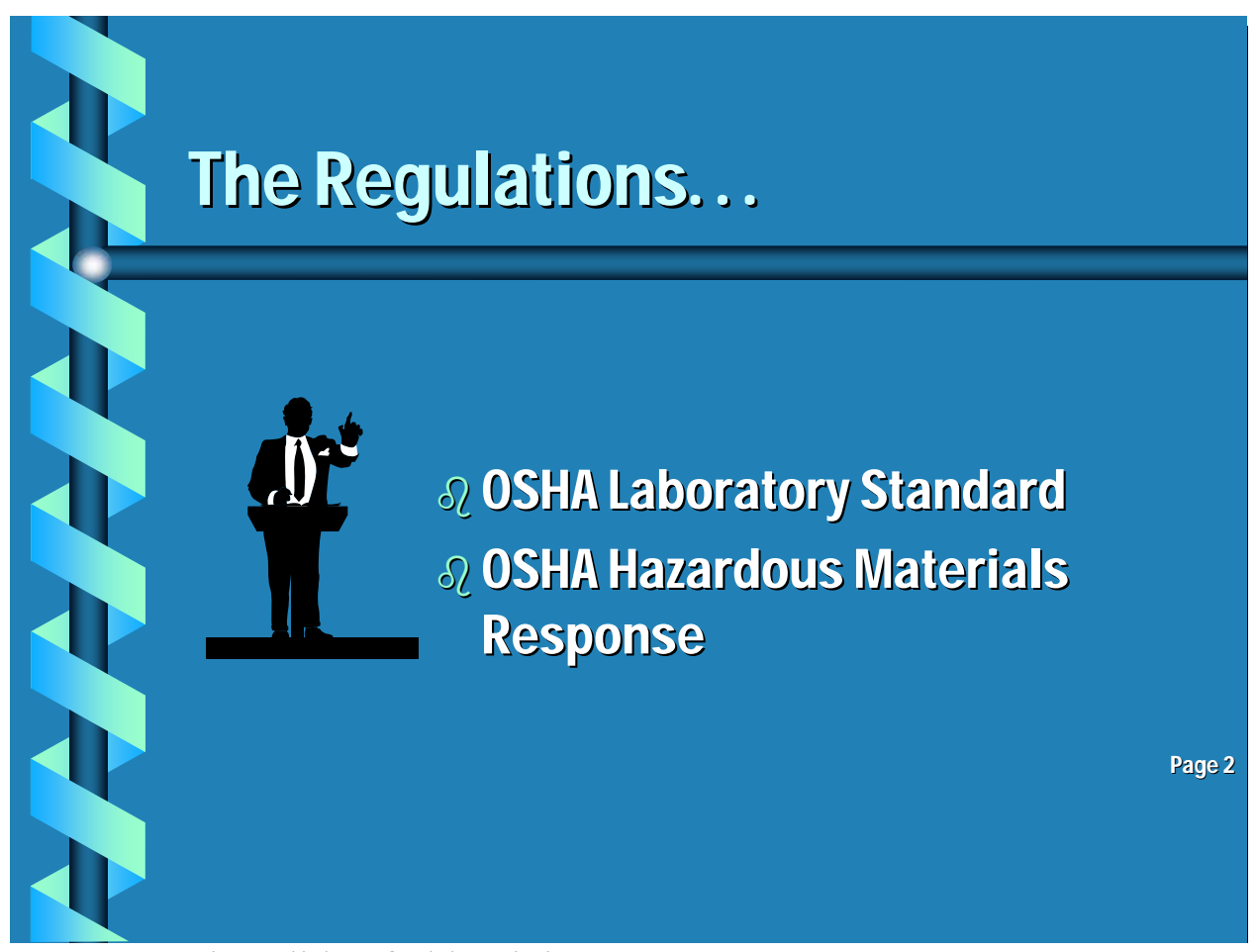

Figure 1. First slide of old training. 
The new training was created using Carnegie Mellon University's school colors as the background. This was selected to portray the school working together to provide a safe work environment and the department's desire to come together as a group to work safety. The font was selected based on ease of reading from a distance and the recommended font type and size for group presentations. The photos used in the training were pictures of laboratories at Carnegie Mellon University that employees could relate to, although any identifiers that could reveal the labs identity were removed to prevent any embarrassment or bad feelings. These techniques could help increase similarity and relevance for the employees and lead to the desired behaviors.

The new training began by showing participants what they will be learning:

\section{Objectives}

During this presentation we are going to talk about:

- OSHA regulations, in particular, "The Lab Standard".

- Permissible Exposure Limits (PELs), signs and symptoms of overexposure, medically monitoring, and air monitoring.

- Chemical labels, safe chemical storage, how to detect a chemical release, and Particularly Hazardous Substances (PHS)

- Chemtracker, Personal Protective Equipment (PPE), emergency equipment and the Emergency Response Guide.

Figure 2. First slide is training objectives to be discussed in the new training. 


\section{Objectives....continued}

- Proper use of chemical fume hoods

- Laboratory hazards and general work rules

- Good housekeeping habits and the importance of maintaining a clean and orderly lab.

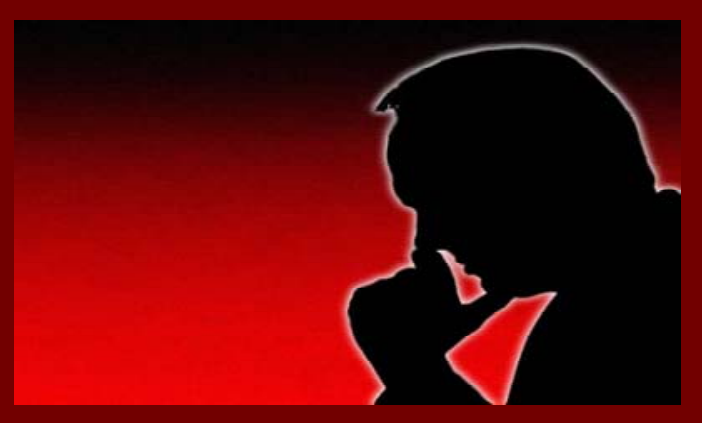

Figure 3. Second slide of objectives in new training.

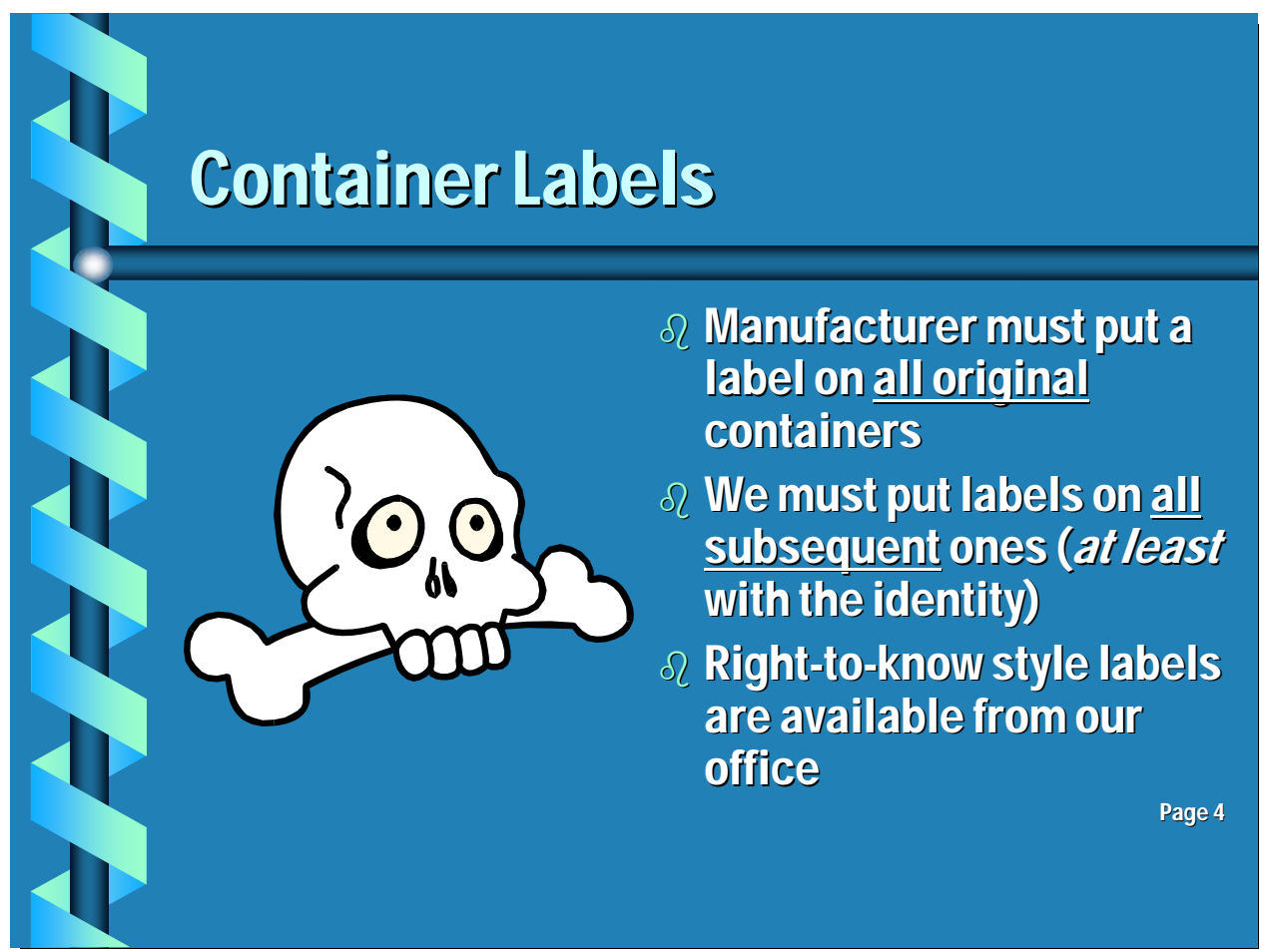

Figure 4. Example from old training concerning labels. 


\section{Container Labels}

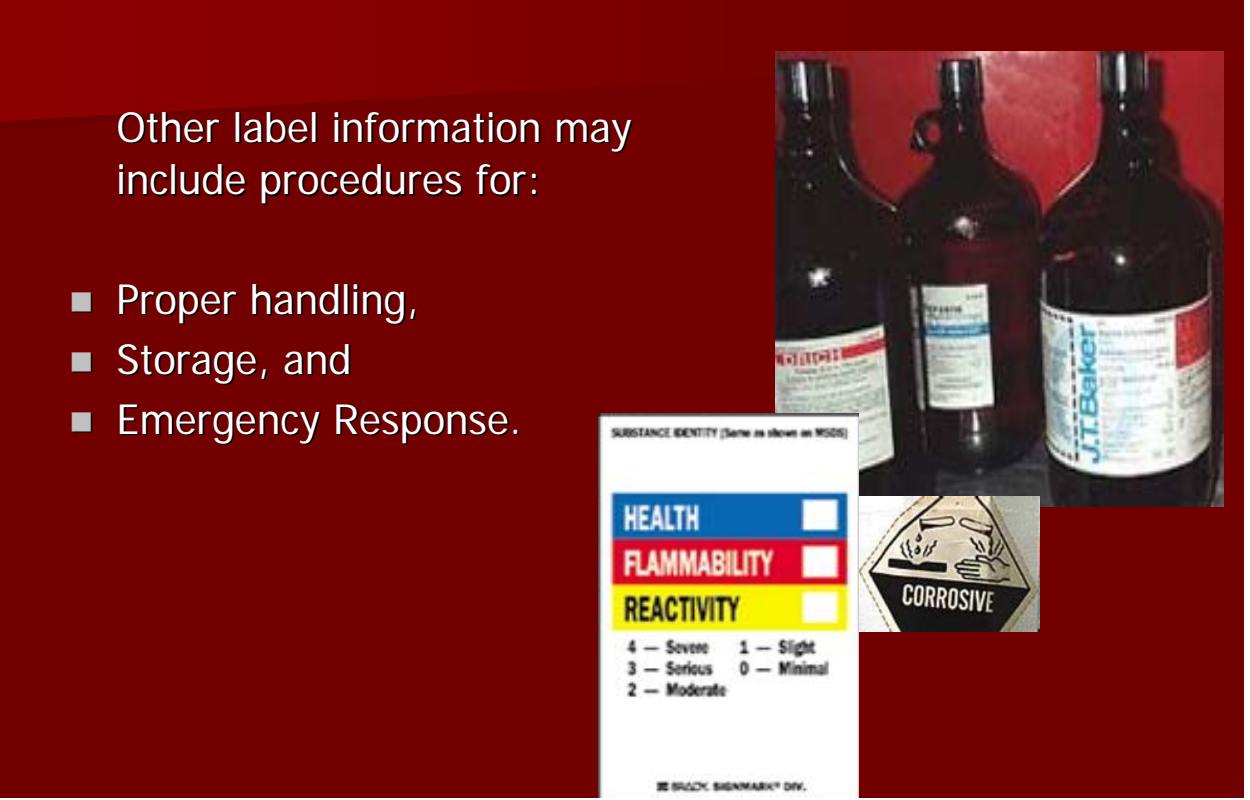

Figure 5. Example from new training concerning labels.

The new training also utilizes real pictures from laboratories on campus as

opposed to clip art as found in the old training. Also, the new training includes sections arranged to provide whole-part-whole so participants get the "big picture" and then can discuss. The new training engaged in discussion prior to the beginning of the training with the participants describing what they hoped to gain from attending the training. Inevitably, the answer, "Learn how to be safe in the laboratory" was discussed. This discussion helped to focus employees and provided relevant reasons for attending the training, other than fulfilling an OSHA requirement. 
Training Dates and Number of Participants

Date Total Number of Employees Type of Training

October 27, 2005

November 15, 2005

November 22, 2005

November 28, 2005

January 18, 2006

January 26, 2006

February 8, 2006

February 23, 2006

March 8, 2006
11

7

13

4

17

10

2

3

6
Old

Old

Old

Old

New

New

New

New

New

Table 2. Participants in training sessions.

As can be seen in Table 2, the number of participants in any training session varied from a low of two to a high of seventeen. There were several reasons for this; the time of year, the university was closed or classes were not being held, time of day training was held (morning or afternoon), and if a new laboratory was recently commissioned. Generally, there were two training sessions a month, but sometimes this was altered due to demand or lack of it. Participants would sign up for the training through the EH\&S website. They would enter their name, department, principal investigator's name, and then chose which session they wanted to attend. 
The EH\&S website is maintained by the department. Once an employee registers for a training sessions the information is stored into a permanent database. This information is then updated as the employee receives additional training, transfers to a different laboratory or leaves the university altogether. As a backup to the database, each employee signs a sign-in sheet before the training starts. The sign-in sheet along with the employee quizzes are then maintained in a file as additional verification that the employee had attended the required training. These files must be presented at the request of an OSHA inspector to provide proof that the university is in compliance with the OSHA Laboratory Standard. If during the course of an EH\&S laboratory inspection an employee is found that has not taken the training, the employee is told to sign up for a training session within thirty days. If after thirty days the employee still has not registered for the training, their supervisor is notified and the employee's lab privileges are revoked. If an OSHA inspection reveals that employees are working with hazardous materials and have not received the proper training the university is subject to being fined. The advantage of having two systems (database and hardcopy) is that the information is double checked and fewer employees are allowed to work without the required training. The principal investigators are to submit a list of their employees annually and this list to compared against the EH\&S database.

\section{Description of New Training Session}

The new training sessions occurred in a classroom setting exactly like the old training. The setting rotated between two campus locations in an effort to accommodate the employees. One session was held on the main campus and the other in Mellon Institute were a large number of laboratories are located. The training sessions occurred 
in conference rooms or classrooms where PowerPoint presentations could easily be utilized. All students were given a manual which covered all the same information which was covered in the class. The manual was the same manual used in the old training. Each participant was also given an EH\&S pencil, which was to remind them to practice safety while in the laboratory. The instructor stood in the front of the class during the training. The training opened with a short speech which focused on improving safety on the campus of Carnegie Mellon University. Then a short exercise followed that allowed the entire class to participate. Each employee that answered a question received an EH\&S flashlight. This was done to increase participation and comfort level as well as to allow the adults to feel less bashful and more willing to take a risk by answering questions. This exercise allowed the instructor to quickly assess the level of laboratory safety knowledge the class possessed and provided areas of focus. The participants were then shown the objectives that would be discussed during the training session and were told to interrupt if they had a question or comment. During the training, the employees were asked about specific hazards in their work environment chemicals and then these hazards were discuss amongst the class. This added relevance for each employee and allowed the class the opportunity to become more involved with the training. The employees and trainer interacted throughout the training session in order to accommodate specific questions and concerns.

At the end of the training session, after all questions had been addressed, a quiz was given. The quiz was a ten question multiple choice test. The tests were graded and a score of at least seventy percent was necessary to pass. If someone failed the quiz they were required to retake the training. The quiz served to strengthen those points that were 
felt to be of most importance to the employee's safety. The employees were notified only if they failed the quiz; otherwise the quiz was attached to the sign-up sheet and filed.

\section{Population}

The participants in the study were Carnegie Mellon University employees attending laboratory safety and hazardous waste training. The employees took the required training in order to be allowed to work in the laboratories at Carnegie Mellon. The employees were partially comprised of undergraduate, graduate, and post doctorate students. Some of the employees were researchers and technicians hired from outside the university. Faculty members made up the final group of employees who attended the training. The participants represent both genders, were ethnically diverse, and represented several different academic departments within the university. While the age of the participants was not an area of interest, it was estimated that the ages of the employees ranged from seventeen to sixty three years of age. Some departments were better represented then others because of the nature of the work performed. Chemistry and Chemical Engineering had a higher number of participants than Computer Science or Physics. The employees attended various training sessions given from October 2005 through March 2006. During this time, 73 employees participated in the training.

The training was presented in two locations, one on the main campus and one on the Mellon Institute campus of Carnegie Mellon University. The trainings were given twice per month; one at the beginning and one at the end of the month, rotated between the two locations. The number of participants in each training session varied greatly from two to seventeen participants in each. The employees were registered for the training in advance through an online registration system. The principal investigator (PI) 
in each laboratory was responsible for seeing that all workers in the laboratory enrolled in the training prior to beginning their research.

\section{Sample Population}

For this study it was determined that twenty participants from each training (old and new) would be sufficient to produce enough data points to ensure the proper power level for statistical tests. Each participant would be observed three times at random intervals after receiving the training. This generated a total of sixty observations per training type.

It was discovered that twenty employees could be produced from four different academic departments in equal numbers. Five participants from chemistry, chemical engineering, materials science engineering and biology were observed. This represented fifteen observations from each department per training type. Each employee was observed within one week of attending the training and then randomly an additional two times, the safety violations documented each time for each participant. To make sure the randomness was maintained, names were drawn from a hat to determine which participates would be observed on any particular day. If that person was not working in the lab on that day then another name would be drawn. This process was repeated until everyone had three observation periods.

The same procedures were followed for both training groups. It was hoped that by using random observations for both groups any bias due to time would be eliminated or reduced. It was a concern of the author that the holiday period (Thanksgiving, Christmas and Hanukkah) would produce some bias in that people tend to be more careless around that period of the year. It should be noted that it was not necessary to notify the 
employees that they were part of the study since as employees of the university they are observed in the laboratories by the EH\&S department. All information was kept completely confidential and individual results were not released to anyone at Carnegie Mellon University.

\section{Procedure Used to Observe Participants}

The laboratory auditor performed all the observations for the study. The auditor would determine which employees/laboratories would be observed and then determine when the most appropriate time would be to schedule a visit to that lab. This was accomplished by contacting the lab manager or principal investigator via email or phone call to establish when the employee would be working in the lab. The PI was not informed about the study. Regular laboratory inspections are setup with the same procedure so there is no reason to believe this contact would skew the results in anyway. Once the auditor entered the lab and identified the participant(s), the auditor recorded the required information. If at all possible, no contact with the employee was made, however if questioned, the auditor would respond that it was a "routine" inspection. No information as to the true reason for the visit was revealed so as to not change behavior nor were any of the results communicated to the participant with one exception. If an employee was observed doing something which was considered to be immediately dangerous to life or property, then the employee would be told to stop or correct his/her actions. The observation period would be rescheduled for another time.

Since the individual was generally not aware that they were being observed, each observation is considered to be an independent event. That is to say, the results of one 
observation did not alter future observations. There is no reason to believe that the employee's behavior was altered by the observations themselves, since the participate did not know their results.

\section{Instruments}

Observations were recorded on a record sheet (See Appendix B) and then the data was transferred to an Excel spreadsheet (See Appendix C). The instrument was designed with input from the same expert members of the Delphi Process group. The laboratory auditor technician that would be recording the data had the final input after consensus from the group was reached. The laboratory auditor technician completed the record sheet as the laboratories were inspected on a random basis. The technician observed the training participant within one week after attending the training session. The following observations occurred as the technician was able to find the employee working in the laboratories. The researcher entered the data into Excel and SPSS to analyze the data through the use of t-tests.

\section{Variables}

The decision on which behaviors/safety procedures to observe and record was a group effort of the EH\&S staff. The process attempted to identify those areas where the employee's health and safety would be most improved. Also taken into consideration were those safety violations that were observed the most in past inspections. The variables were chosen on the basis of their lack of subjectivity as well. This eliminated or greatly curtailed any bias on the part of the person doing the observing and recording. 
Either the violation occurred or it didn't, all the variables are a "yes" or "no" type decision. The laboratory auditor recorded observations on the following behaviors:

- Wearing eye protection- must have safety glasses on if in the lab

- Wearing lab coat- must be worn if required by the laboratory PI

- Wearing gloves- proper gloves worn according to chemical they are working with

- Wearing proper clothing- wearing closed-toed shoes, hair pulled back, and no shorts

- Utilizing proper housekeeping practices- work area neat and orderly

- Evidence of eating- eating or any evidence of eating

- Evidence of drinking- drinking or any evidence of drinking

- Containers labeled correctly- primary and secondary containers labeled properly

- Hazardous waste container properly labeled- correctly labeled with approved label

- Hazardous waste container properly closed- screw top lid closed completely

- Hazardous waste in secondary containment- storage container must be stored in an additional container

- Working alone in the laboratory 


\section{Data Analysis}

\section{Research Question}

\section{Data Source}

\section{Data Analysis}

Is there a significant

decrease in the safety

violations of participants

attending the new training?
Observations of employees

on three occasions, record

sheets
Comparing averages of

violations
Is there a difference among

the departments regarding safety violations?
Record sheets from

observations

Record sheets from

observations
Comparing averages of

violations
Is there a significant

difference between male

and female participants

regarding safety violations?

Table 3. Data analysis methods.

Once all the data were collected, a t-test was computed to check for significant differences between old and new training groups. The author compared averages of 
numbers of violations among departmental groups, and between male and female employees, and training session attended. The three assumptions regarding the t-test were present: independence of observations, equality of variances, and normality. In order to limit Type I error, a .05 significance level or alpha will be used (95\% confidence interval).

Table 4 is included to demonstrate the timeline followed by the author. During the months the new training was developed, the old training was in place and the participants were observed.

\section{Date}

August 2005

September 2005

September 2005

September 2005

\section{Activity}

Begin discussions with

Environmental Health and

Safety staff to revise

training

Attend old training session

to observe

Begin researching learning

and training theory as it

relates to adults

Begin bi-weekly planning

sessions with staff and

expert panel assembled
Application
Preliminary

Preliminary

Literature Review and

Training Development

Training Preparation, Research Methodology 
Date

October 2005

October 2005

November 2005

November 2005

December 2005

December 2005

January 2006
Activity

Decision to randomly select Methodology

participants to represent

specific departments in the

university

Bi-weekly planning

meetings continue, expert

panel also involved

Old Training Sessions

Data Collection

continue, participants

observed

Consensus achieved in New Training Preparation/

training presentation Development

New Training Quiz

Training Preparation/

developed

Development

New Training Presenter

Practices in front of

Training Preparation/

Development

Environmental Health and

Safety staff

New Training Sessions

Training Implemented begin 
Date

January 2006

March 2006

March 2006

April 2006
Activity

New Training participants

observed by Laboratory

Auditor Technician

February 2006- March 2006

participants observed

Development of Excel

spread sheet and begin at

enter data

Final participants in new

training observed

Begin analysis of data

through means and t-tests
Application

Data Collection

Data Collection

Data Analysis

Data Collection

Data Analysis

Table 4. Methodology timeline.

\section{Limitations}

As the researcher, I offer the following limitations to my study:

- There was a small sample size, only 20 in each group. I used 40 of the 73 total participants in order to have departmental groups that were evenly matched. The sample size was selected after discussing practicality and time issues with the staff.

- There was no baseline data on the selected participants to see if the training alone was actually responsible for the decrease in infractions. 
- Only the beginning portion of the newly designed training was actually implemented. There was an on-line portion designed for the future and a handson test instead of the paper/pencil test; therefore, further observations would need to be done to see if there would be more impact.

- The presenter changed between the old and new training sessions. Therefore, the personality of the presenter may or may not have had an impact. Both presenters were experts in the field and both knew the content of the training extremely well. The presenter in the old training worked with the panel to develop the new training.

\section{Chapter 4-Results}

In this chapter, the results of the study will be presented in both statistical as well as written in descriptive terms. The overall research question for the study was: To what extent does personal relevance impact behavior after attending a laboratory safety training session? The hypothesis for the study was that the participants in the new training would show a significant decrease in the number of safety violations observed in Carnegie Mellon University's laboratories during laboratory inspections. The hypothesis was supported when comparing the old and new training participants' behavior with the use of the t-test.

The first assumption of the t-test is the independence of observations. Each observation evaluated the twelve variables and was scored separately and each observation was done on separate occasions and dated (See Appendix F). Carnegie Mellon University's laboratory auditor technician did the observations. As mentioned in 
Chapter Three, the participants were not made aware of the results of any of the observation periods, therefore the assumption that their behavior was not altered by previously being observed ensures that each observation period is independent.

The second assumption of the t-test is the equality of variance. It was assumed that the variances found among the sample population would be similar to the variances that could be found in the entire population. The participants were selected randomly by drawing names from a hat to find representatives from the four departments. The entire population of seventy-three was not observed due to time and practicality issues.

The third assumption necessary for the t-test is found to be present: normality, the results of the number of violations is shown in figure six below and represents a normal curve. The Central Limit Theorem's general rule of thumb is $n \geq 30$ is sufficient to give a normal shaped sampling distribution.

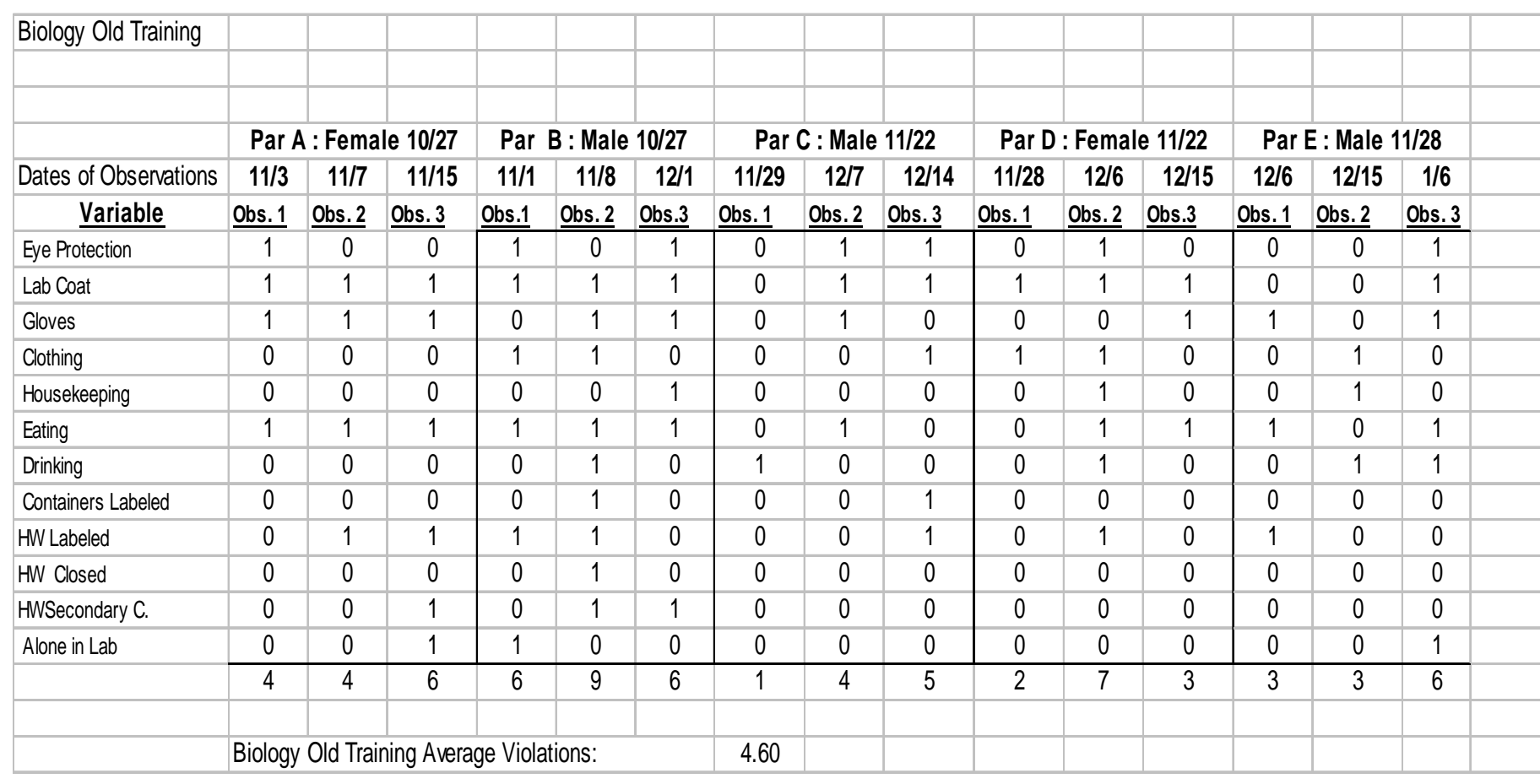

Figure 6. Example of spreadsheet data for the biology department participants in the old training. 
In Figure six an example of the data collected through the observations is presented. The example table is for the Biology Department, old training group. The table displays the gender of each participant and the date of the training attended. On the next line is the date of each observation for each participant. Then each variable is listed and the employee scored during each observation for each variable. The variable that list a zero are those variables in which there was not a violation noted. If there is a one listed, a safety violation was observed during that inspection. The bottom line is the total violations for each observation. The average for all biology employees attending the old training was 4.60 violations. The tables for all departments, old and new can be found in Appendix I.

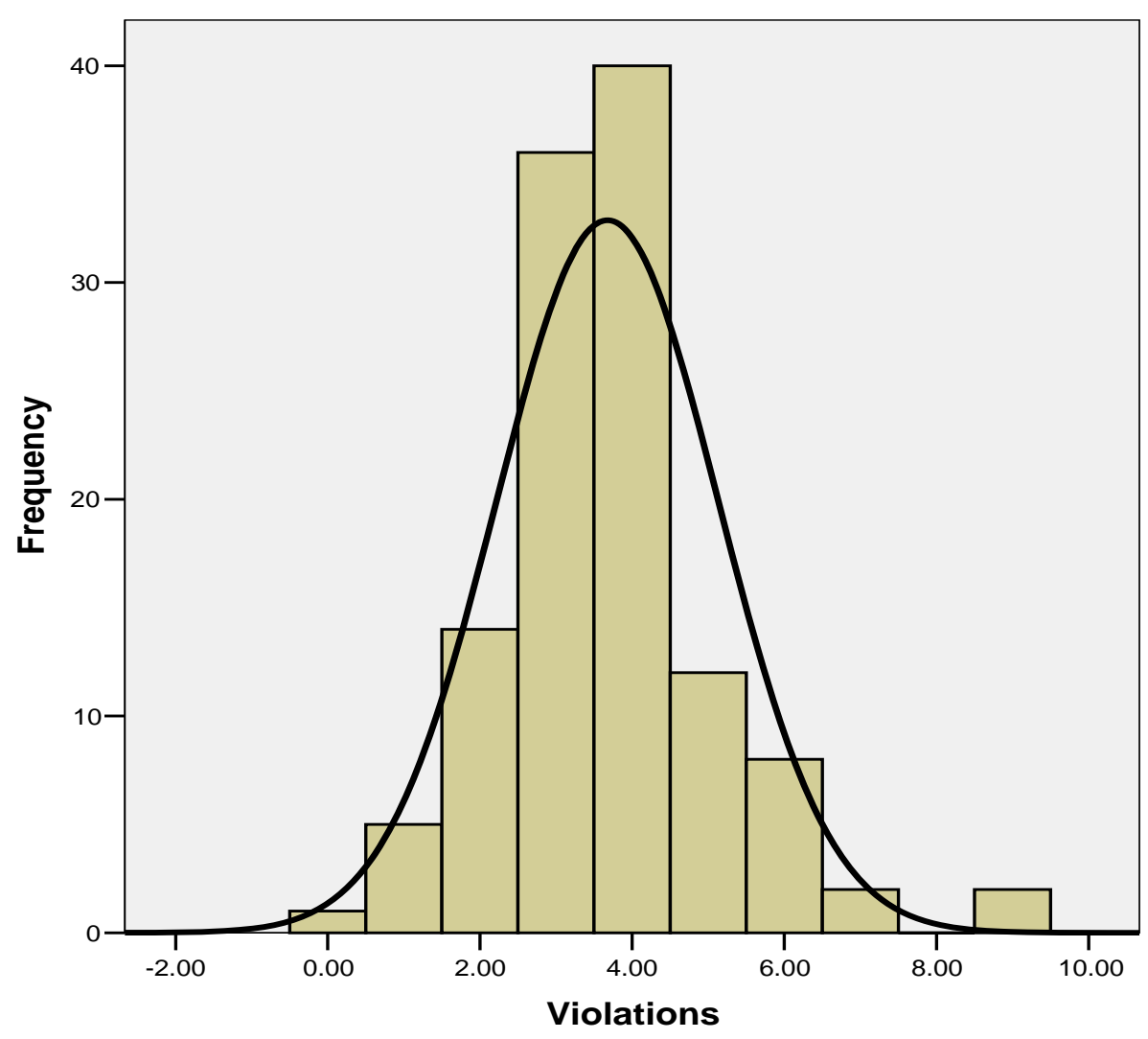

Mean $=3.675$

Std. Dev. = 1.45615

$N=120$

Figure 7. Histogram of violations recorded. 
This histogram shown in Figure 7 displays the number of violations and the frequency the number of violations occurred, the data appears to be distributed normally. As shown in the Tables 5 and 6 below, there was a significant difference between the participants that attended the new training sessions when compared to those participants attending the old training. Table 5 shows the average number of violations in each training group. The old training averaged 4.17 violations where as the new training averaged 3.18 violations. The average difference was a nearly one violation improvement between the old training and new training.

Number of Participants

20

20
Old Training:

average number

of safety violations
New Training:

average number

of safety violations

Table 5. Average safety violations comparing old and new training group participants.

A t-test was computed, to determine if the difference was significant. I used the following assumptions: independence of observations, equality of variance, and normality and the results were as presented in the table 6 . 
Table 6

T-test Results Comparing Old and New Training

Training

Mean

Std. Deviation

$\mathrm{N}$

95\% Confidence

Interval of the

Difference

Lower

Upper

New

3.18

1.20

60

Old

4.17

1.53

60

Table 6. t-test results comparing old and new training group participants.

Therefore, since the interval of .49 to 1.48 does not include zero, the data support the hypothesis, that there were be a decrease in the number of safety violations between the old and new training groups, and I am able to reject the null hypothesis. The hypothesis was one-way only, that there would be a decrease in the number of violations.

In order to further evaluate the results, the researcher compared averages of violations among departments, between males and females, and according to the training session they attended. This was done in order to try to eliminate other causes for the decrease in violations.

As shown in Table 7, each department in the old training yielded approximately the same number of violations and after using t-tests (See Appendix G); therefore, since 
the intervals included zero, I am 95\% confident that the department comparisons showed no significant difference.

Table 7

Old training violations by department

\begin{tabular}{lccc} 
Department & Mean & N & Std. Deviation \\
\hline Biology & 4.60 & 15 & 2.10 \\
Chemistry & 4.40 & 15 & 1.76 \\
Chemical Engineering & 3.80 & 15 & .99 \\
Material Science Engineering & 3.87 & 15 & .92
\end{tabular}

Table 7. Old training violations by department.

As shown in Table 8, each department in the new training yielded approximately the same number of violations and the t-tests (See Appendix G) confirmed that the department comparisons showed no difference. In the appendix, B represents the Biology department, C, Chemistry, CE, Chemical Engineering, and M represents the Material Science Engineering department. 
Table 8

New Training Violations by Department

\begin{tabular}{lccc} 
Department & Mean & $\mathrm{N}$ & Std. Deviation \\
\hline Biology & 3.27 & 15 & 1.33 \\
Chemistry & 3.33 & 15 & 1.05 \\
Chemical Engineering & 2.93 & 15 & .59 \\
Material Science Engineering & 3.20 & 15 & 1.20 \\
& & & \\
\hline
\end{tabular}

Table 8. New training violations by department.

In the sample population of forty participants, seven were female. When comparing the means of males and females, there was found to be no statistical difference in the means as shown in the table below. However, due to the small number of females in either training group, the significance of these numbers has not been determined. 
Table 9

Comparison of Males and Females Participating in the Old Training

Group

Mean

Std. Deviation

$\mathrm{N}$

95\% Confidence

Interval of the

Difference

Lower

Upper

Male

4.18

1.55

48

Female

4.08

1.50

12

$-.89$

1.10

Table 9. Comparison of males and females in the old training.

Table 10

Comparison of Males and Females Participating in the New Training

\begin{tabular}{|c|c|c|c|c|c|}
\hline \multirow[t]{4}{*}{ Group } & \multirow[t]{4}{*}{ Mean } & \multirow[t]{4}{*}{ Std. Deviation } & \multirow[t]{4}{*}{$\mathrm{N}$} & \multicolumn{2}{|c|}{$95 \%$ Confidence } \\
\hline & & & & \multicolumn{2}{|c|}{ Interval of the } \\
\hline & & & & \multicolumn{2}{|c|}{ Difference } \\
\hline & & & & Lower & Upper \\
\hline Male & 3.10 & 1.15 & 48 & & \\
\hline \multirow[t]{2}{*}{ Female } & 3.50 & 1.38 & 12 & & \\
\hline & & & & -1.17 & .38 \\
\hline
\end{tabular}

Table 10. Comparison of males and females in the new training. 


\section{Summary}

The overall research question regarding the number of safety violations decreasing for participants attending the new training sessions was supported. The average number of safety violations decreased by .99 when compared to the participants of the old training group. The interval of .49 to 1.48 does not include zero; therefore, the data support the hypothesis and I am able to reject the null hypothesis with $95 \%$ confidence. $\left(\mu_{1}-\mu_{2} \neq 0\right)$ After also examining male and female, and the four departments, (biology, chemistry, chemical engineering and materials science engineering), it is noted that the data were not significant. The numbers in some of the comparisons were not large enough to be able to draw statistically strong evidence, just points of interest and discussion. Therefore, it was assumed that the impact of the new training resulted in a decrease of .99 average safety violations.

\section{Chapter 5-Conclusions}

After analyzing the results from the two training groups, my hypothesis was supported that the new training participants showed a significant decrease in safety violations. There was an average decrease of .99 violations when comparing the two groups. In order to further support my results, I examined the data among departments, and between genders (male and female); the only instance of a significant difference in means occurred between the old and new training groups. The data supported the hypothesis that the number of violations would decrease among participants attending the new training. 
The training may have accounted for this decrease; but, ultimately, it was the employees' behavior that was responsible for the decrease. There was no baseline data collected for each participant prior to training; therefore, it was assumed that the training was responsible for the decrease. There was an area of improvement in the number of violations per employee.

If the training did affect the behavior of the employee, the desired effect should continue. The new training was developed to try to accomplish this goal. In order to be more similar to their actual working environment, actual photos and information the employee would encounter was utilized. Research had shown that, similarity of the information and the ease of integrating the information into the workplace, are crucial to employees' behavior change and information transfer to the workplace. These elements also aid in the employee seeing personal relevance in the training, therefore, paying attention to the information.

\section{Climate of Safety}

Each Principal Investigator (PI) for a given laboratory is responsible for the climate of safety present in their laboratory. This is directed through the Chemical Hygiene Plan that Carnegie Mellon University developed and follows. It is ultimately the PI that is responsible to make sure their employees are properly trained and protected from laboratory hazards.

To affect the climate of safety present in the laboratories on their campus is the ultimate goal of the Environmental Health and Safety Department at Carnegie Mellon University. This is demonstrated in their desire to improve their safety programs and 
incorporate the needed elements to affect such change. The employees in the training, PIs, graduate students, post-docs, technicians, or other employees, need to take the skills learned back to the laboratories and put them into practice.

The method of accountability is also being improved through more laboratory inspections and greater communication between the Environmental Health and Safety Department, Department Heads, and laboratories. This is also a necessary component in order to keep their employees safe.

This climate of safety can further be maintained through follow-up trainings and laboratory inspections and then communication regarding the inspection findings. The training planned for Phase II, the online and hands-on portion, allows for even more individualized information to be presented and more personal relevance and participation to be added for the employee. This would hopefully decrease even further the number of safety violations present on the campus. Through inspections and heightened awareness of safety behaviors, the behavior in the laboratories on the campus should be even safer in the future.

\section{Is Statistically Significant, Realistically Significant?}

Is the decrease of one violation realistically significant concerning laboratory workers safety? When examining the results, the violations were found to be statistically significant when comparing average violations. When OSHA or the Environmental Protection Agency (EPA) inspects the laboratories, even one violation could result in fines and sanctions. Therefore, when eliminating safety violations, overall safety and laboratory quality is improved. It is important to note that even one safety violation could result in injury, property damage, or negate research results. It is important to 
continue to strive to improve the overall climate of safety in the laboratories. This one violation reduction could mean an eye saved from a chemical splash if that person wears safety glasses since attending the training. Any reduction in violations means that the laboratories are safer following the training than before the training. Employees must continue to receive the most up-to-date information regarding safety policies and monitoring must be provided to assure the policies are being followed.

Therefore, realistically, even a decrease of one is significant. The decrease in violations could have saved a life, property, or research quality.

\section{Implications for Carnegie Mellon University Environmental Health and Safety}

As a researcher, I would recommend the continuation of employing Andragogic principles and adult motivational strategies in training programs. The decrease in safety violations noted through this research study was significant. The educational principles of personal relevance and similarity were not difficult to include within the structure of the existing training. The adults were able to see value in the training because; the adults discussed the purpose and were involved from the beginning of the training session. The process could further be improved by moving on to the next step with the addition of the on-line portion of the training. This method furthers the impact of adult learning principles by allowing adults to work at their own pace and chose the time and place for the lesson. The adults are then further instructed to work in their laboratory and find hazardous chemicals they work with, MSDS forms and any questions specific to their needs and bring this information to the in-person portion of the training. This will further increase the relevance and similarity to their environment to enhance transfer.

In summary: 
- The employees need to see how the training is relevant to their individual situations. This can be accomplished by activities, discussions, role plays, or even through the on-line activities. Adults must be able to assess the situation and have a purpose for paying attention.

- Continue to monitor the laboratories and employees. This monitoring and reporting results enhances the climate of safety within the university. This also serves to provide valuable feedback to the Environmental Health and Safety Department as to needs for future training and refresher courses.

- Employ methods that enable adults to work at their own pace and within their areas to learn material and then discuss the application of that material. This enhances prior knowledge and gives the employee a basis to build on with the inperson training portion.

\section{Implications for Training Professionals}

Training professionals should strive to incorporate as many principles of adult learning into their training presentation as possible. The principles this researcher, as well as others, found to be most critical are:

- Relevance-The material presented should seem relevant to the adult participants. This is best accomplished by the adults realizing and recognizing this relevance their selves.

- Similarity - The information presented should closely resemble the employees workplace conditions in order to ease the transfer of skills. The trainer must be able to spend time in the workplace or provide activities in which the participants 
can supply the similarity through materials they bring to the training or discussions and role play.

- Active Participation - The employees should be able to interact with the other employees and the trainer. The atmosphere should be one in which the employees feel safe to risk participating. It takes adults longer to perform some activities as well as longer to feel safe to speak out and ask questions.

- Providing Objectives - By showing the objectives in the beginning the adults are able to see the "big picture" and know the direction of the training. The adults are also able to gage time and know when the training is almost over. Adults have many demands on their time and attention so it is important to give the parameters of the training in advance.

\section{Suggestions for Further Study}

As a researcher, I would recommend further study by adding a component to establish a baseline for each participant prior to training. This would require additional cooperation from the university, because registration procedures would need to be modified to accommodate this process. This would further allow the researcher to be able to evaluate the affect of the training.

Another area of interest would be to see if providing corrective action and incentives would impact behavior. If the employee was corrected after each observation, it would be interesting to see the behavior decreased due to remediation and reminders of the policies. Providing incentives to employees following the safety protocols may also affect transfer of skills. It would be interesting to also follow the other laboratory 
workers surrounding the participants to see if the incentives or reminders affected their behavior as well.

The individual laboratory PIs might be trained to evaluate and document the behavior and allow the laboratory auditor technician the ability to also assess the employees. This practice would enable interrater reliability to be measured. This would also allow for more observations and the entire population could be monitored instead of selecting a sample group.

Once the additional training methods, both online and the hands-on laboratory experience are in place, further evaluation should be implemented. These methods should enable a person to tailor the training for their individual needs using chemicals or materials in their specific environment.

Also, since there was a change in the presenter between the old and new training sessions, it would be interesting to continue to evaluate the progress of the next phase of the training since the new presenter will remain the same.

Other areas of interest would be including surveys inquiring the satisfaction level of the training and level of participation envisioned by each participant. This would allow the researcher to see if the relevance is actually felt by the participants as they are involved in the training.

\section{Summary}

Incorporating Andragogic learning principles into the laboratory safety training program at Carnegie Mellon University made the training more relevant to the employees. The employees were able to see the reason for attending the training other than just meeting the regulations established by the governmental agencies. By knowing 
the objectives of the training in the beginning, the participants were aware of what would be taught and they would be able to see the training as a whole prior to examining the parts. The employees knew that they were attending the training to improve their safety and help ensure the safety of their fellow laboratory workers. Then they were taken through the smaller portions that demonstrated how to accomplish those goals. At the end of the training, the participants were graded on their learning and the trainer was able to note potential areas for greater focus.

After evaluating the new training through observations of training participants, it is noted that the number of violations has decreased. However, there is still room for more improvement in the number of safety violations present in the laboratories on campus. Continuing to improve the training and evaluation systems should keep the number of violations steadily decreasing and enable the climate of safety to be improved at Carnegie Mellon University. By training the new employees and monitoring their progress the impact of the training program should steadily increase. The number of violations remaining in the laboratories is such that continued improvement of training practices is warranted. The second phase of the training including the online portion and hands-on laboratory sessions should be implemented and then evaluated to see if the violations continue to decrease. The laboratory inspections should continue and violations reported to Principal Investigators in the laboratories. 


\section{References}

Adams, S. J. (2000). Improving Safety Instruction and Results; Five Sound Principles of Sound Training. American Society of Safety Engineers (December), 40-43.

Alexander, N., P. (1999). Understanding Adults as Learners. Child Care Information Exchange, 11, 82-86.

Boyce, A. (2004). Effective Training Begins With Needs Assessment. Occupational Health and Safety, 72-76.

Broadwell, M., M. (1995). The Supervisor and On-the-Job Training. Reading, MA: Addison-Wesley Publishing Company.

Brown, J. (2002). Training Needs Assessment: A Must for Developing an Effective Training Program. Public Personnel Management, 31(4), 569-579.

Conner, M. L., \& (1997-2004). Andragogy and Pedagogy. Ageless Learner Retrieved March 3, 2006, from http://agelesslearner.com/intros/andragogy.html

DeSimone, R., L.; Harris, David M. (1998). Human Resource Development. Philadelphia. PA: Harcourt, Inc.

Draft Model Training Program for Hazard Communication. Retrieved September 22, 2005. from http://www.osha.gov/dsg/hazcom/MTP101703.html.

Dwyer, B. (2001). Successful Training Strategies for the Twenty-First Century: Using Recent Research on Learning to Provide Effective Training Strategies. The International Journal of Educational Management, 15(6), 312-318.

Hollinghead, A. B. (1998). Group and Individual Training, The Impact of Practice on Performance. Small Group Research, 29(2), 254-280. 
Hughes, C., L.; Flowers, Vincent, S. (1976). Strategies for Effective Training. Training Strategies.

Jones, E. (1986). Teaching Adults: An Active Learning Approach. Washington DC: National Association for the Education of Young Children.

Kirkpatrick, D.L. (1994). Evaluating Training Programs: The Four Levels. San Francisco, CA: Berrett-Koehler.

Klane, J. (2004). Really Effective Training. Occupational Health and Safety, 190-195.

Knowles, M. (1984a). The Adult Learner: A Neglected Species (3rd edition). Houston, TX: Gulf Publishing Company.

Knowles, M. (1984b). Andragogy in Action. San Francisco, CA: Jossey-Bass.

Laird, D. (1985). Approaches to Training and Development. Reading, MA: AddisonWesley Publishing Company.

Lyons, P. (1988). Cooperative Learning Methods and the Adult Learner. Higher Education (August).

Mitchell, G. (1993). The Trainer's Handbook: The AMA Guide to Effective Training. Amacom, NY: American Management Association.

Munoz, M. A., Munoz, Maria D. (1999). The Role of Occupational Training and Evaluation in the Learning Organization. University of Louisville, Louisville.

Noe, R. A. (2002). Employee Training and Development. Second Edition (Second Ed.). Columbus, McGraw-Hill.

Pedone, M. J. (1992). Designing an Effective Training Program. Environmental Testing and Analysis, 1(5), 34. 
Prudent Practices in the Laboratory: Handling and Disposal of Chemicals. Retrieved March 3, 2006. from http://www.nap.edu/readingroom/books/prudent/index.html. Robotham, G. (2001). Safety Training That Works. American Society of Safety Engineers (May), 33-37.

Sims, R., R.; Sims, Serbrenia, J. (Ed.). (1995). The Importance of Learning Styles: Understanding the Implications for Learning, Course Design, and Education. Westport, CT: Greenwood Press.

Thoms, K. J. (2001). They're Not Just Big Kids: Motivating Adult Learners. Paper presented at the Annual Mid-South Instructional Technology Conference, Murfreesboro, TN.

Trenerry, R. (2002). Talking About Training, Literacy and Numeracy Training Practices in Industry: A Comparative Study Across Five Industries. Australia, South Australia: Asult Literacy and Numeracy Australian Research Consortium.

Wagonhurst, C. (2002). Developing Effective Training Programs. The Journal of Research Administration, 33(2).

Whitley, Bernard E. (1996). Principles of Research in Behavioral Science (Second Edition). New York, NY: McGraw-Hill.

Wise, D. E., Patsy. (2003). Characteristics of Effective Training: Developing a Model to Motivate Action. Journal of Extension, 41(2).

Wlodkowski, R. (1993). Enhancing Adult Motivation to Learn: A Guide to Improving Instruction and Increasing Learner Achievement. San Francisco, CA: JosseyBass. 


\section{Appendix A}

\section{Safety Standards for Carnegie Mellon Laboratories}

\section{Taken from Carnegie Mellon University’s Chemical Hygiene Plan:}

\subsection{Protective Clothing}

Protective clothing such as chemically-resistant gloves, lab coats, aprons, or suits should be used when working with hazardous materials. The Principal

Investigator or Laboratory Instructor is responsible for determining the protective clothing needed. The Chemical Hygiene Officer may be consulted as a resource for clothing selection.

Protective clothing should be inspected prior to each use.

\subsubsection{Eye Protection}

Eye protection is mandatory for all entries into a work area within a laboratory where hazardous chemicals are used. The Principal

Investigator or Laboratory Instructor will determine the level of eye protection required. All eye protection used should meet ANSI Z87.1 requirements.

\subsection{Eating, smoking, etc.}

Eating, drinking, smoking, gum chewing, or application of cosmetics should not occur in areas where laboratory chemicals are present. Laboratory workers should be sure to wash their hands before eating, drinking, smoking, etc. outside the laboratory environment.

Avoid storage, handling, or consumption of food or beverages in storage areas, refrigerators, glassware, or utensils that are also used for laboratory operations.

\subsection{Personal apparel}

Confine long hair and loose clothing. Wear closed-toed shoes at all times in the laboratory. Appropriate protective clothing (e.g., aprons, lab coats, safety glasses, etc.) should be kept in the laboratory and worn routinely.

\subsection{Personal housekeeping}

Keep the work area clean and uncluttered, with chemicals and equipment being properly labeled and stored; clean up the work area on completion of an operation and at the end of each day. 


\section{Appendix B}

\section{Observational Record Sheet}

Rubric for follow-up observations:

Participant ID

Dept/Lab

1 point per violation of safety standard

0 if following safety standard

\begin{tabular}{|l|l|l|l|}
\hline Behavior & Observation 1 & Observation 2 & Observation 3 \\
\hline Eye protection & & & \\
\hline Lab coat worn & & & \\
\hline Use of gloves & & & \\
\hline Appropriate clothing & & & \\
\hline Working alone & & \\
\hline Housekeeping practices & & & \\
\hline $\begin{array}{l}\text { Evidence of drinking in } \\
\text { the lab }\end{array}$ & & & \\
\hline $\begin{array}{l}\text { Evidence of eating in the } \\
\text { lab }\end{array}$ & & & \\
\hline Labeling of containers & & & \\
\hline Hazardous waste labeled & & & \\
\hline $\begin{array}{l}\text { Hazardous waste } \\
\text { container closed }\end{array}$ & & & \\
\hline $\begin{array}{l}\text { Hazardous waste in } \\
\text { secondary containment }\end{array}$ & & & \\
\hline Total & & & \\
\hline
\end{tabular}




\section{Appendix C}

\section{Excel Spreadsheet Data}

\section{Department}

\begin{tabular}{|c|c|c|c|c|c|c|c|c|c|c|c|c|c|c|c|}
\hline & $\underline{A}$ & $\underline{A}$ & $\underline{A}$ & B & B & B & C & c & c & $\underline{D}$ & $\underline{D}$ & $\underline{\mathrm{D}}$ & E & E & E \\
\hline Eye Protection & & & & & & & & & & & & & & & \\
\hline Lab coat & & & & & & & & & & & & & & & \\
\hline Gloves & & & & & & & & & & & & & & & \\
\hline Clothing & & & & & & & & & & & & & & & \\
\hline Working Alone & & & & & & & & & & & & & & & \\
\hline Housekeeping & & & & & & & & & & & & & & & \\
\hline Drinking & & & & & & & & & & & & & & & \\
\hline Eating & & & & & & & & & & & & & & & \\
\hline $\begin{array}{l}\text { Containers } \\
\text { Labeled }\end{array}$ & & & & & & & & & & & & & & & \\
\hline HW labeled & & & & & & & & & & & & & & & \\
\hline HW closed & & & & & & & & & & & & & & & \\
\hline HW container & & & & & & & & & & & & & & & \\
\hline Total Violations & & & & & & & & & & & & & & & \\
\hline
\end{tabular}
A- Participant 1
3 observations
B- Participant 2
3 observations
C- Participant 3
3 observations
D- Participant 4
3 observations
E- Participant 5
3 observations 


\section{Appendix D}

\section{Lab Inspection Form}

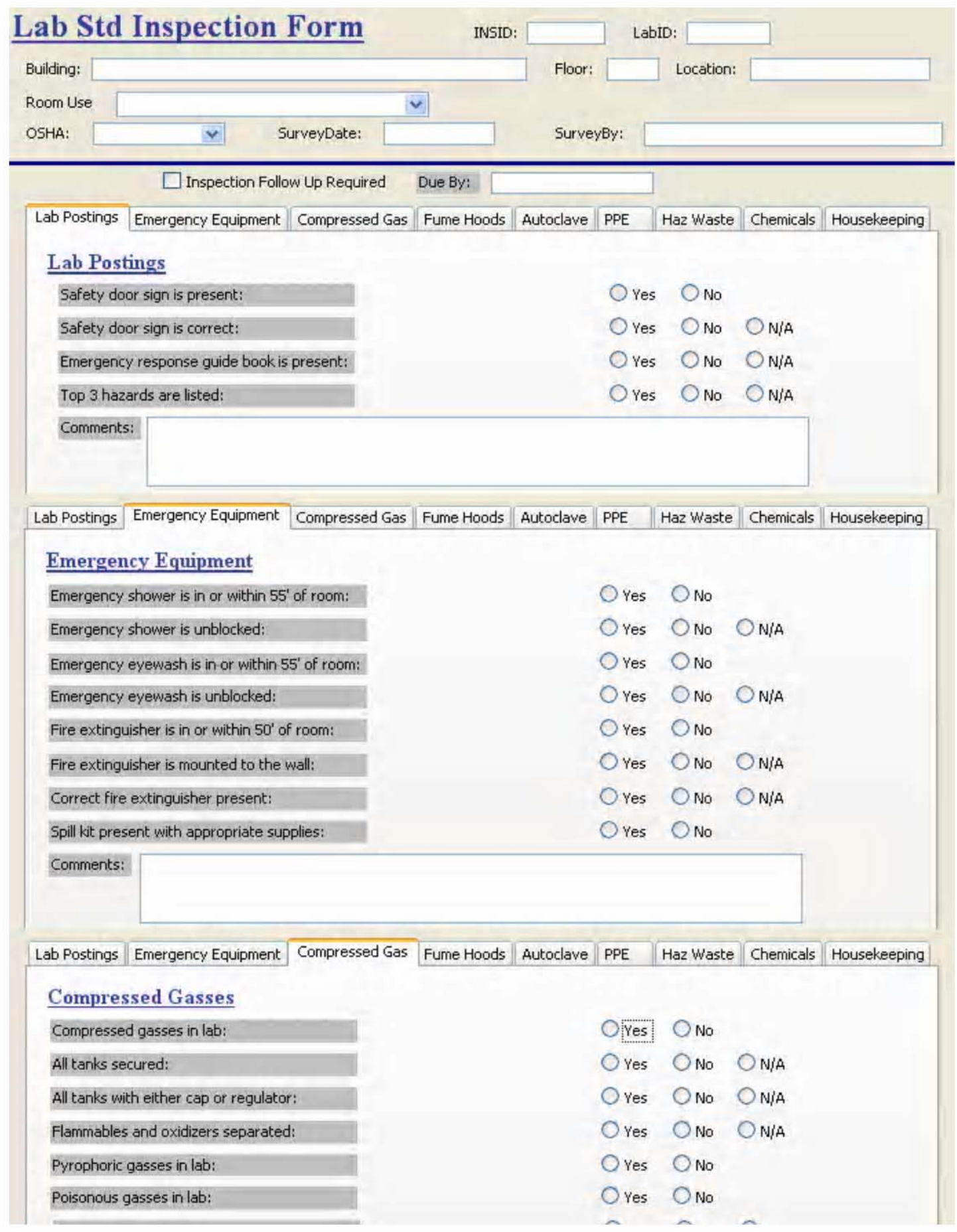




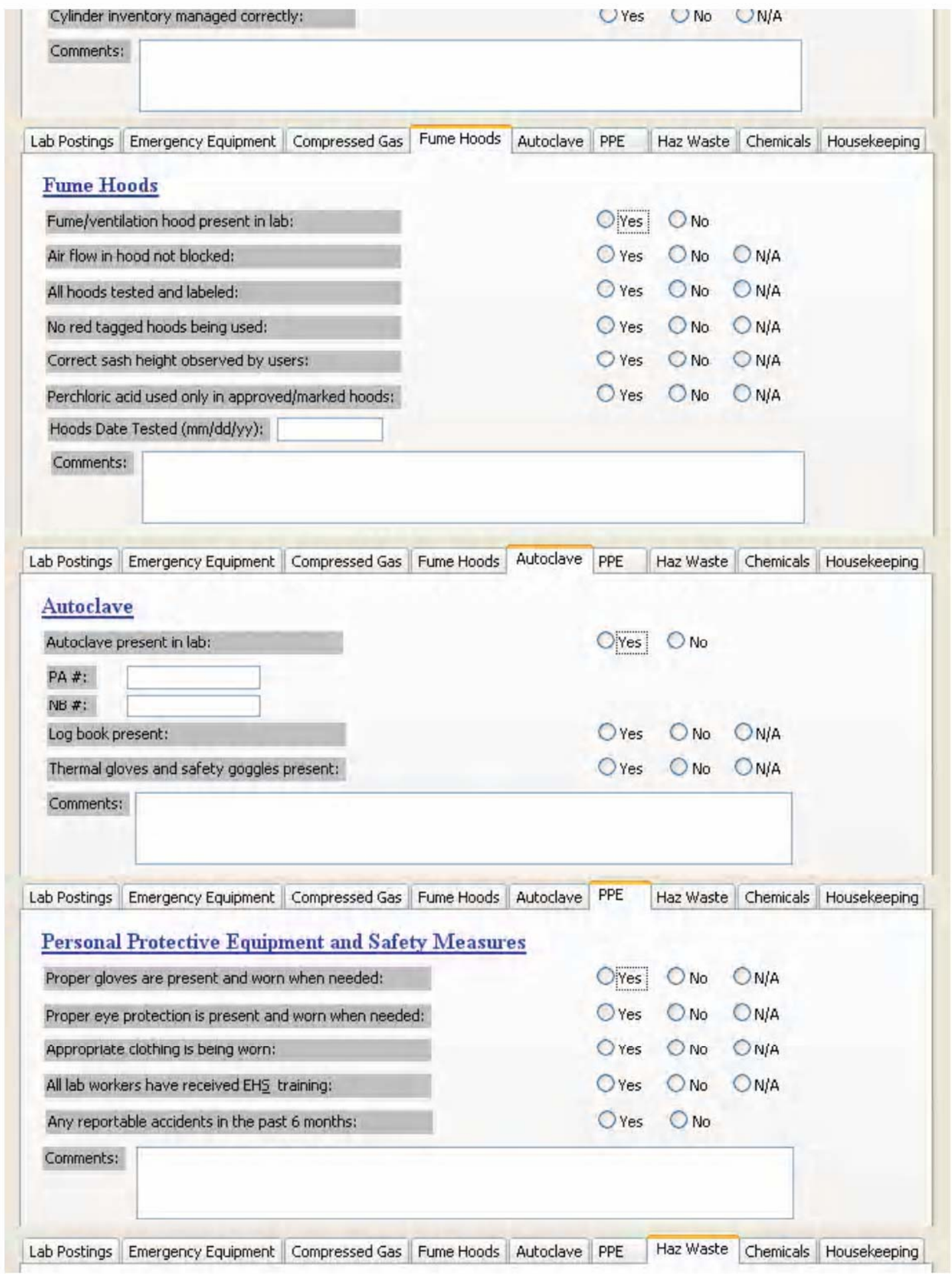




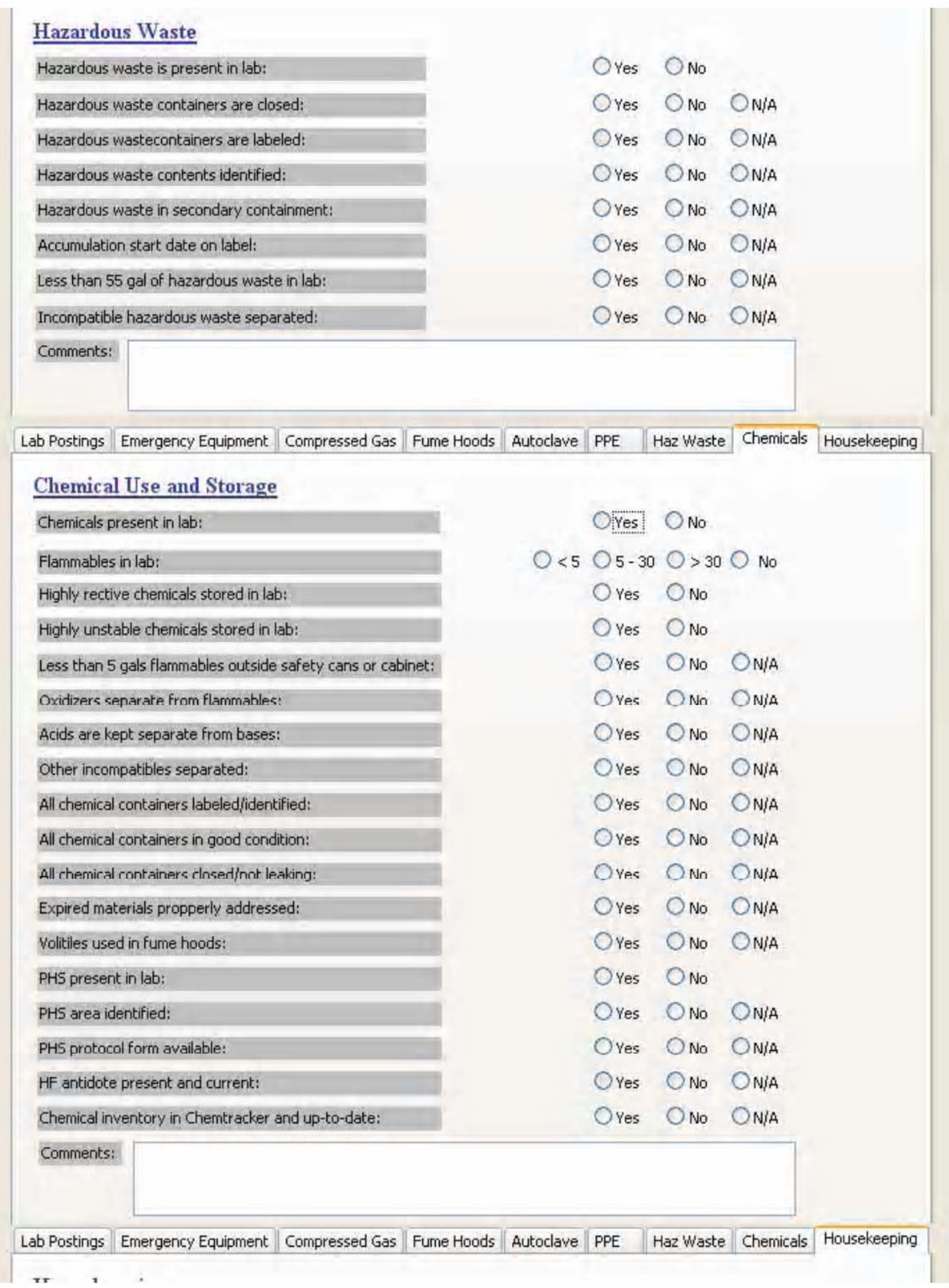



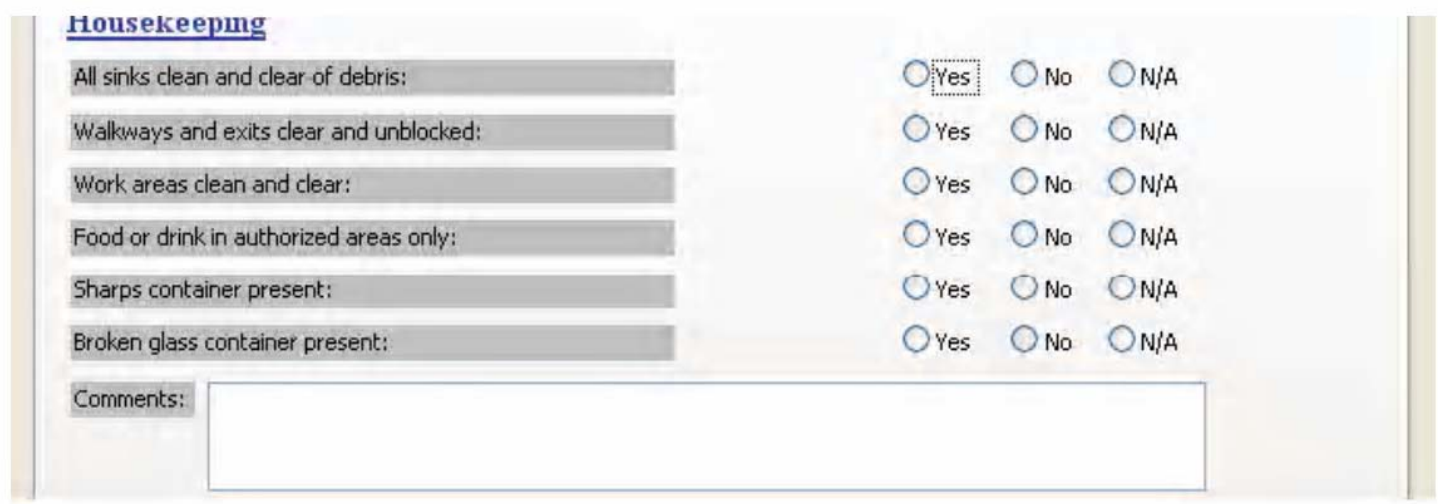


\section{Appendix E}

\section{Old Training Slides}
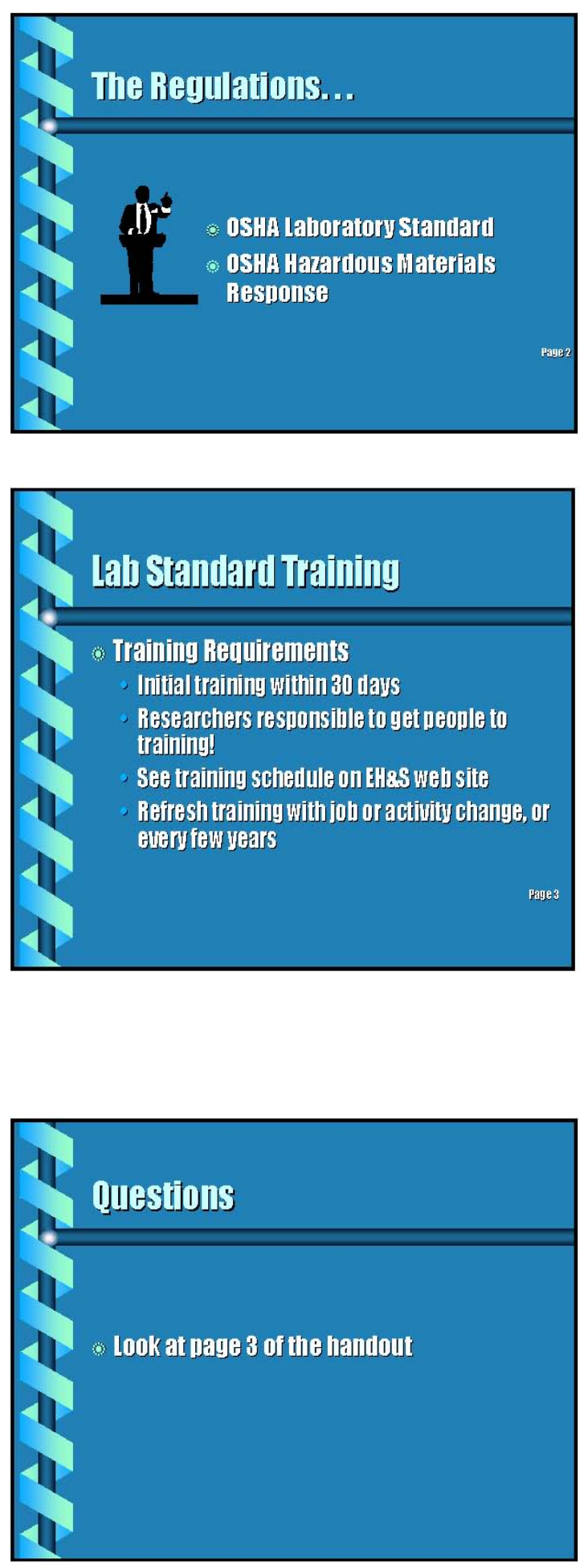
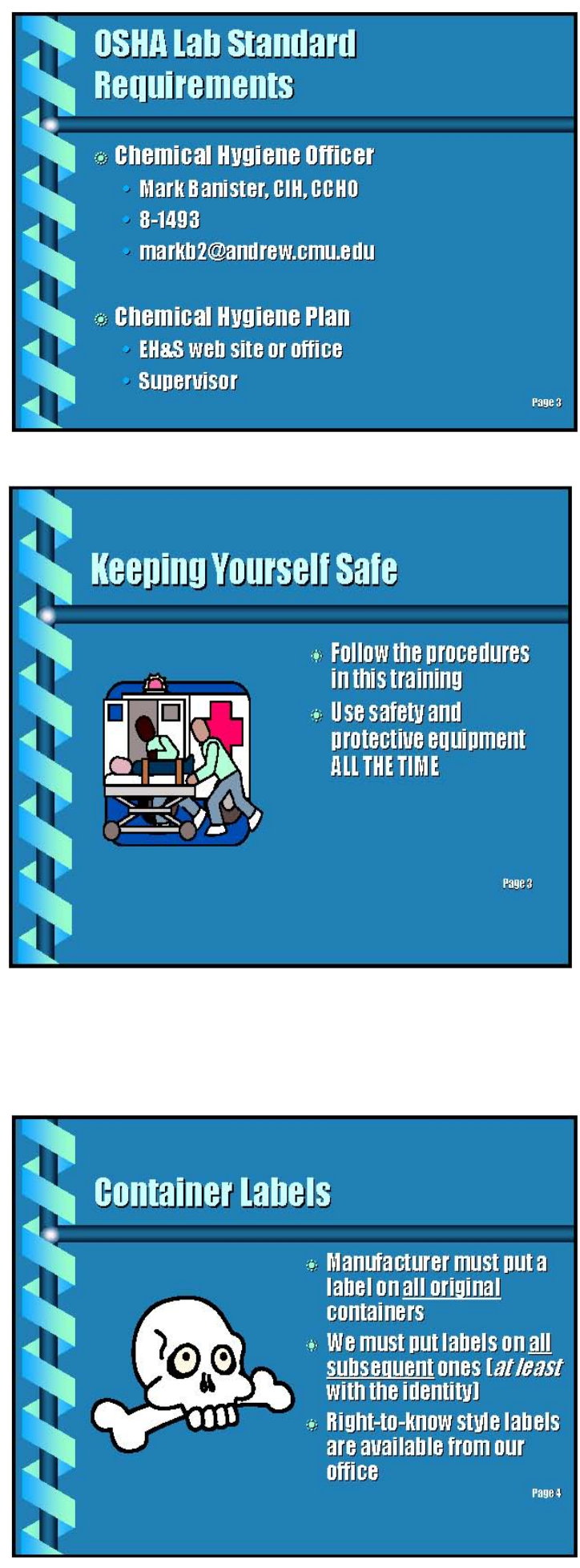

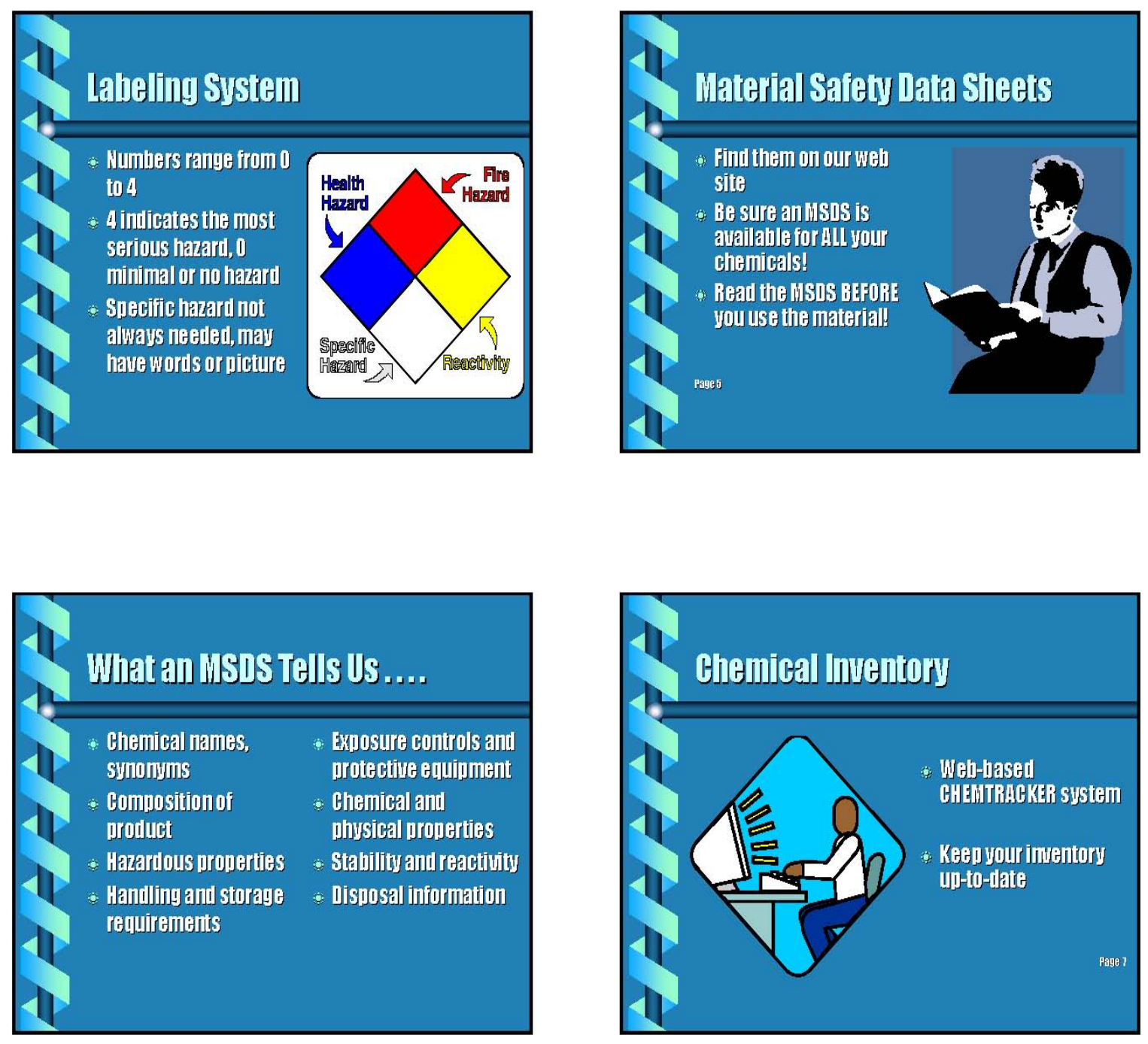

\section{QUEStions/LOMELOd'}

Page 5: Do you know what wash hotites you have in your latis Are they laheleip

Page 7: Do you know where the uisus are in yould lates

Page 7: Do you know who hand los the intentory in youls labs

Hherk out these things when you return!

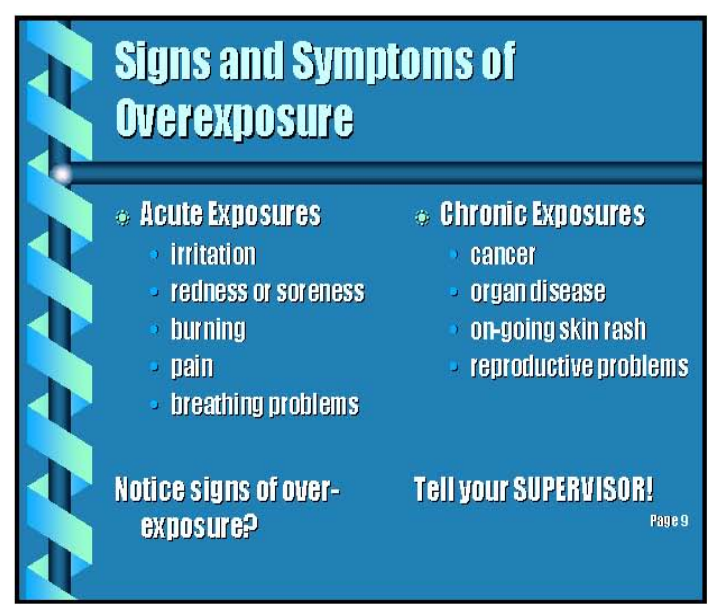



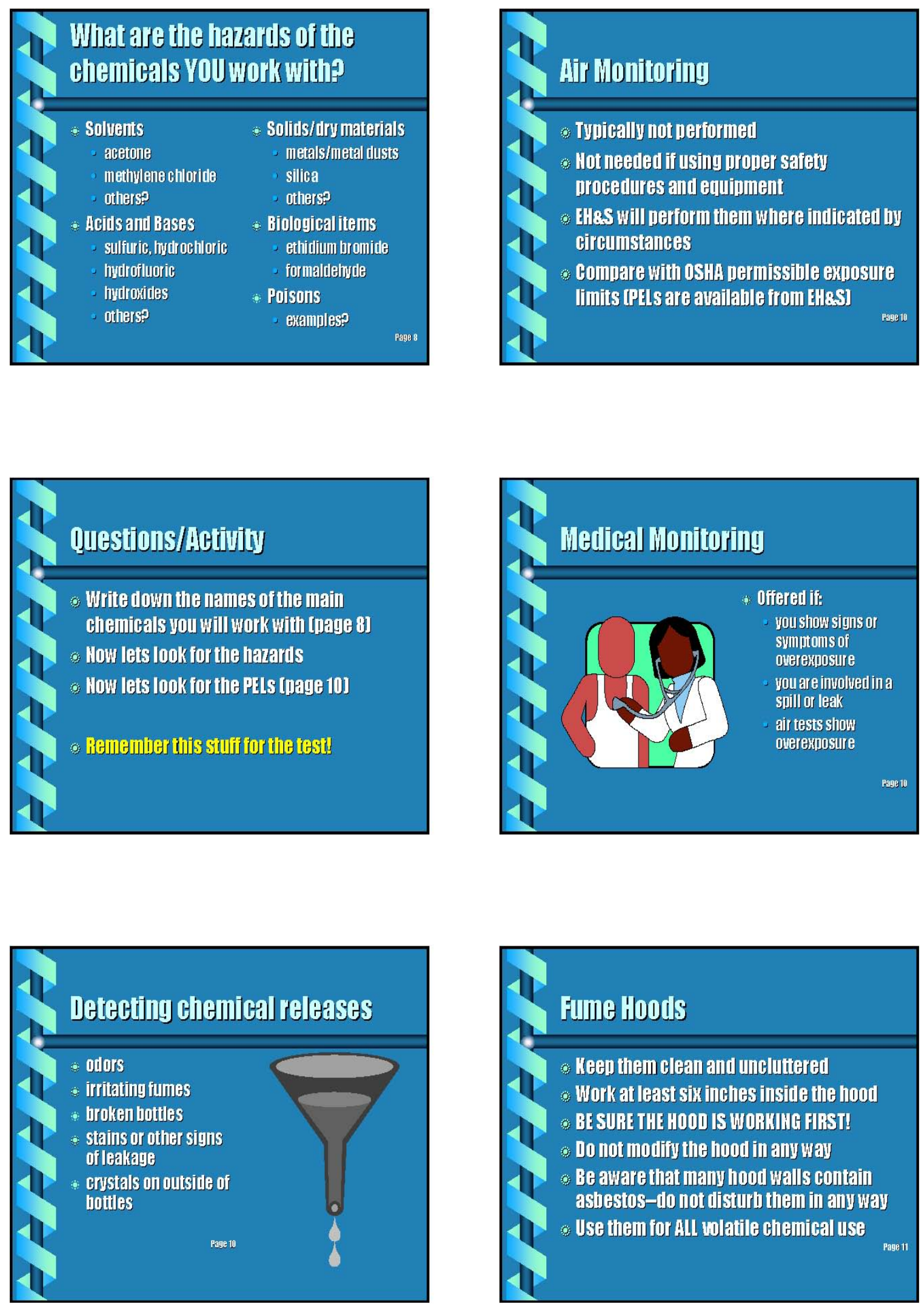

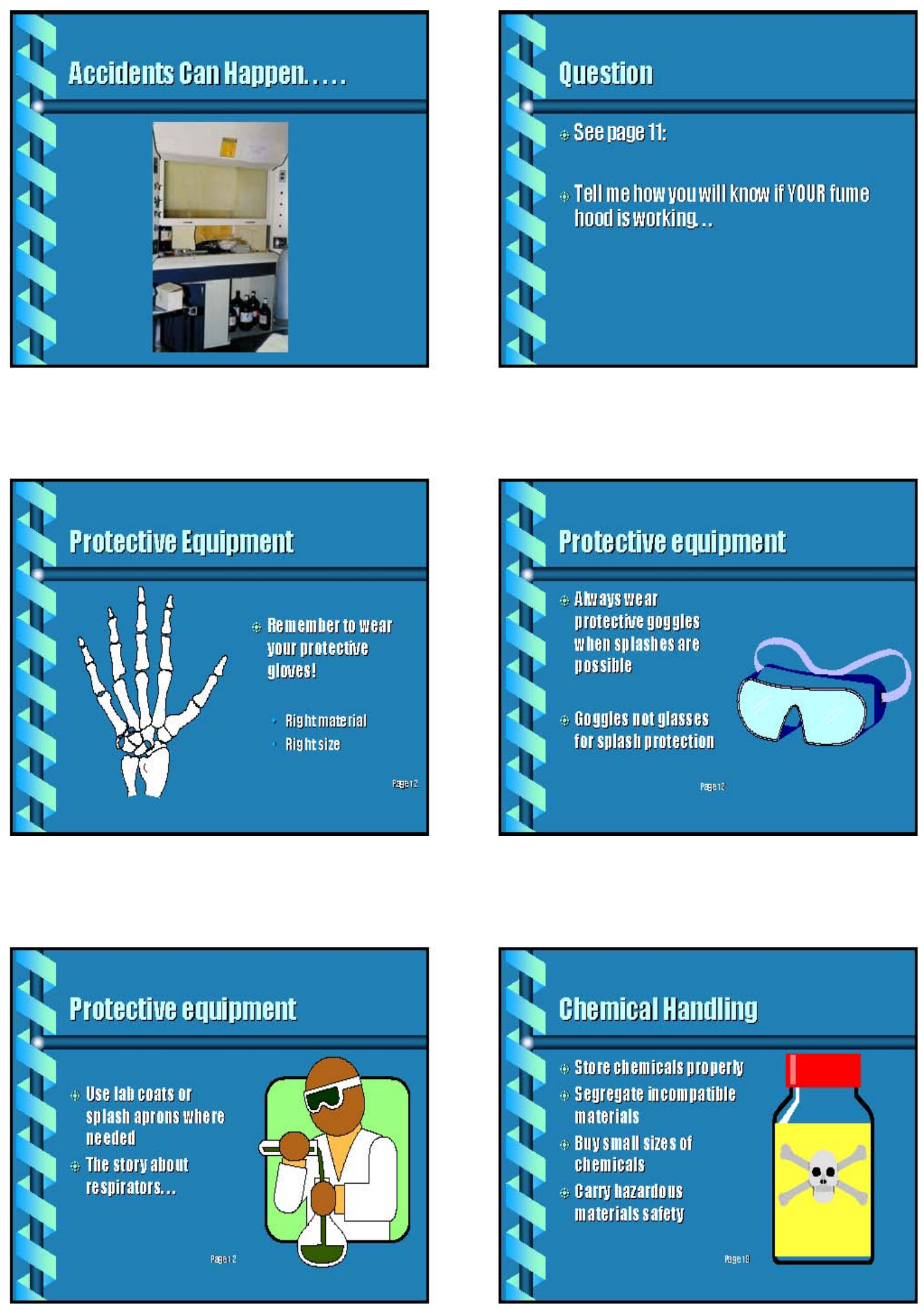

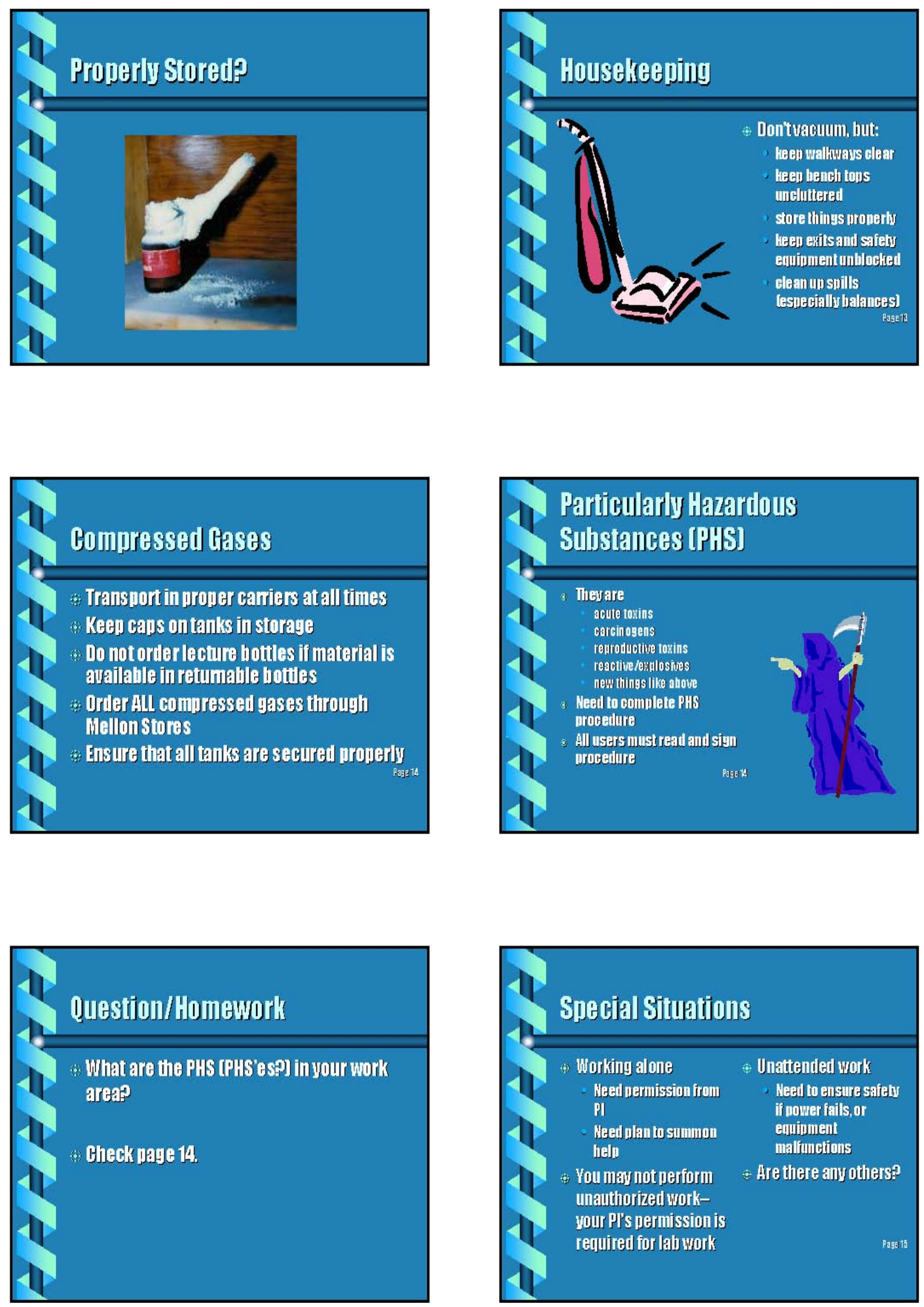

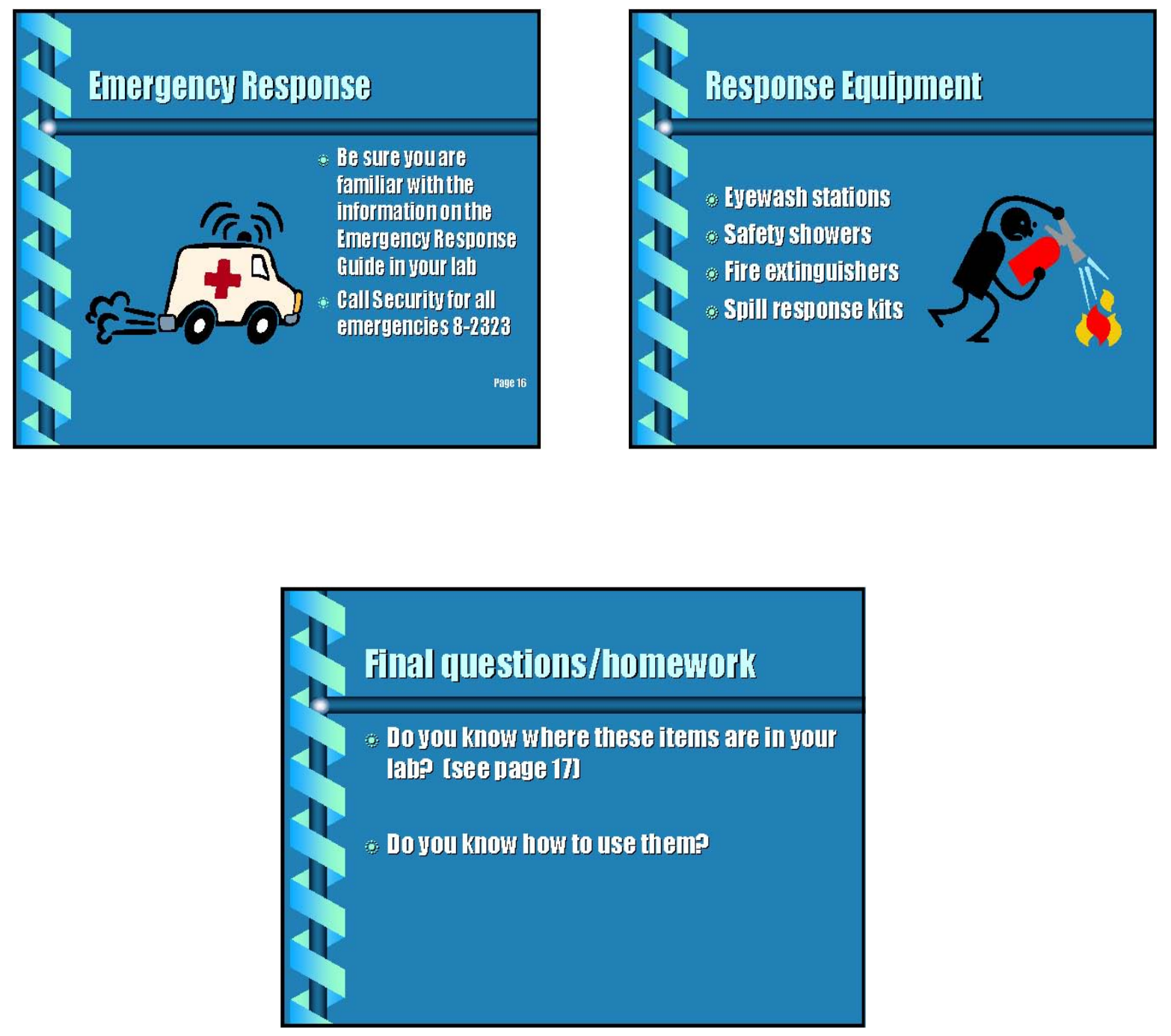


\section{Appendix F}

\section{New Training Slides}

\section{Carnegie Mellon University}

Environmental Health and

Safety Department's

Laboratory Safety Training

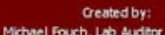

Machael Fouch, Lis Audtor Techiciar

\section{Objectives}

During this presentation we are going to talk about:

- OSHA regulations, in particular, "The Lab Standard".

- Permissible Exposure Limits (PELs), signs and symptoms

of overexposure, medically monitoring, and air

monitoring.

- Chemical labels, safe chemical storage, how to detect a chemical release, and Particularly Hazardous Substances (PHS)

- Chemtracker, Personal Protective Equipment (PPE) emergency equipment and the Emergency Response Guide.

\section{The OSHA Applicable Regulations}

\section{Objectives....continued}

- Proper use of chemical fume hoods

- Laboratory hazards and general work rules

- Good housekeeping habits and the importance of maintaining a clean and orderly lab.

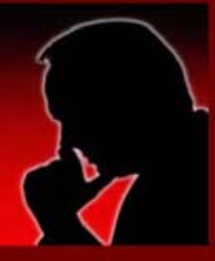

An Occupational Safety and Health Administration (OSHA) regulation, "Hazardous waste operations and emergency response", addresses workers in laboratory areas. All persons who work with hazardous chemicals may have a responsibility in the event of a spill or leak of a hazardous chemical. This regulation requires that such persons be trained in the proper actions, should this occur.
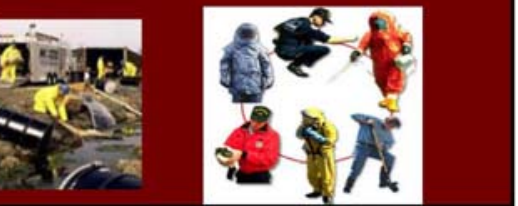


\section{The OSHA Applicable Regulations}

OSHA has also promulgated a regulation that is applicable to all employees who work in a laboratory with hazardous chemicals. It is generally spoken of as the "Lab Standard". The Lab Standard has the following requirements of employers:

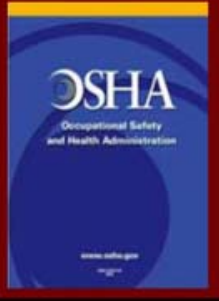

\section{Lab Standard Requirements}

2. Maintain employee exposures below the OSHA permissible exposure levels (PELs)

3. Determine employee exposures to hazardous chemicals

4. Provide employees with information and training about potential over-exposures to hazardous chemicals

5. Offer medical consultations in cases of potential overexposures to hazardous chemicals

5. Identify the hazards of the chemicals employees work with

6. Identify respirator use and limitations

\section{Lab Standard Requirements:}

1. Prepare a Chemical Hygiene Plan (CHP) outlining how the employer will comply with the requirements of the regulation.

OSHA requires that employers of laboratory workers name a Chemical Hygiene Officer ( $\mathrm{CHO}$ ) to oversee the requirements of the Lab Standard.

The CHO for Carnegie Mellon University is: Mark Banister $\mathrm{CIH}, \mathrm{CCHO}, \mathrm{CHMM}$ Phone: 412-268-1493 Cell: 412-527-5616 Email: markb2@andrew.cmu.edu

\section{The Chemical Hygiene Plan}

OSHA requires the preparation of a Chemical Hygiene Plan (CHP) to outline how Carnegie Mellon University will comply with the Lab Standard. It contains procedures and requirements that all laboratory workers must follow. This document is available to employees of laboratories in one of two ways:

$\therefore$ The EH\&S web site,

http://www.cmu,edu/ehs/chemsafety.htm

$\therefore$ From the EH\&S office

\section{Permissible Exposure Limits}

OSHA sets permissible exposure limits (PELs) to protect workers against the health effects of exposure to hazardous substances. PELs are regulatory limits on the amount or concentration of a substance in the air.

Currently, approximately 500 PELs have been established. Existing PELs are contained in 29 CFR 1910.1000 , the air contaminants standard.

U.S. Department of Labor

\section{Permissible Exposure Limits}

As an example, let's take a look at Chloroform:

Chloroform....50 ppm or $240 \mathrm{mg} / \mathrm{m}^{3}$, this information comes from 29 CFR TABLE Z-1 Limits for Air Contaminants. - 1910.1000
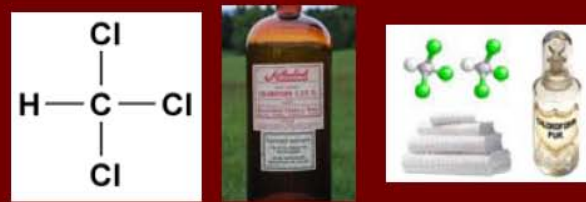


\section{Permissible Exposure Limits}

Unless otherwise stated, the PEL's are given in terms of the worker's average exposure over an 8-hour work day. Supposedly, most individuals breathing this

concentration, eight hours per day, forty hours per week, over a working lifetime, should not experience any health damage.

\section{Detecting Chemical Releases in the Laboratory}

There are several clues which can be used to detect a chemical release:

1) Odors

2) Irritating fumes

3) Broken bottles

4) Stains or other signs of leakage

5) Crystals on the outside of bottles or containers.

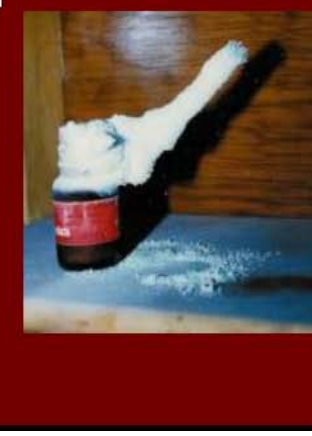

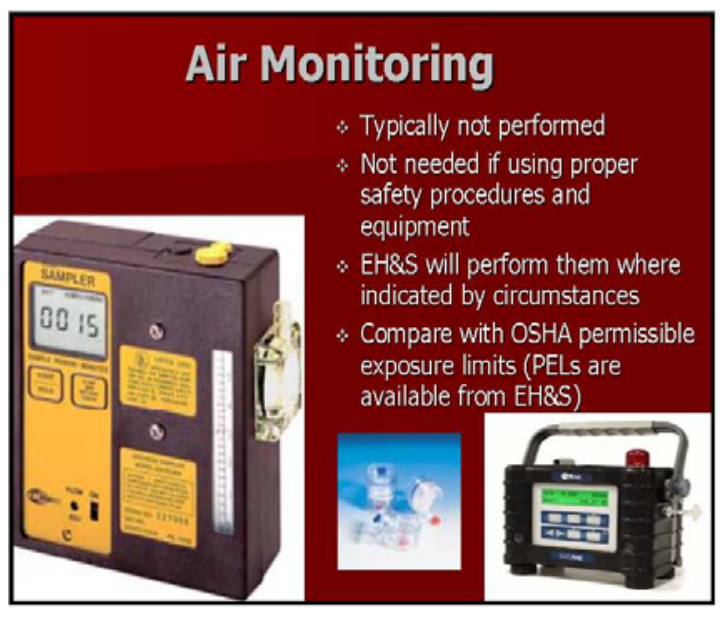

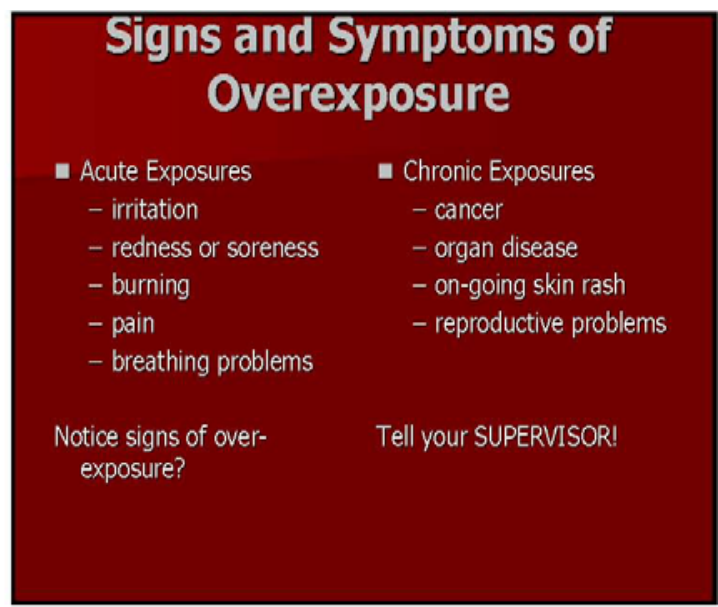




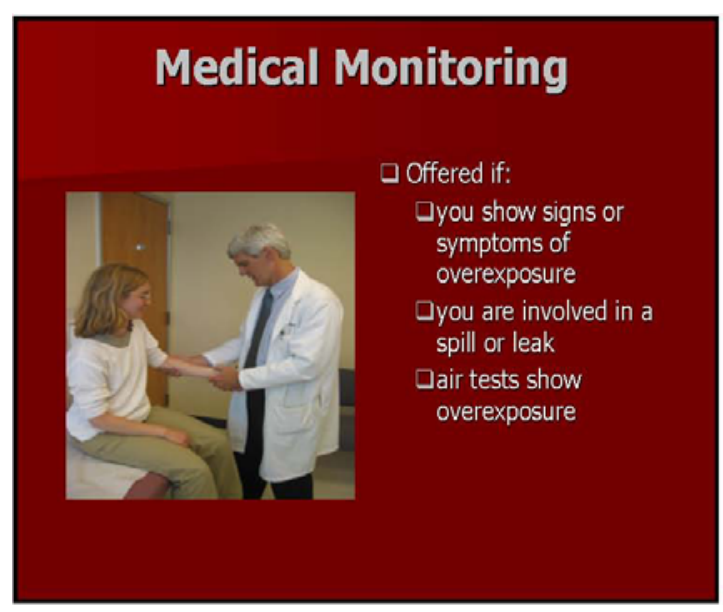

\section{Routes of Entry}

There are several different ways a chemical can entry your body:

Absorption - the chemical can be absorbed through your skin

Inhalation - you can breathe in the chemical's fumes or vapors

Ingestion - you can swallow the chemical

Injection - you can inject the chemical with an

accidental needle stick or broken glass

\section{What are the hazards of the chemicals YOU work with?}

Chemicals can be:

Corrosive - sulfuric acid, hydrochloric acid Flammable - acetone, ether

Toxic - mercury, arsenic

Oxidizer - peroxides, nitrates

Carcinogens - benzene, chloroform

\section{Respirator Use...}

In most cases, the use of a respirator will not be necessary if you are using your chemicals in a safe manner (i.e. in a fume hood or well ventilated area). However, if you feel that you need to use a respirator, you must contact the EH\&S office to arrange a fit test and be entered into the respirator protection program. This is to ensure that you are medically able to

withstand the use of a respirator and that it is properly fitted so it can provide the proper protection.

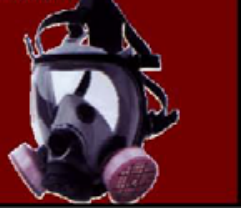

\section{Container Labels}

There are two applicable rules for us regarding the labeling of chemical containers:

1. You are NOT permitted to remove or deface a manufacturer's label from a container until the container has been emptied.

2. All secondary chemical containers (such as wash bottles, containers with specially prepared dilutions or mixtures, or any different storage container we have placed hazardous materials into) must be labeled. In other words, ALL containers in the laboratory must be labeled with at least the container contents.

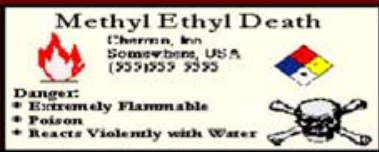

\section{Container Labels}

Labels are good references for information on chemical hazards. Labels on containers of purchased chemicals include:

- The common name of the substance.

- An appropriate hazard warning.
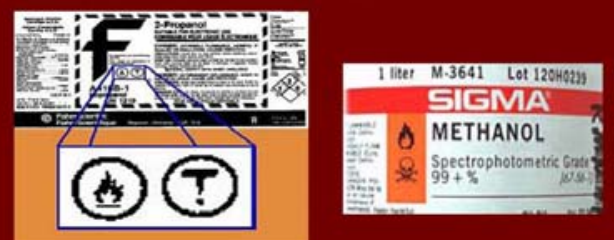

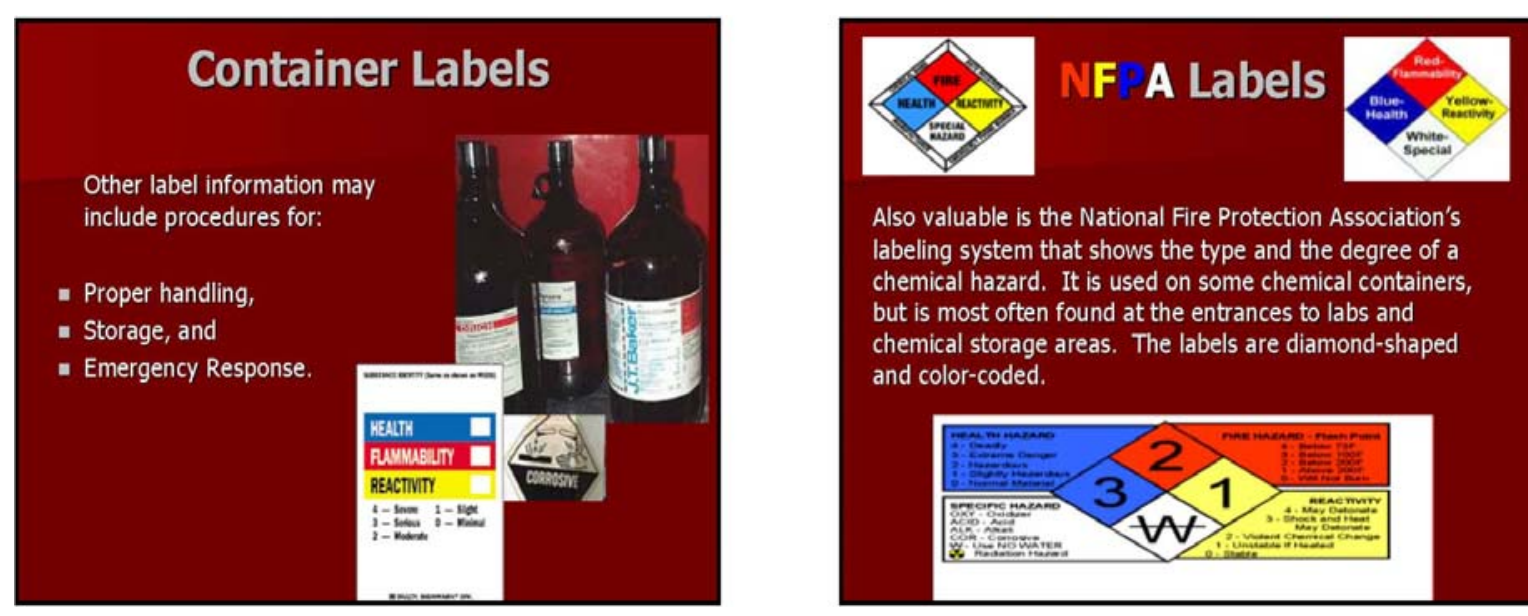

Also valuable is the National Fire Protection Association's labeling system that shows the type and the degree of a chemical hazard. It is used on some chemical containers, but is most often found at the entrances to labs and chemical storage areas. The labels are diamond-shaped and color-coded.
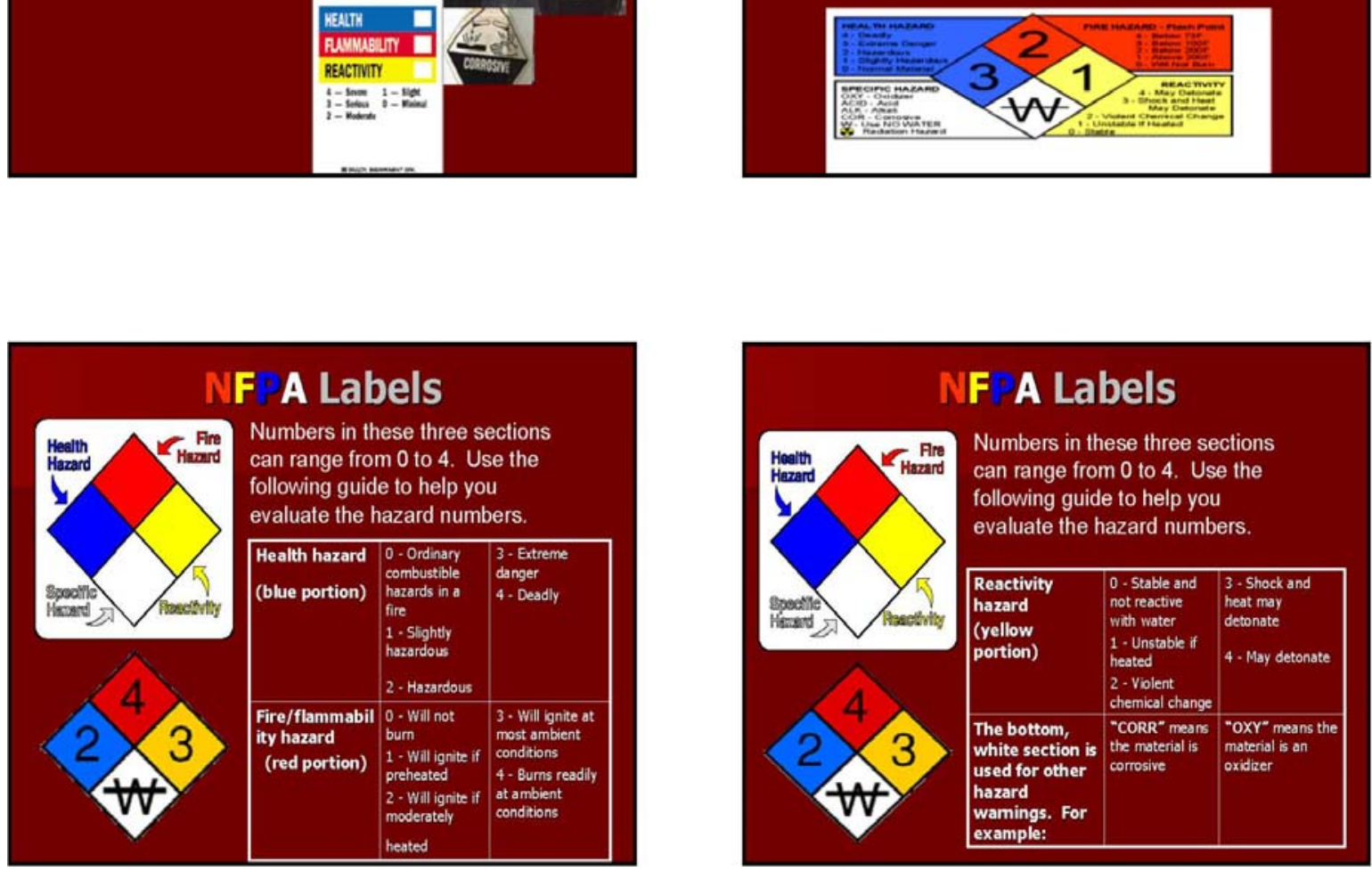

\section{Material Safety Data Sheets}

Another important reference for health and safety

information is the Material Safety Data Sheets, or MSDS. A MSDS is prepared for each chemical by its manufacturer. It describes the physical and chemical properties of the product, the health hazards, and appropriate emergency response procedures. And, it can tell you of acute and chronic effects that can be caused by exposures to hazardous chemicals.
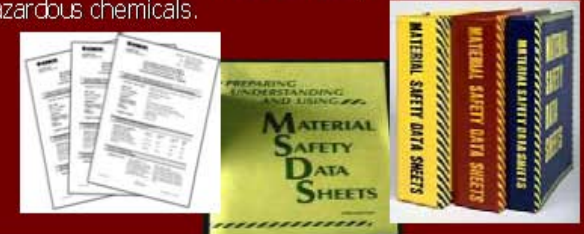

\section{Material Safety Data Sheets}

Material Safety Data Sheets can be found at the Environmental Safety Department's website

https://www.cmu.edu/ehs/LabSafety/msdslinks.htm

Reading an MSDS is sometimes challenging as there are many different formats used and they vary widely in their depth of information. For assistance in interpreting an MSDS, campus users may contact EH\&S at 8-8182. 


\section{Chemical Inventory System}

Carnegie Mellon University uses a program called chemtracker for it's chemical inventory system. The chemtracker system was originally developed at Stanford University to handle their large number of material containers and to maintain chemical inventory for addressing environmental compliance issues.

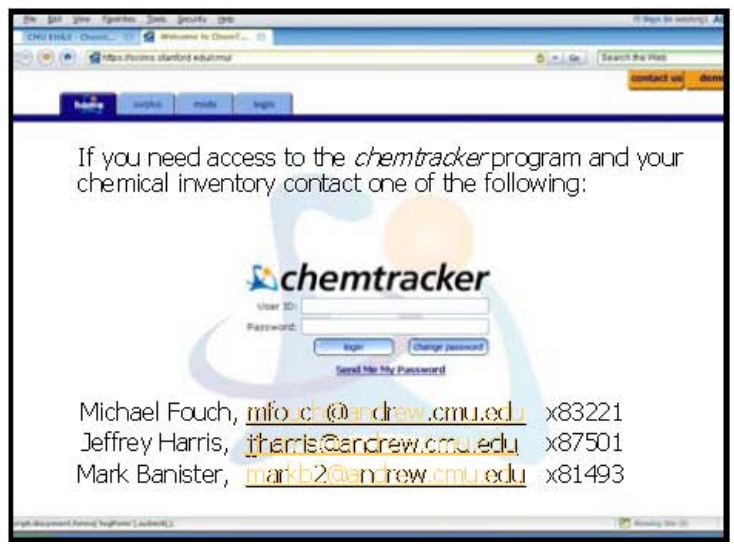

\section{Chemical Storage}

Safe storage of chemicals is a necessity in every laboratory. It will:

> Provide for effective management of chemicals.

> Lessen the risk of fire.

> Prevent accidental mixing of incompatible chemicals in emergencies.

> Minimize exposure to corrosive and toxic chemicals.

\section{Chemical Storage}

Safe chemical storage may seem to be a matter of common sense. In fact, it requires an awareness of each chemical's potential hazards, and a lot of thought.

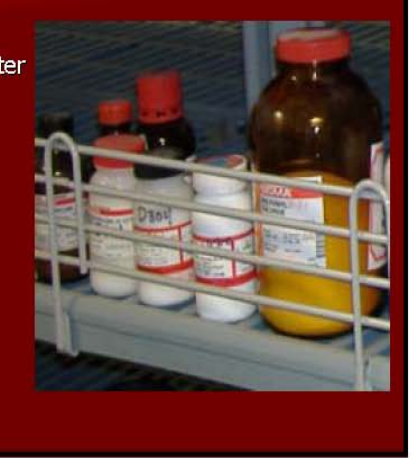

\section{Rules of Thumb for Safe Chemical Storage}

Do not store more chemicals than you will need over a reasonable period.

Always read the chemical's label and mark it with the date of receipt before storing.

- Never store a chemical with an obscured or missing label.

Separate chemicals into compatible groups.

Designate separate storage areas for highly toxic chemicals. 


\section{Safe Handling of Compressed Gas Cylinders}

Due to the nature of gas cylinders, special storage, use and handling precautions in accordance with OSHA regulations are necessary. Compressed gases are classified based upon their chemical and physical hazards.
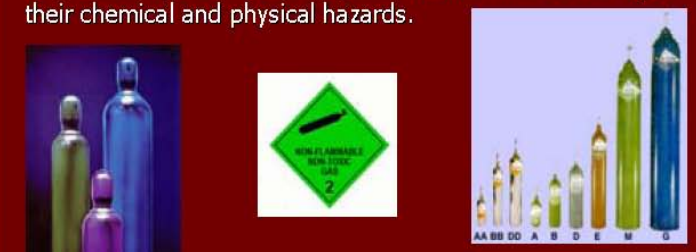

\section{Safe Handling of Compressed} Gas Gylinders

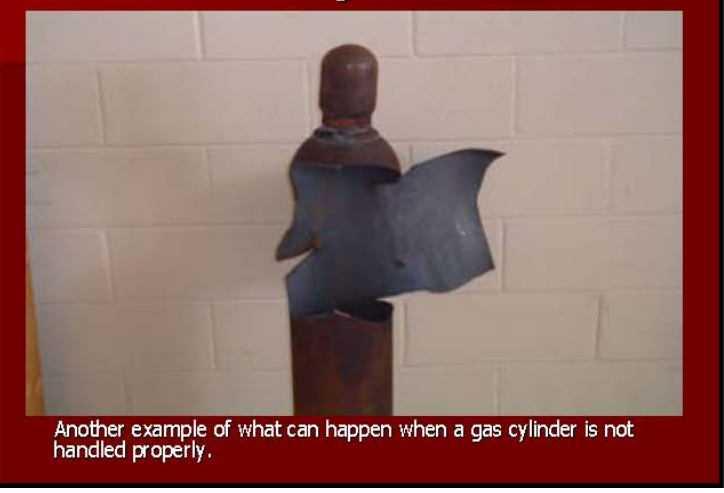

\section{Safe Handling of Compressed Gas Cylinders}

All compressed gas cylinders in service or in storage shall be secured to prevent falling/tipping/rolling and shall be stored and used valve end up. They can be secured with straps or chains connected to a wall bracket or other fixed surface, or by use of a cylinder stand.

The user shall keep valve protection caps on cylinders at all times except when cylinders are connected to dispensing equipment.
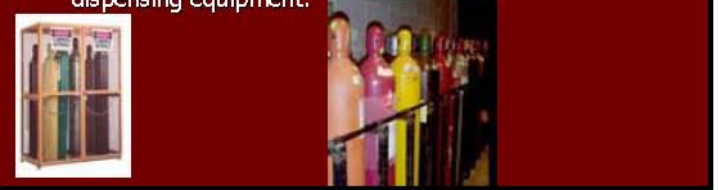

Safe Handling of Compressed Gas Cylinders

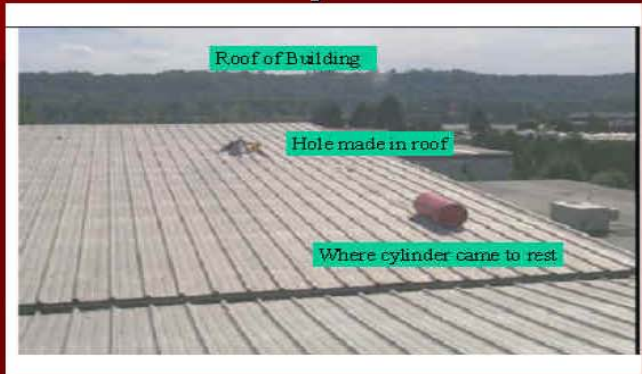

An example of what can happen when a gas cylinder is not handled properly.

\section{Safe Handling of Compressed Gas Cylinders}

Gases may represent a hazard because they are:

Flammable

Asphyxiate

Oxidizer

Corrosive

Toxic

Oryogenic

and/or Under High Pressure
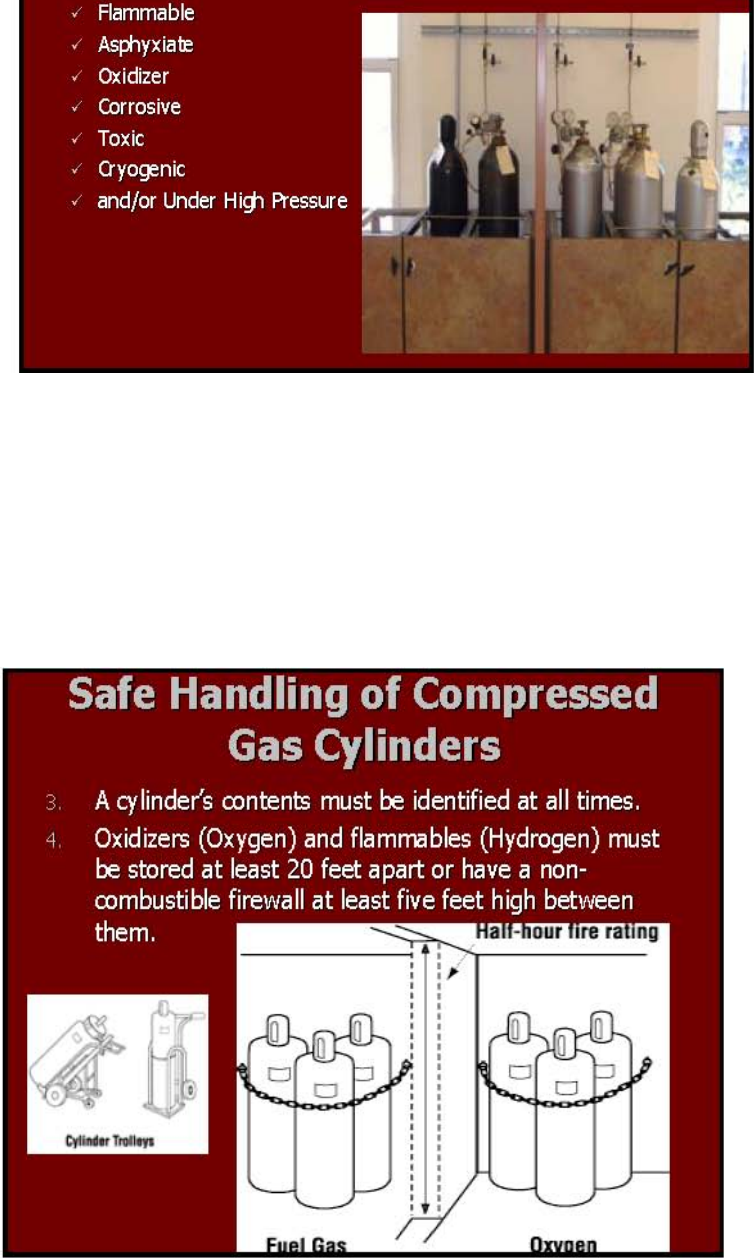


\section{Laboratory Hazards}

Laboratory hazards are often classified into two categories, those due to unsafe acts by persons and those due to unsafe conditions in the workplace environment. Of the two, hazards arising from unsafe acts are more prevalent than hazards related to unsafe conditions.
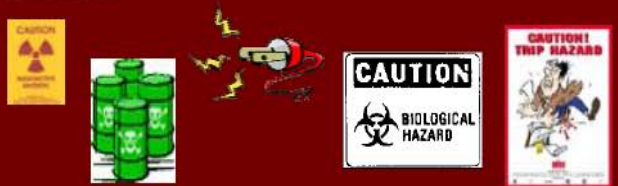

Young J.A. (1987). Improwing Safety in the Chemical Laboratary. New York, John Wiley and Sons.

\section{Laboratory Hazards}

Here is some laboratory examples of unsafe acts:

- Violations of safety rules

- Operating equipment without proper training, or without authority

- Altering safety devices so as to make them inoperative

- Using equipment that is in a defective condition

- Servicing or altering electrically energized equipment

- Using unsuitable protective equipment or clothing, or not using such at all

- Taking shortcuts

- Horseplay

- Failure to warn or to protect co-workers while adequately protecting one's self.

- Poor record keeping

\section{Laboratory Hazards}

Here is some laboratory examples of unsafe conditions:

- Inoperative emergency equipment (fire extinguishers, safety showers, eyewash fountains)

- Unsatisfactory training in the use of emergency equipment.

- Poor housekeeping

- Narrow clearances in passageways, spaces between laboratory benches or between bench and wall, exit doorways, area in which emergency equipment is located.

- Improperly designed storage areas, inadequate shelving

- Crowded lab bench surfaces

- Improper electrical wiring

- Inoperative warning systems

\section{Laboratory Hazards}

If you need additional training because your lab contains biological hazards or radiation hazards...

For Radiation Safety Training please contact

John Zoll, Radiation Safety Officer,

(412) 268-7502 jzoll@andrew.cmu.edu

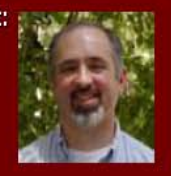

For Biological Safety Training please contact:

Andrew Lawson, Biological Safety Officer, (412) 268-8405 alawson@andrew.cmu.edu

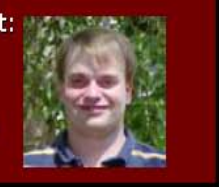

\section{Particularly Hazardous Substances (PHS)}

- They are

- acute toxins

- carcinogens

- reproductive toxins

- reactive/explosives

new things like above

- Need to complete PHS

procedure

- All users must read and sign

procedure

\section{General Work Rules in the Lab}

- Working alone

- Need permission from PI

- Need plan to summon help

- You may not perform unauthorized work--your PI's permission is required for lab work

- Unattended work

- Need to ensure safety if power fails, or equipment malfunctions 


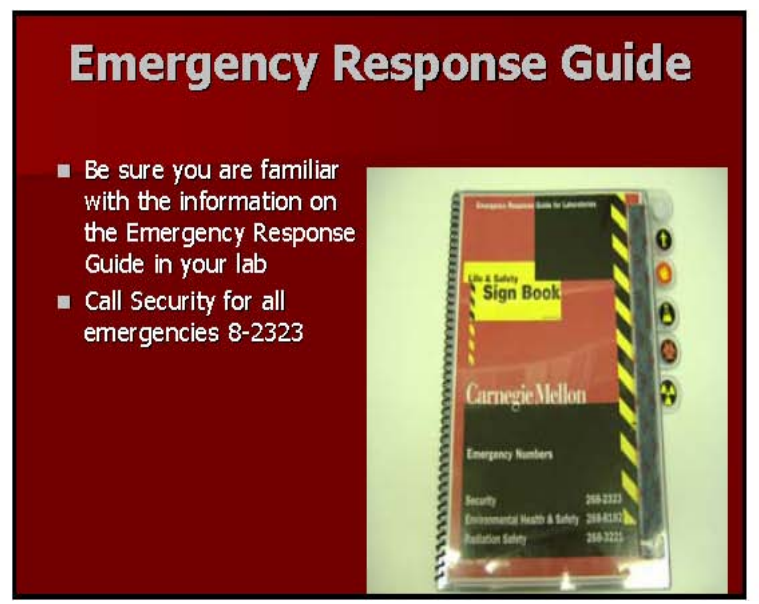

\section{Chemical Fume Hoods}

When using a chemical fume hood make sure you always:

- Keep them clean and uncluttered

- Work at least six inches inside the hood

- BE SURE THE HOOD IS WORKING FIRST!

- Do not modify the hood in any way

- Be aware that many hood walls contain asbestos--do not disturb them in any way

- Use them for ALL volatile chemical use

\section{Emergency Response Guide}

Be sure you know the location and proper usage of:

- Eyewash stations

- Safety showers

- Fire extinguishers

- Spill response kits
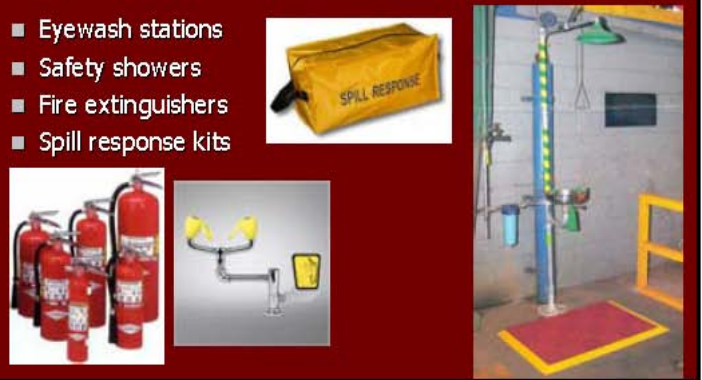

\section{Chemical Fume Hoods}

This is a video showing the effects of having the sash opened completely and how the fumes inside are not completely contained.

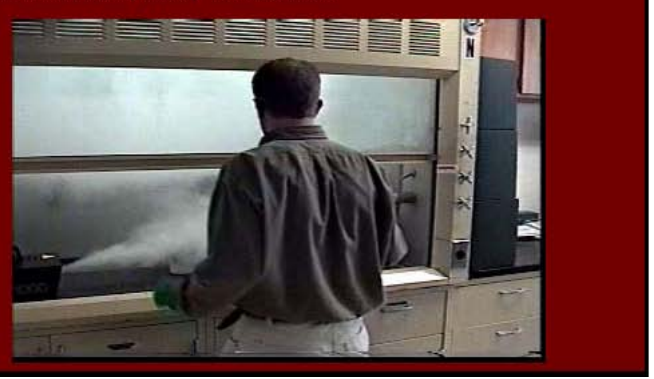

\section{Personal Protective Equipment}

- Remember to wear your protective gloves!

- Right material

- Right size

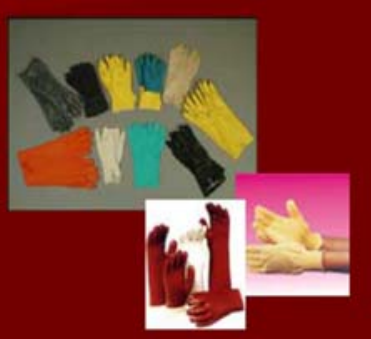

\section{Personal Protective Equipment}

- Always wear protective goggles when splashes are possible

- Goggles not glasses for splash protection

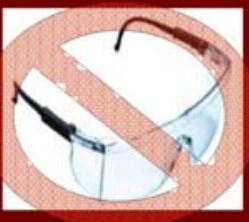

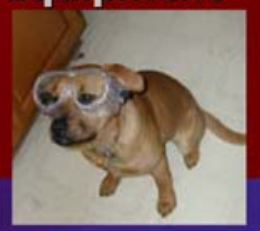

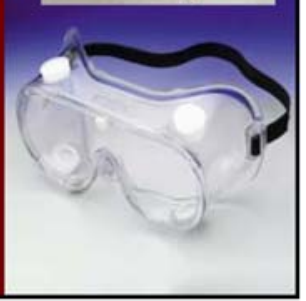



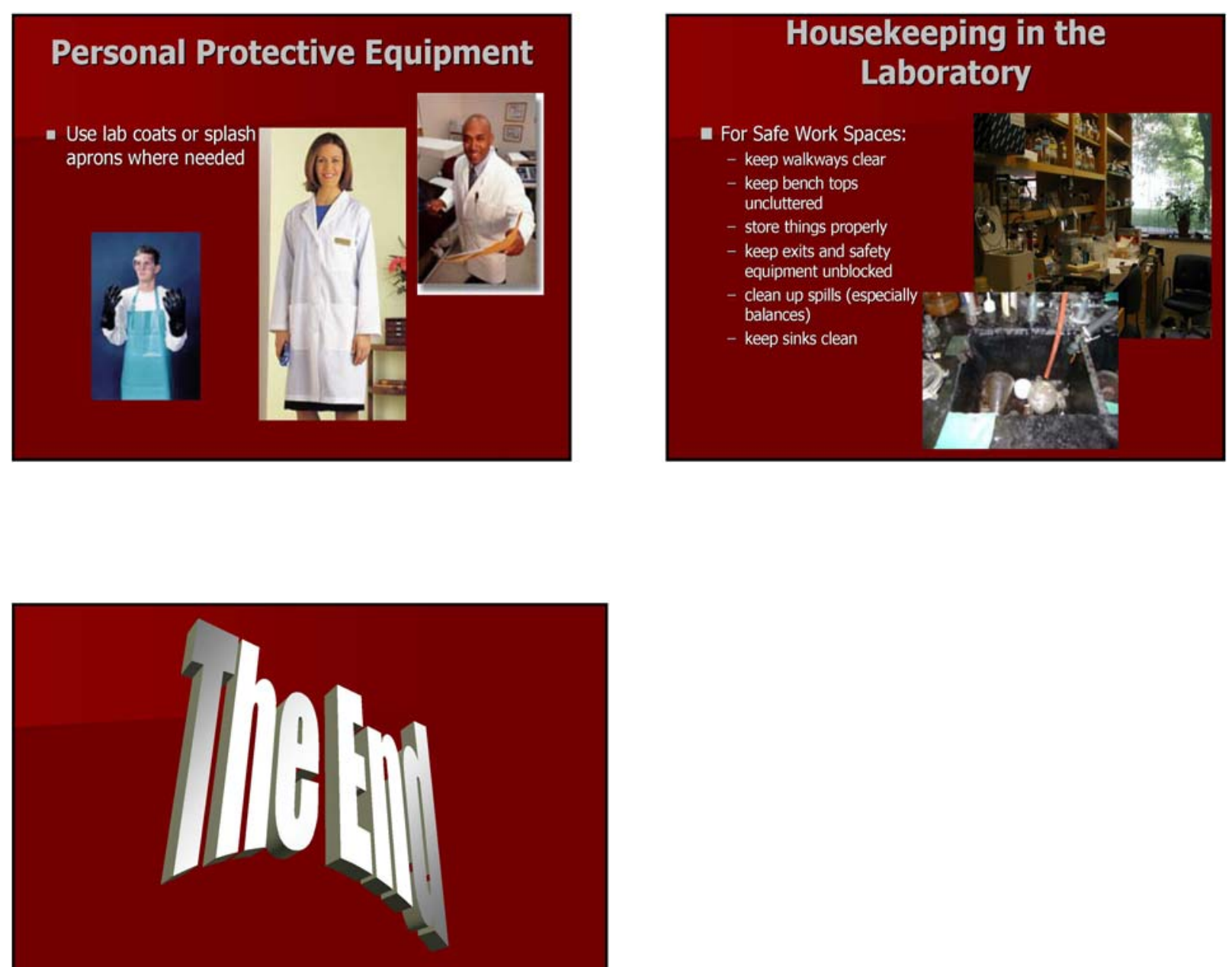

Any Questions??? 


\section{Appendix G}

\section{Comparison Among Departments}

\begin{tabular}{|c|c|c|c|c|c|c|c|c|c|}
\hline \multicolumn{10}{|c|}{ Independent Samples Test } \\
\hline & $\begin{array}{r}\text { Levene' } \\
\text { Equality o }\end{array}$ & $\begin{array}{l}\text { est for } \\
\text { ariances }\end{array}$ & \multicolumn{7}{|c|}{ t-test for Equality of Means } \\
\hline & \multirow[b]{2}{*}{$\mathrm{F}$} & \multirow[b]{2}{*}{ Sig. } & \multirow[b]{2}{*}{$\mathrm{t}$} & \multirow[b]{2}{*}{ df } & \multirow[b]{2}{*}{ Sig. (2-tailed) } & \multirow{2}{*}{$\begin{array}{c}\text { Mean } \\
\text { Difference }\end{array}$} & \multirow{2}{*}{$\begin{array}{l}\text { Std. Error } \\
\text { Difference }\end{array}$} & \multicolumn{2}{|c|}{$\begin{array}{c}95 \% \text { Confidence } \\
\text { Interval of the } \\
\text { Difference }\end{array}$} \\
\hline & & & & & & & & Lower & Upper \\
\hline $\begin{array}{c}\text { Violations Equal variances } \\
\text { assumed }\end{array}$ & 7.838 & .009 & 1.330 & 28 & .194 & .80000 & .60159 & -.43229 & 2.03229 \\
\hline $\begin{array}{l}\text { Equal variances } \\
\text { not assumed }\end{array}$ & & & 1.330 & 20.206 & .198 & .80000 & .60159 & -.45406 & 2.05406 \\
\hline
\end{tabular}

t-test of Biology and Chemical Engineering Departments-Old

With zero included in the interval -.43229 and 2.03229, I am 95\% confident that there is no significant difference between these departments. 
Independent Samples Test

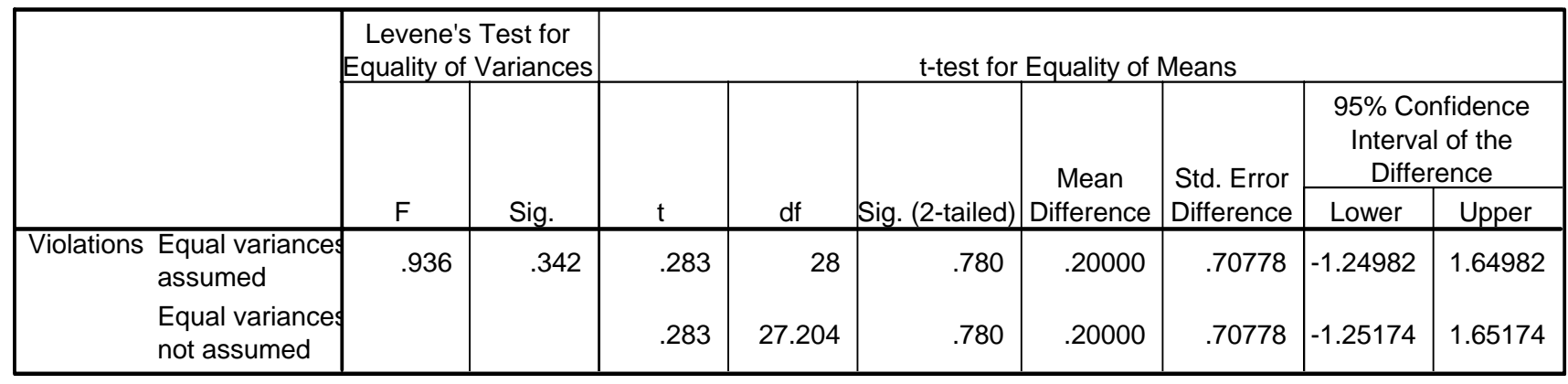

\section{t-test of Biology and Chemistry Departments - Old}

With zero included in the interval -1.24982 and 1.64982 , I am $95 \%$ confident that there is no significant difference between these departments. 
Independent Samples Test

\begin{tabular}{|c|c|c|c|c|c|c|c|c|c|}
\hline & \multicolumn{2}{|c|}{$\begin{array}{l}\text { Levene's Test for } \\
\text { Equality of Variances }\end{array}$} & \multicolumn{7}{|c|}{ t-test for Equality of Means } \\
\hline & \multirow[b]{2}{*}{$\mathrm{F}$} & \multirow[b]{2}{*}{ Sig. } & \multirow[b]{2}{*}{$\mathrm{t}$} & \multirow[b]{2}{*}{$\mathrm{df}$} & \multirow[b]{2}{*}{ Sig. (2-tailed } & \multirow{2}{*}{$\begin{array}{c}\text { Mean } \\
\text { Difference }\end{array}$} & \multirow{2}{*}{$\begin{array}{l}\text { Std. Error } \\
\text { Difference }\end{array}$} & \multicolumn{2}{|c|}{$\begin{array}{l}95 \% \text { Confidence } \\
\text { Interval of the } \\
\text { Difference }\end{array}$} \\
\hline & & & & & & & & Lower & Upper \\
\hline $\begin{array}{r}\text { Violations } \\
\text { Equal variance } \\
\text { assumed } \\
\text { Equal variance } \\
\text { not assumed }\end{array}$ & 10.659 & .003 & $\begin{array}{l}1.241 \\
1.241\end{array}$ & $\begin{array}{r}28 \\
19.147\end{array}$ & $\begin{array}{l}.225 \\
.230\end{array}$ & $\begin{array}{l}.73333 \\
.73333\end{array}$ & $\begin{array}{l}.59094 \\
.59094\end{array}$ & $\begin{array}{l}-.47715 \\
-.50287\end{array}$ & $\begin{array}{l}1.94381 \\
1.96954\end{array}$ \\
\hline
\end{tabular}

t-test of Biology and Materials Science Engineering Departments-Old

With zero included in the interval -.47715 and 1.94381, I am 95\% confident that there is no significant difference between these departments. 
Independent Samples Test

\begin{tabular}{|c|c|c|c|c|c|c|c|c|c|}
\hline & $\begin{array}{r}\text { Levene's } \\
\text { Equality o }\end{array}$ & $\begin{array}{l}\text { est for } \\
\text { ariances }\end{array}$ & \multicolumn{7}{|c|}{ t-test for Equality of Means } \\
\hline & \multirow[b]{2}{*}{$\mathrm{F}$} & \multirow[b]{2}{*}{ Sig. } & \multirow[b]{2}{*}{$\mathrm{t}$} & \multirow[b]{2}{*}{$\mathrm{df}$} & \multirow[b]{2}{*}{ Sig. (2-tailed) } & \multirow{2}{*}{$\begin{array}{c}\text { Mean } \\
\text { Difference }\end{array}$} & \multirow{2}{*}{$\begin{array}{l}\text { Std. Error } \\
\text { Difference }\end{array}$} & \multicolumn{2}{|c|}{$\begin{array}{l}95 \% \text { Confidence } \\
\text { Interval of the } \\
\text { Difference }\end{array}$} \\
\hline & & & & & & & & Lower & Upper \\
\hline $\begin{array}{c}\text { Violations Equal variance } \\
\text { assumed } \\
\text { Equal variance } \\
\text { not assumed }\end{array}$ & .560 & .460 & $\begin{array}{l}-.189 \\
-.189\end{array}$ & $\begin{array}{r}28 \\
27.711\end{array}$ & $\begin{array}{l}.851 \\
.851\end{array}$ & $\begin{array}{l}-.06667 \\
-.06667\end{array}$ & $\begin{array}{l}.35277 \\
.35277\end{array}$ & $\begin{array}{l}-.78928 \\
-.78962\end{array}$ & $\begin{array}{l}.65594 \\
.65628\end{array}$ \\
\hline
\end{tabular}

t-test of Chemical Engineering and Materials Science Engineering Departments-Old

With zero included in the interval -.78928 and .65594, I am 95\% confident that there is no significant difference between these departments. 
Independent Samples Test

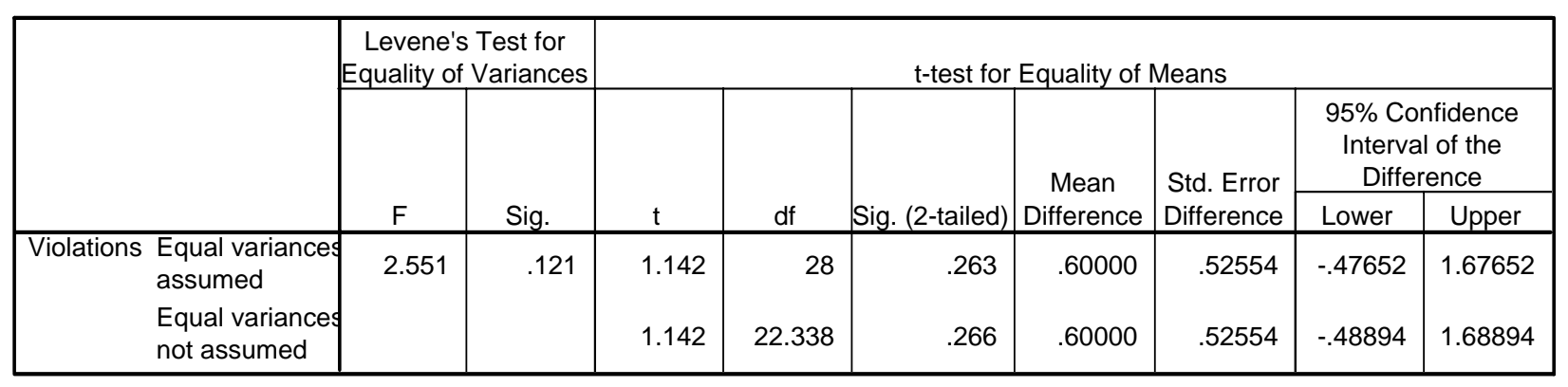

t-test of Chemistry and Chemical Engineering Departments-Old

With zero included in the interval -.47652 and 1.67652, I am 95\% confident that there is no significant difference between these departments. 
Independent Samples Test

\begin{tabular}{|c|c|c|c|c|c|c|c|c|c|c|}
\hline & \multicolumn{2}{|c|}{$\begin{array}{c}\text { Levene's Test for } \\
\text { Equality of Variances }\end{array}$} & \multicolumn{7}{|c|}{ t-test for Equality of Means } \\
\hline & & \multirow[b]{2}{*}{$\mathrm{F}$} & \multirow[b]{2}{*}{ Sig. } & \multirow[b]{2}{*}{$\mathrm{t}$} & \multirow[b]{2}{*}{ df } & \multirow[b]{2}{*}{ Sig. (2-tailed) } & \multirow{2}{*}{$\begin{array}{c}\text { Mean } \\
\text { Difference }\end{array}$} & \multirow{2}{*}{$\begin{array}{l}\text { Std. Error } \\
\text { Difference }\end{array}$} & \multicolumn{2}{|c|}{$\begin{array}{l}95 \% \text { Confidence } \\
\text { Interval of the } \\
\text { Difference }\end{array}$} \\
\hline & & & & & & & & & Lower & Upper \\
\hline Violations & $\begin{array}{l}\text { Equal variances } \\
\text { assumed }\end{array}$ & 4.352 & .046 & 1.039 & 28 & .308 & .53333 & .51331 & -.51814 & 1.58481 \\
\hline & $\begin{array}{l}\text { Equal variances } \\
\text { not assumed }\end{array}$ & & & 1.039 & 21.026 & .311 & .53333 & .51331 & -.53408 & 1.60075 \\
\hline
\end{tabular}

t-test of Chemistry and Materials Science Engineering Departments_-Old

With zero included in the interval -.51814 and 1.58481, I am 95\% confident that there is no significant difference between these departments. 
Independent Samples Test

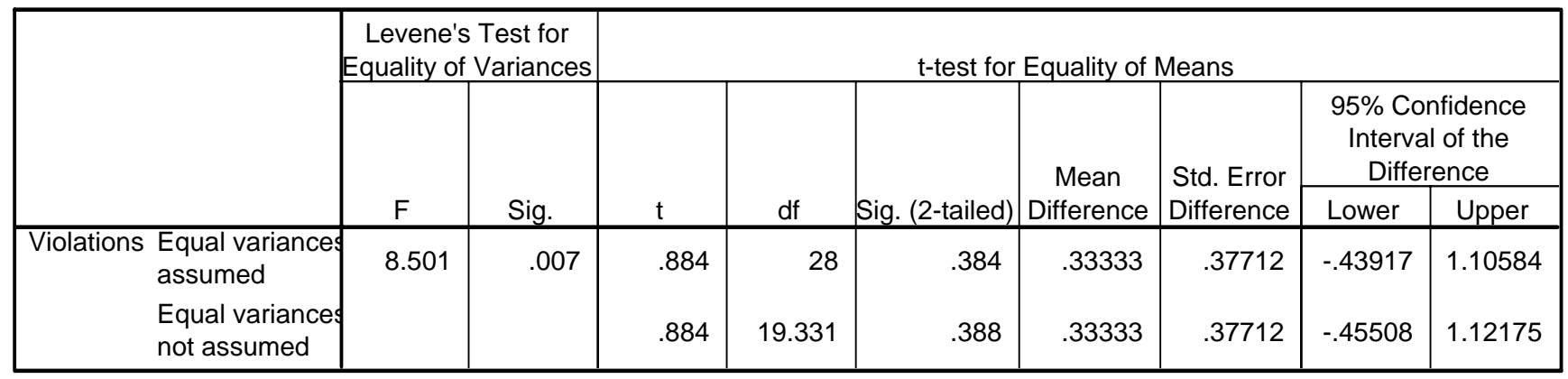

t-test of Biology and Chemical Engineering Departments- New

With zero included in the interval -.43917 and 1.10584, I am 95\% confident that there is no significant difference between these departments. 
Independent Samples Test

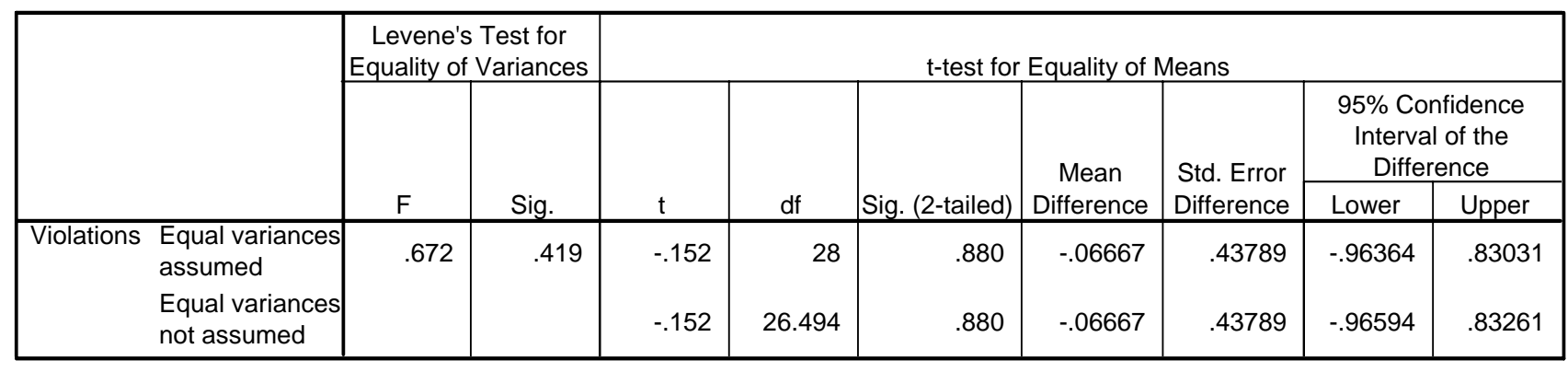

t-test of Biology and Chemistry Departments- New

With zero included in the interval -.96364 and .83031 , I am $95 \%$ confident that there is no significant difference between these departments. 
Independent Samples Test

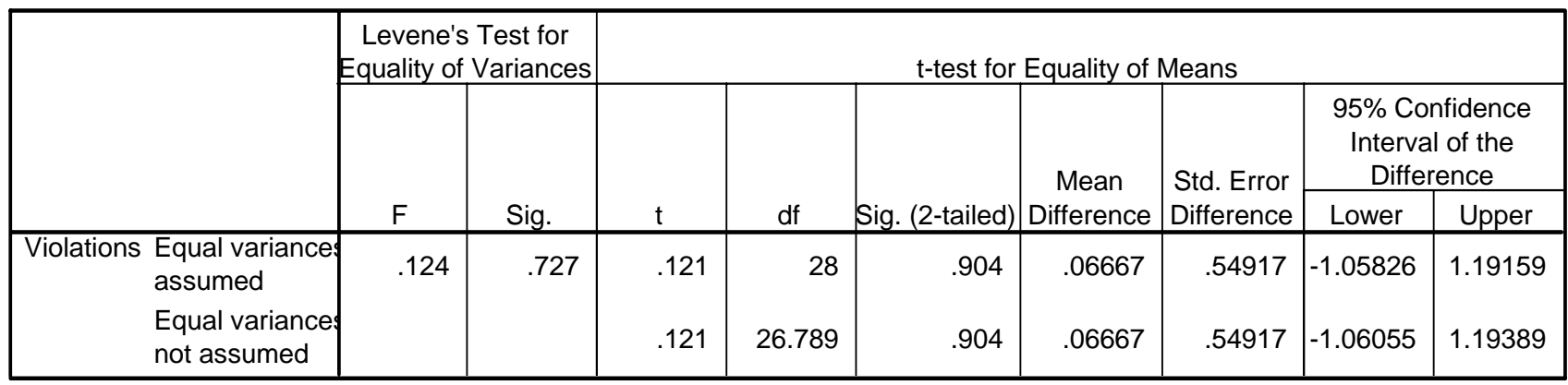

t-test of Biology and Materials Science Engineering Departments- New

With zero included in the interval -1.05826 and 1.19159 , I am 95\% confident that there is no significant difference between these departments. 
Independent Samples Test

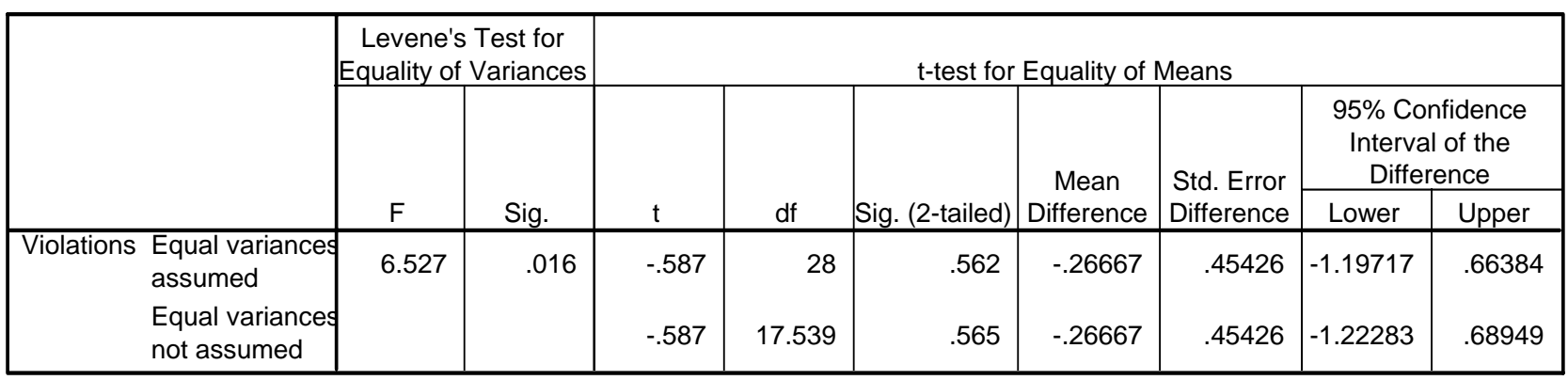

t-test of Chemical Engineering and Materials Science Engineering Departments- New

With zero included in the interval -1.19717 and .66384 , I am $95 \%$ confident that there is no significant difference between these departments. 
Independent Samples Test

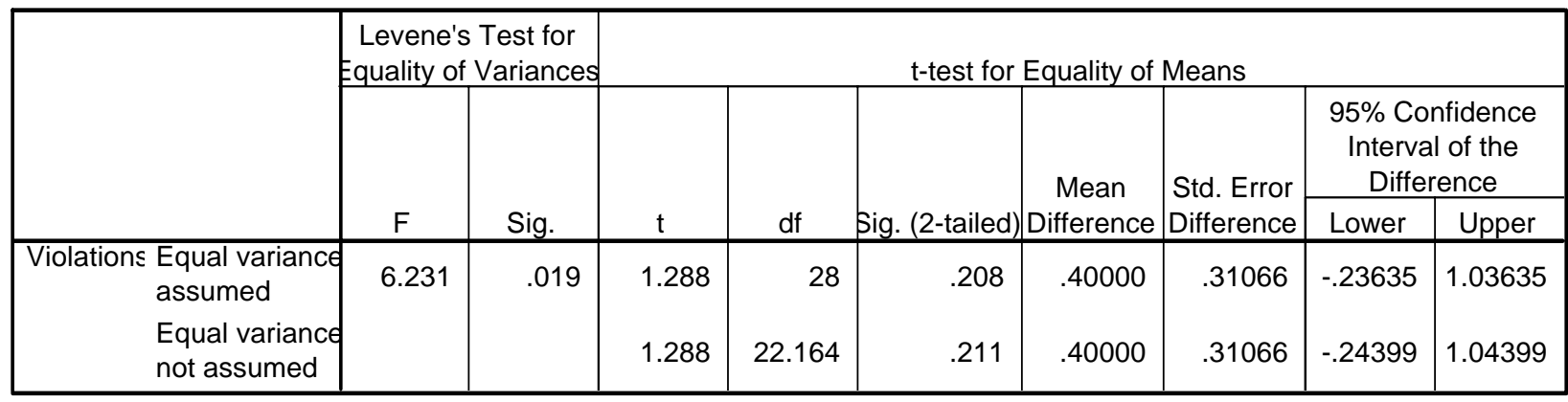

t-test of Chemistry and Chemical Engineering Departments-New

With zero included in the interval -.23635 and 1.0365 , I am $95 \%$ confident that there is no significant difference between these departments. 
Independent Samples Test

\begin{tabular}{|c|c|c|c|c|c|c|c|c|c|c|}
\hline & \multicolumn{2}{|c|}{$\begin{array}{l}\text { Levene's Test for } \\
\text { Equality of Variances }\end{array}$} & \multicolumn{7}{|c|}{ t-test for Equality of Means } \\
\hline & & \multirow[b]{2}{*}{$\mathrm{F}$} & \multirow[b]{2}{*}{ Sig. } & \multirow[b]{2}{*}{$\mathrm{t}$} & \multirow[b]{2}{*}{ df } & \multirow[b]{2}{*}{ Sig. (2-tailed) } & \multirow{2}{*}{$\begin{array}{c}\text { Mean } \\
\text { Difference }\end{array}$} & \multirow{2}{*}{$\begin{array}{l}\text { Std. Error } \\
\text { Difference }\end{array}$} & \multicolumn{2}{|c|}{$\begin{array}{l}95 \% \text { Confidence } \\
\text { Interval of the } \\
\text { Difference }\end{array}$} \\
\hline & & & & & & & & & Lower & Upper \\
\hline Violations & $\begin{array}{l}\text { Equal variances } \\
\text { assumed }\end{array}$ & 1.015 & .322 & .264 & 28 & .794 & .13333 & .50584 & -.90283 & 1.16950 \\
\hline & $\begin{array}{l}\text { Equal variances } \\
\text { not assumed }\end{array}$ & & & .264 & 23.643 & .794 & .13333 & .50584 & -.91150 & 1.17817 \\
\hline
\end{tabular}

t-test of Chemistry and Materials Science Engineering Departments—New

With zero included in the interval -.90283 and 1.16950 , I am 95\% confident that there is no significant difference between these departments. 


\section{Appendix $\mathbf{H}$}

\section{Chemical Hygiene Training Test}

Name

Date

Andrew ID

Department

1. Name at least one activity you perform where you may be exposed to a hazardous chemical. Name the chemical. Name a symptom of overexposure to that chemical.

\begin{tabular}{|l|l|l|}
\hline \multicolumn{2}{|c|}{ Chemical } & \\
\hline & & \\
\hline & & \\
\hline & & \\
\hline
\end{tabular}

2. Where can you find a copy of Carnegie Mellon University's Chemical Hygiene Plan?
a.) Check the OSHA web site
b.) Check the CMU web site
c.) Contact the Department of Environmental Health and Safety
d.) $\mathrm{B}$ and $\mathrm{C}$, above

3. The Permissible Exposure Limit for a material is
a.) A list of who is allowed to use a given chemical
b.) The maximum level of a chemical you can be exposed to, on an 8 hour average, without expected harm
c.) The maximum level of a chemical you can be exposed to in a year
d.) A number from the diamond on the chemical label

4. When should you read an MSDS for a particular chemical?
a.) Every three months
b.) Prior to using the material
c.) When preparing the chemical inventory
d.) Just before lab safety training 
5. You think you have signs or symptoms of a chemical overexposure. You should:
a.) Contact your supervisor (and Campus Police, for emergency overexposures)
b.) Call your doctor
c.) Go to a hospital emergency room
d.) Ask EH\&S to perform an air test

6. Which of the following are ways to detect a release of a hazardous chemical?
a.) Chemical odor
b.) Seeing a broken or leaking container
c.) Unaccounted for loss of the chemical
d.) All of the above

7. Which is the preferred way to prevent an overexposure to a hazardous chemical?
a.) Work in a hood and/or use protective gloves and eyewear
b.) Use a respirator appropriate for the chemical you are using
c.) Wear an air monitor while you work
d.) Only work a half shift

8. On a chemical label warning "diamond", which number indicates the most serious hazard?
a.) One
b.) Three
c.) Four
d.) Ten

9. You transfer a chemical material to a hand-held squeeze bottle and store it in the proper storage cabinet. What are your labeling requirements?
a.) The material needs no label
b.) The container needs no label unless it is carcinogenic
c.) The material needs a label identifying the contents of the bottle
d.) The material only need the "diamond" designation with the correct numbered ratings

10. You are planning to work with a PHS. Which of the following must be done before you start?
a.) Get approval from your supervisor and wear a respirator throughout the work
b.) Work with a "buddy" at all times
c.) Get approval from your supervisor and follow the written PHS procedure
d.) All of the above 


\section{Appendix I}

\section{Excel Spreadsheet with Data}

Biology Old Training

Biology Department

\begin{tabular}{|c|c|c|c|c|c|c|c|c|c|c|c|c|c|c|c|}
\hline \multirow{3}{*}{ Dates of Observations } & \multicolumn{3}{|c|}{ Par A : Female 10/27 } & \multicolumn{3}{|c|}{ Par B : Male 10/27 } & \multicolumn{3}{|c|}{ Par C : Male 11/22 } & \multicolumn{3}{|c|}{ Par D : Female 11/22 } & \multicolumn{3}{|c|}{ Par E : Male 11/28 } \\
\hline & $11 / 3$ & $11 / 7$ & $11 / 15$ & $11 / 1$ & $11 / 8$ & $12 / 1$ & $11 / 29$ & $12 / 7$ & $12 / 14$ & $11 / 28$ & $12 / 6$ & $12 / 15$ & $12 / 6$ & $12 / 15$ & $1 / 6$ \\
\hline & Obs. 1 & Obs. 2 & Obs. 3 & Obs.1 & Obs. 2 & Obs.3 & Obs. 1 & Obs. 2 & Obs. 3 & Obs. 1 & Obs. 2 & Obs.3 & Obs. 1 & Obs. 2 & Obs. 3 \\
\hline Eye Protection & 1 & 0 & 0 & 1 & 0 & 1 & 0 & 1 & 1 & 0 & 1 & 0 & 0 & 0 & 1 \\
\hline Lab Coat & 1 & 1 & 1 & 1 & 1 & 1 & 0 & 1 & 1 & 1 & 1 & 1 & 0 & 0 & 1 \\
\hline Gloves & 1 & 1 & 1 & 0 & 1 & 1 & 0 & 1 & 0 & 0 & 0 & 1 & 1 & 0 & 1 \\
\hline Clothing & 0 & 0 & 0 & 1 & 1 & 0 & 0 & 0 & 1 & 1 & 1 & 0 & 0 & 1 & 0 \\
\hline Housekeeping & 0 & 0 & 0 & 0 & 0 & 1 & 0 & 0 & 0 & 0 & 1 & 0 & 0 & 1 & 0 \\
\hline Eating & 1 & 1 & 1 & 1 & 1 & 1 & 0 & 1 & 0 & 0 & 1 & 1 & 1 & 0 & 1 \\
\hline Drinking & 0 & 0 & 0 & 0 & 1 & 0 & 1 & 0 & 0 & 0 & 1 & 0 & 0 & 1 & 1 \\
\hline Containers Labeled & 0 & 0 & 0 & 0 & 1 & 0 & 0 & 0 & 1 & 0 & 0 & 0 & 0 & 0 & 0 \\
\hline HW Labeled & 0 & 1 & 1 & 1 & 1 & 0 & 0 & 0 & 1 & 0 & 1 & 0 & 1 & 0 & 0 \\
\hline HW Closed & 0 & 0 & 0 & 0 & 1 & 0 & 0 & 0 & 0 & 0 & 0 & 0 & 0 & 0 & 0 \\
\hline HWSecondary C. & 0 & 0 & 1 & 0 & 1 & 1 & 0 & 0 & 0 & 0 & 0 & 0 & 0 & 0 & 0 \\
\hline \multirow[t]{3}{*}{ Alone in Lab } & 0 & 0 & 1 & 1 & 0 & 0 & 0 & 0 & 0 & 0 & 0 & 0 & 0 & 0 & 1 \\
\hline & 4 & 4 & 6 & 6 & 9 & 6 & 1 & 4 & 5 & 2 & 7 & 3 & 3 & 3 & 6 \\
\hline & \multicolumn{6}{|c|}{ Biology Old Training Average Violations: } & 4.60 & & & & & & & & \\
\hline
\end{tabular}

Biology New Training

Par. A : Male 1/18 Par. B : Female 1/18 Par. C : Female 1/26 Par.D : Male 2/8 Par. E : Male 2/23

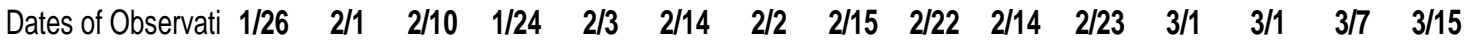

Variable $\quad$ Obs. 1 Obs. 2 Obs. 3 Obs. 1 Obs. 2 Obs. 3 Obs. 1 Obs. 2 Obs. 3 Obs. 1 Obs. 2 Obs. 3 Obs. 1 Obs. 2 Obs. 3

\begin{tabular}{ll|l|l|l|l|l|l|l|l|l|l|l|l|l|l}
\multicolumn{1}{c}{ Eye Protection } & 0 & 0 & 0 & 0 & 1 & 0 & 0 & 0 & 0 & 1 & 1 & 0 & 0 & 0 & 0 \\
Lab Coat & 1 & 1 & 0 & 1 & 1 & 1 & 1 & 1 & 1 & 0 & 0 & 1 & 1 & 1 & 1 \\
Gloves & 1 & 1 & 0 & 0 & 1 & 1 & 0 & 1 & 1 & 1 & 0 & 1 & 0 & 0 & 0 \\
Clothing & 0 & 0 & 0 & 0 & 0 & 0 & 0 & 0 & 0 & 0 & 0 & 0 & 0 & 0 & 0 \\
Housekeeping & 0 & 1 & 0 & 0 & 0 & 0 & 0 & 0 & 0 & 0 & 0 & 0 & 0 & 0 & 0 \\
Eating & 0 & 0 & 0 & 1 & 1 & 0 & 0 & 1 & 0 & 1 & 0 & 1 & 0 & 1 & 0 \\
Drinking & 0 & 1 & 1 & 0 & 0 & 0 & 0 & 0 & 0 & 0 & 1 & 0 & 0 & 1 & 0 \\
Containers Labeled & 0 & 0 & 0 & 0 & 1 & 1 & 0 & 0 & 0 & 0 & 0 & 0 & 0 & 0 & 0 \\
HW Labeled & 0 & 0 & 1 & 0 & 0 & 0 & 0 & 1 & 0 & 0 & 0 & 0 & 0 & 0 & 1 \\
HW Closed & 0 & 0 & 0 & 1 & 1 & 0 & 0 & 0 & 0 & 0 & 1 & 0 & 0 & 0 & 0 \\
HWSecondary C. & 0 & 0 & 0 & 1 & 0 & 1 & 0 & 0 & 0 & 0 & 0 & 0 & 0 & 0 & 0 \\
Alone in Lab & 0 & 0 & 1 & 0 & 0 & 0 & 0 & 0 & 0 & 1 & 1 & 1 & 0 & 0 & 1 \\
& 2 & 4 & 3 & 4 & 6 & 4 & 1 & 4 & 2 & 4 & 4 & 4 & 1 & 3 & 3
\end{tabular}

Biology New Training Average Violations: $\quad 3.27$ 
Chemical Engineering Old Training

\section{Chemical Engineering Department}

Chemical Engineering Old Training

Par. A : Male 10/27 Par. B : Male 11/15 Par.C : Male 11/22 Par. D : Male 11/28ar. E : Male 11/2ع

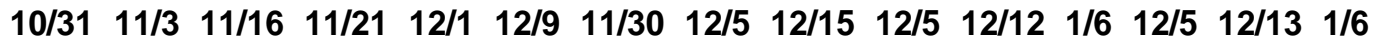

Variable $\quad$ Obs. 1 Obs. 2 Obs. 3 Obs. 1 Obs. 2 Obs. 3 Obs. 1 Obs. 2 Obs. 3 Obs. 1 Obs. 2 Obs. Obs. 1 Obs. 2 Obs. 3

Eye Protection
Lab Coat
Gloves
Clothing
Housekeeping
Eating
Drinking
Containers Labeled
HW Labeled
HW Closed
HWSecondary C.
Alone in Lab

\begin{tabular}{lll|lll|lll|lll|lll}
1 & 1 & 0 & 1 & 0 & 1 & 0 & 1 & 0 & 0 & 0 & 1 & 0 & 0 & 0 \\
1 & 1 & 1 & 1 & 1 & 1 & 1 & 1 & 1 & 1 & 1 & 0 & 1 & 1 & 1 \\
0 & 1 & 1 & 0 & 1 & 1 & 1 & 1 & 0 & 0 & 0 & 1 & 1 & 1 & 1 \\
0 & 0 & 0 & 0 & 1 & 0 & 0 & 0 & 0 & 0 & 1 & 0 & 0 & 1 & 0 \\
0 & 0 & 0 & 1 & 0 & 0 & 0 & 0 & 0 & 0 & 0 & 0 & 0 & 0 & 0 \\
1 & 1 & 1 & 1 & 1 & 1 & 0 & 0 & 1 & 1 & 0 & 1 & 1 & 1 & 1 \\
0 & 0 & 0 & 0 & 1 & 0 & 0 & 0 & 0 & 0 & 0 & 0 & 0 & 0 & 0 \\
0 & 0 & 0 & 0 & 0 & 0 & 0 & 0 & 0 & 0 & 0 & 0 & 0 & 0 & 0 \\
0 & 0 & 0 & 0 & 0 & 0 & 1 & 0 & 1 & 0 & 0 & 1 & 0 & 0 & 0 \\
0 & 1 & 0 & 0 & 0 & 0 & 0 & 0 & 0 & 1 & 0 & 1 & 0 & 0 & 0 \\
0 & 0 & 1 & 0 & 0 & 0 & 0 & 0 & 0 & 0 & 0 & 0 & 0 & 0 & 0 \\
0 & 1 & 0 & 0 & 0 & 0 & 1 & 0 & 1 & 0 & 0 & 0 & 0 & 0 & 0 \\
3 & 6 & 4 & 4 & 5 & 4 & 4 & 3 & 4 & 3 & 2 & 5 & 3 & 4 & 3
\end{tabular}

Chemical Engineering Old Training Average Violations:

3.8

Chemical Engineering New Training

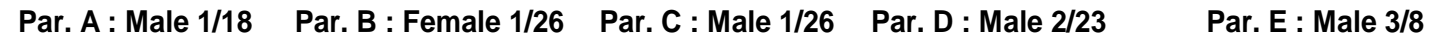

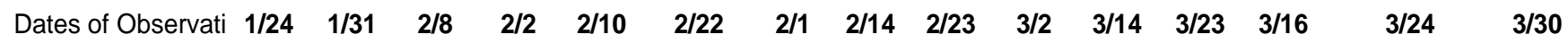

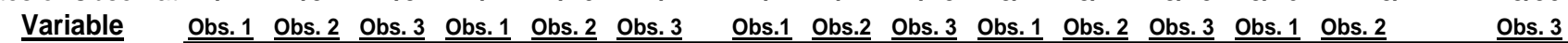

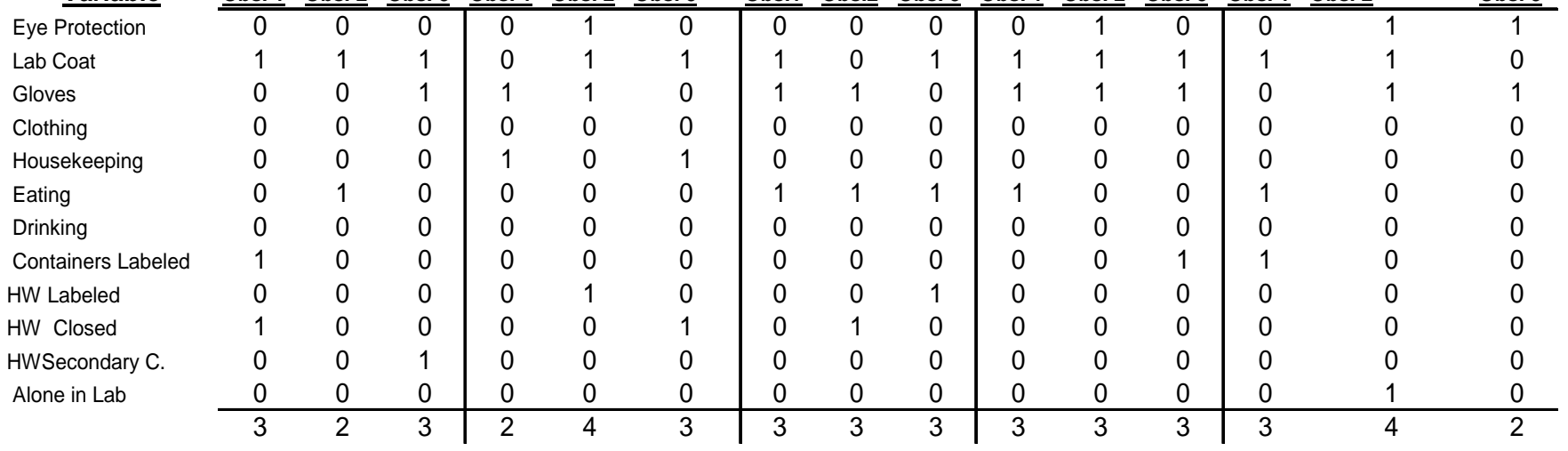
Chemical Engineering New Training Average Violations: 
Chemistry Old Training

\author{
Chemistry Department
}

Par. A : Male 10/27 Par.B : Male 10/27 Par. C : Male 11/15 Par. D : Male 11/22 Par. E : Male 11/22

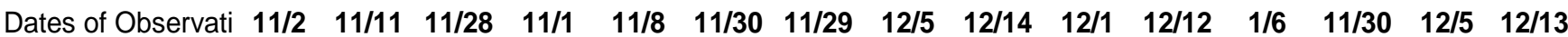

Variable $\quad \underline{\text { Obs. } 1}$ Obs. 2 Obs. 3 Obs. 1 Obs. 2 Obs. 3 Obs. 1 Obs. 2 Obs. 3 Obs. 1 Obs. 2 Obs. 3 Obs. 1 Obs. 2 Obs. 3

\begin{tabular}{llll|lllllllllllll} 
Eye Protection & 1 & 0 & 1 & 1 & 1 & 1 & 0 & 1 & 0 & 0 & 0 & 0 & 0 & 0 & 1 \\
Lab Coat & 1 & 1 & 1 & 1 & 1 & 1 & 1 & 1 & 1 & 0 & 1 & 1 & 1 & 1 & 1 \\
Gloves & 1 & 1 & 1 & 0 & 1 & 0 & 1 & 1 & 1 & 1 & 0 & 1 & 1 & 1 & 1 \\
Clothing & 1 & 0 & 1 & 0 & 0 & 0 & 0 & 0 & 0 & 0 & 0 & 0 & 0 & 0 & 0 \\
Housekeeping & 1 & 1 & 0 & 1 & 0 & 0 & 0 & 1 & 1 & 0 & 1 & 0 & 0 & 1 & 0 \\
Eating & 0 & 0 & 0 & 1 & 0 & 1 & 1 & 1 & 1 & 0 & 1 & 0 & 0 & 1 & 0 \\
Drinking & 1 & 1 & 0 & 1 & 0 & 0 & 0 & 0 & 0 & 0 & 0 & 0 & 0 & 0 & 1 \\
Containers Labeled & 1 & 0 & 1 & 0 & 0 & 0 & 0 & 0 & 1 & 0 & 1 & 1 & 0 & 0 & 0 \\
HW Labeled & 1 & 0 & 0 & 0 & 0 & 0 & 0 & 0 & 0 & 1 & 0 & 0 & 0 & 0 & 0 \\
HW Closed & 0 & 0 & 0 & 0 & 0 & 0 & 0 & 0 & 0 & 0 & 0 & 0 & 0 & 1 & 0 \\
HWSecondary C. & 1 & 0 & 0 & 0 & 0 & 0 & 0 & 0 & 0 & 0 & 1 & 0 & 0 & 0 & 0 \\
Alone in Lab & 0 & 0 & 0 & 0 & 0 & 0 & 1 & 1 & 0 & 0 & 0 & 0 & 0 & 0 & 1 \\
& 9 & 4 & 5 & 5 & 3 & 3 & 4 & 6 & 5 & 2 & 5 & 3 & 2 & 5 & 5
\end{tabular}

Chemistry Old Training Average Violations:

4.4

Chemistry New Training

Par. A : Female 1/18 Par. B : Male 1/18 Par. C : Male 1/26 Par. D : Male 1/26 Par. E : Male 2/8

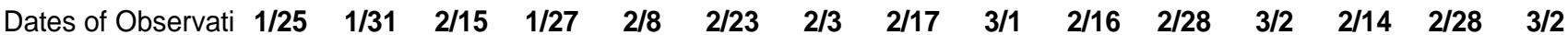

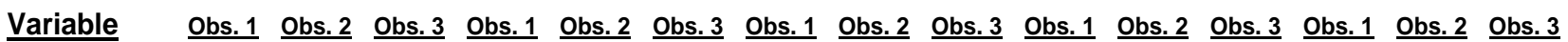

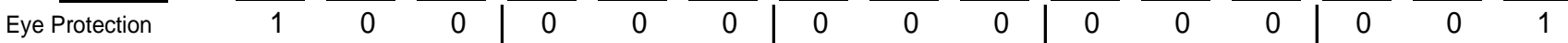
\begin{tabular}{llll|lll|lll|lll|lll} 
Lab Coat & 1 & 1 & 1 & 0 & 1 & 1 & 1 & 1 & 1 & 0 & 1 & 1 & 1 & 1 & 1
\end{tabular} \begin{tabular}{llll|lll|lll|llllll} 
Gloves & 0 & 0 & 1 & 1 & 1 & 1 & 1 & 1 & 1 & 0 & 1 & 0 & 0 & 0 & 0
\end{tabular} \begin{tabular}{llll|lll|lll|llllll} 
Clothing & 1 & 0 & 0 & 0 & 0 & 0 & 0 & 0 & 0 & 1 & 0 & 1 & 1 & 0 & 0
\end{tabular} \begin{tabular}{llll|lll|lll|lllll} 
Housekeeping & 1 & 0 & 0 & 0 & 0 & 0 & 0 & 0 & 0 & 0 & 0 & 0 & 1 & 0 \\
\hline
\end{tabular} \begin{tabular}{llll|lll|lll|llllll} 
Eating & 0 & 1 & 1 & 0 & 1 & 0 & 0 & 1 & 1 & 1 & 0 & 1 & 1 & 0 & 0
\end{tabular} \begin{tabular}{llll|lll|lll|llllll} 
Drinking & 0 & 0 & 0 & 0 & 0 & 0 & 0 & 0 & 0 & 1 & 0 & 0 & 0 & 0 & 0
\end{tabular}

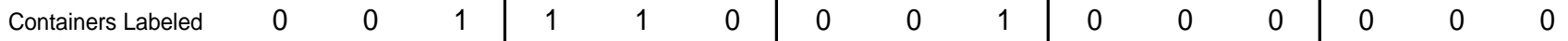
\begin{tabular}{llll|lll|lll|llllll} 
HW Labeled & 0 & 0 & 1 & 0 & 0 & 0 & 0 & 0 & 0 & 0 & 0 & 1 & 0 & 0 & 0
\end{tabular} \begin{tabular}{llll|lll|lll|llllll} 
HW Closed & 0 & 0 & 0 & 0 & 0 & 0 & 0 & 0 & 0 & 1 & 0 & 0 & 0 & 0 & 0
\end{tabular}

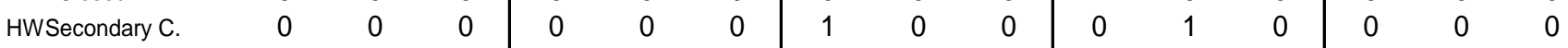

Alone in Lab

\begin{tabular}{lll|lll|lllllll|lll}
0 & 1 & 0 & 0 & 0 & 0 & 1 & 0 & 0 & 0 & 0 & 0 & 0 & 0 & 0 \\
\hline 4 & 3 & 5 & 2 & 4 & 2 & 4 & 3 & 4 & 4 & 3 & 4 & 4 & 1 & 3
\end{tabular}

Chemistry New Training Average Violations: $\quad 3.33$ 


\section{Materials Science Engineering Department}

Materials Science Old Training

Par. A : Female 10/27 Par. B : Male 10/27 Par. C : Male 11/15 Par. D : Male 11/15 Par. E : Male 11/22

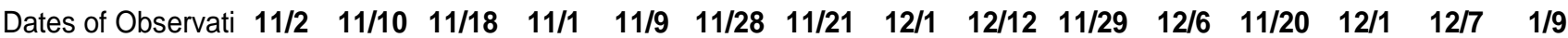

Variable $\quad$ Obs. 1 Obs. 2 Obs. 3 Obs. 1 Obs. 2 Obs. 3 Obs. 1 Obs. 2 Obs. 3 Obs. 1 Obs. 2 Obs. 3 Obs. 1 Obs. 2 Obs. 3

\begin{tabular}{llll|llllllllllllll} 
Eye Protection & 0 & 0 & 0 & 0 & 1 & 0 & 0 & 0 & 0 & 0 & 0 & 0 & 1 & 0 & 0 \\
Lab Coat & 1 & 1 & 1 & 1 & 1 & 1 & 1 & 1 & 1 & 1 & 1 & 0 & 1 & 1 & 1 \\
Gloves & 0 & 0 & 1 & 1 & 1 & 0 & 1 & 1 & 0 & 1 & 1 & 1 & 1 & 1 & 0 \\
Clothing & 0 & 1 & 1 & 0 & 0 & 0 & 0 & 1 & 0 & 0 & 0 & 1 & 0 & 0 & 0 \\
Housekeeping & 1 & 1 & 0 & 1 & 0 & 0 & 1 & 0 & 0 & 1 & 0 & 0 & 1 & 0 & 0 \\
Eating & 1 & 0 & 1 & 0 & 1 & 0 & 1 & 1 & 0 & 1 & 1 & 0 & 0 & 1 & 1 \\
Drinking & 1 & 0 & 0 & 0 & 0 & 0 & 0 & 0 & 0 & 0 & 0 & 0 & 0 & 0 & 0 \\
Containers Labeled & 0 & 0 & 0 & 0 & 0 & 1 & 1 & 0 & 0 & 0 & 0 & 0 & 0 & 0 & 0 \\
HW Labeled & 0 & 0 & 0 & 1 & 0 & 0 & 0 & 0 & 1 & 0 & 0 & 1 & 0 & 0 & 0 \\
HW Closed & 1 & 0 & 0 & 0 & 0 & 0 & 0 & 0 & 1 & 0 & 0 & 0 & 0 & 0 & 1 \\
HWSecondary C. & 1 & 0 & 0 & 0 & 0 & 0 & 0 & 0 & 0 & 0 & 0 & 0 & 0 & 0 & 0 \\
Alone in Lab & 0 & 0 & 0 & 0 & 0 & 0 & 0 & 0 & 0 & 0 & 1 & 1 & 0 & 0 & 1 \\
& 6 & 3 & 4 & 4 & 4 & 2 & 5 & 4 & 3 & 4 & 4 & 4 & 4 & 3 & 4
\end{tabular}

Materials Science Old Training Average Violations: $\quad 3.87$

Materials Science New Training

Par. A : Male 1/18 Par. B : Male 1/26 Par. C : Male 1/26 Par. D : Male 2/23 Par. E : Male 3/8

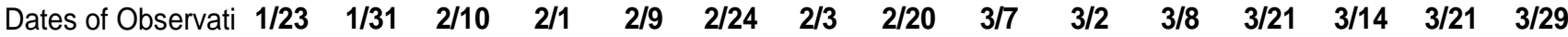

Variable $\quad \underline{\text { Obs. } 1} \underline{\text { Obs. } 2}$ Obs. 3 Obs. 1 Obs. 2 Obs.3 Obs. 1 Obs. 2 Obs. 3 Obs. 1 Obs. 2 Obs. 3 Obs. 1 Obs. 2 Obs. 3

\begin{tabular}{llll|lll|lll|ll|lllll} 
Eye Protection & 0 & 1 & 0 & 0 & 0 & 0 & 1 & 1 & 0 & 0 & 1 & 1 & 0 & 0 & 0 \\
Lab Coat & 0 & 1 & 1 & 1 & 1 & 0 & 1 & 1 & 0 & 1 & 1 & 1 & 1 & 1 & 0 \\
Gloves & 0 & 1 & 0 & 1 & 0 & 1 & 1 & 1 & 0 & 1 & 1 & 0 & 0 & 1 & 0 \\
Clothing & 0 & 0 & 1 & 0 & 0 & 0 & 0 & 1 & 0 & 0 & 0 & 0 & 0 & 0 & 0 \\
Housekeeping & 0 & 0 & 0 & 1 & 0 & 0 & 0 & 0 & 0 & 0 & 0 & 0 & 0 & 0 & 0 \\
Eating & 1 & 1 & 1 & 1 & 1 & 1 & 1 & 0 & 0 & 0 & 0 & 0 & 0 & 1 & 0 \\
Drinking & 0 & 0 & 0 & 0 & 0 & 0 & 1 & 0 & 0 & 1 & 0 & 0 & 1 & 0 & 0 \\
Containers Labeled & 0 & 0 & 0 & 0 & 0 & 0 & 1 & 0 & 0 & 0 & 0 & 0 & 0 & 0 & 0 \\
HW Labeled & 0 & 0 & 0 & 0 & 0 & 0 & 0 & 0 & 1 & 0 & 0 & 0 & 1 & 0 & 0 \\
HW Closed & 0 & 0 & 1 & 0 & 1 & 0 & 0 & 0 & 1 & 0 & 0 & 0 & 0 & 0 & 0 \\
HWSecondary C. & 0 & 0 & 0 & 0 & 0 & 1 & 0 & 0 & 0 & 0 & 0 & 0 & 0 & 0 & 0 \\
Alone in Lab & 0 & 0 & 0 & 0 & 0 & 0 & 1 & 1 & 0 & 0 & 0 & 0 & 1 & 0 & 0 \\
& 1 & 4 & 4 & 4 & 3 & 3 & 7 & 5 & 2 & 3 & 3 & 2 & 4 & 3 & 0
\end{tabular}

Materials Science New Training Average of Violations: $\quad 3.2$ 